\title{
GTAPINGAMS: Multiregional and Small Open Economy Models
}

\author{
By Bruno LANZ ${ }^{\mathrm{a}}$ AND Thomas F. Rutherford ${ }^{\mathrm{b}}$
}

This paper describes the implementation in the General Algebraic Modeling Language (GAMs) of an economic equilibrium model based on the Global Trade Analysis Project (GTAP) dataset. We call this model and the ancillary programming tools GTAPINGAMS. Relative to previous installments of GTAPINGAMS, an innovation in this model is that it can easily switch between global multiregional (GMR) and small open economy (SOE) closures. We also include the possibility to compare results for alternative representations of final demand, based on Cobb-Douglas, linear expenditure system and constant difference in elasticities demand systems. In this paper we outline the model structure, document the associated equilibrium conditions and describe computer programs which calibrate the model to the desired regional and sectoral aggregation from the GTAP 9 dataset. We perform a few calculations which illustrate how alternative structural assumptions influence the policy conclusions derived from the model.

JEL codes: $\mathrm{C} 6, \mathrm{C} 8, \mathrm{D}_{5}, \mathrm{~F}_{1}, \mathrm{R} 1$

Keywords: Applied economic analysis; Multiregional models; Small open economy models; Calibration; Trade policy.

\section{Introduction}

Analysis of policies affecting markets in multiple countries requires both data and theory. The Global Trade Analysis Project (GTAP) consortium provides data, and the analysts confronts this data with a theoretical perspective. ${ }^{1}$ Despite some

${ }^{a}$ University of Neuchâtel, Department of Economics and Business; A.-L. Breguet 2, CH2000 Neuchâtel, Switzerland (email: bruno.lanz@unine.ch.)

$\mathrm{b}$ University of Wisconsin, Madison, Department of Agricultural and Applied Economics, Taylor Hall, 427 LorchStreet, Madison, WI 53706, USA. (email: rutherford@aae.wisc.edu). ${ }^{1}$ The Global Trade Analysis Project (GTAP) is a research program initiated in 1992 to provide the economic research community with a global economic dataset for use in the quantitative analysis of international economic issues. GTAP has led to the establishment of a global network of researchers who share a common interest of multi-region trade analysis and related issues, notably climate and energy policy. The GTAP project was 
limitations in data coverage and quality, a key practical constraint lies in the informed translation of theoretical insights into quantitative policy evidence. Our paper is intended to facilitate this process. We provide computational tools to exploit GTAP data in conjunction with general equilibrium theory, and thereby contribute to the development of computable general equilibrium (CGE) analysis. In a nutshell, CGE models rationalize micro-consistent input-output matrix with a standard Arrow-Debreu general equilibrium representation of the economy, ${ }^{2}$ and quantify ex-ante the impact of a policy relative to an observed state of affair.

While CGE models represent an increasingly important area of policy research, quantitative results from such analysis are inherently model-dependent, which offers a challenge for their role to inform policy-makers. Therefore, expanding the set of modeling strategies is important both to further the academic state-of-theart and to foster confidence in the use of the results for policy-design purposes. With this in mind, this paper introduces a new version of the GTAPINGAMs model, building on previous contributions by Rutherford (1998) and Rutherford (2005). As we detail below, this version of the distribution includes both global multiregional (GMR) and small open economy (SOE) versions of the GTAPINGAMS model, in which the soE model may be single or multi-regional. In addition, users can now toggle across several representations of final consumer demand, and thus test robustness of model results in that dimension.

The version of the model we present is based on version 9 of the GTAP Data Base (Aguiar, Narayanan, and McDougall, 2016), which represents global production and trade for 140 country/regions, 57 commodities and eight primary factors, two of which (land and natural resources) are "sluggish" (imperfectly mobile across sectors). The data characterize intermediate demand and bilateral trade in three alternative base years (2004, 2007 and 2011), including tax rates on imports and exports and other indirect taxes. Our implementation gives users the option to exploit recently developed tools for parallel computation, which can significantly increase computational speed and makes it less cumbersome to exploit the full dimensionality of the dataset. The dataset also provides trade elasticities and Armington elasticities (Armington, 1969), which determine the international trade

founded by Thomas Hertel, Executive Director of the Center for Global Trade Analysis at Purdue University (see notably Hertel, 1997). The Center's staff of economists is responsible for the regular updates of the database (see e.g. Aguiar, Narayanan, and McDougall, 2016). Software development within the GTAP project has been assisted greatly by the efforts of Ken Pearson, Mark Horridge and other researchers from Centre of Policy Studies, Victoria University(see http:/ / www.gtap.org for a list of applications based on the GTAP framework).

${ }^{2}$ Input-output matrices provide data on value flows between economic sectors and regions for primary production factors, intermediate goods and final consumption products. In their micro-consistent versions, such as those provided in the GTAP data, these matrices provide a complete representation of the economy, such that no value is lost in transaction. The ensuing dataset represents value flows in a closed economic system. 
response of the model, as well as income and price elasticities which characterize final demand. (See Narayanan (2015) for a comprehensive description of key features of the GTAP 9 Data Base.)

By design, the GTAP Data Base is well suited for the formulation of quantitative economic models, which in turn can be used to simulate the effect of policies. The principal programming language for GTAP data and modeling work is the General Equilibrium Modelling PACKage (GEMPACK), details of which can be found at www. copsmodels. com or Harrison and Pearson $(1996,2007))$. In the GEMPACK framework the model is solved as a system of nonlinear equations. The present paper describes a version of the GTAP model which has been implemented in GAMS. The GAMs model is essentially implemented as a nonlinear system of equations, although it can be posed either as a (primal) constrained non-linear optimization problem or a mixed complementarity problem (MCP). ${ }^{3}$ One potentially important difference between the GEMPACK framework and previous GTAPINGAMS releases is the representation of final demand:4 GEMPACK employs a constant difference of elasticities (CDE) demand system (Hanoch, 1975), which allows introducing evidence about own-price and income elasticities, while GTAPINGAMs models uses Cobb-Douglas preferences to represent final demand. The present distribution includes an implementation of the CDE demand system together with a least squares calibration code for the CDE which works with the full GTAP dataset and many aggregations. In addition to the original Cobb-Douglas representation, we also provide the option to use a linear expenditure system (LES) representation, with code to parametrize the function to match own-price and income elasticity data provided in the GTAP dataset.

Therefore, the first and principal contribution of this paper is to document programs included in the GTAPINGAMS version 9 package. These programs permit analyst to: (i) select an appropriate level of sectoral and regional aggregation from the GTAP 9 dataset and hence target a representation that is relevant to the analysis of interest; (ii) systematically filter out small and economically insignificant activity accounts, which significantly improves robustness and efficiency of numerically solution; and (iii) re-balance the filtered dataset to ensure that it represents a micro-consistent system and remains consistent with estimates of own-price and income elasticities of demand. The paper also provides details about core CGE models, which are calibrated to the full GTAP datasets for 2004, 2007 and 2011

3 The canonical GTAPINGAMs model is essentially a nonlinear system of equations, as the model does not include activity analysis nor does it rely on free disposal. Formulation as an MCP imposes some modeling discipline, as equations must be explicitly linked with variables. Extensions of the model to incorporate, e.g., tariff quotas (Hertel, Grant, and Rutherford, 2009) or quantitative restrictions on carbon emissions which may or may not be binding (Böhringer, Carbone, and Rutherford, 2016).

4 See Rutherford (2005) for a discussion of the key differences between the two modeling frameworks. 
benchmark years.

A second contribution is to introduce a new soe version of the model, and to propose an approach to calibrate trade elasticity parameters in the SOE model to match the trade response of the GMR model. This makes it possible to produce consistent comparisons across trade closures. The soE formulation necessitates a modest generalization of the standard GTAP model in which goods produced for domestic and export markets are perfect substitutes. Following a large literature based on Devarajan, Lewis, and Robinson (1990), our sOE model differentiates goods produced for domestic and export markets, applying a constant-elasticityof-transformation (CET) revenue function. The sOE model can be used independently of the GMR model for analysis of trade issues in a one or more countries with fixed terms of trade relative to the rest of the world. It may also be used in combination with the multiregional model to decompose the contribution of changes in terms of trade to economic outcomes, as in Böhringer and Rutherford (2002).

The models developed here offer a very rich framework to evaluate the international impacts of policies. In the present paper, however, we limit ourselves to a simple illustration of how the GMR and SOE models can be used to better understand the role of terms of trade in policy experiments. More specifically, in these simulations we assess the economic impact of unilateral, proportional adjustment of regional import tariffs and export taxes in the US and China. In the GTAP 9 Data Base, average trade taxes are a little less than $2 \%$ in the US, and over $4 \%$ in China. Our results suggest that the optimal rate depends crucially on whether one works with a multiregional or open economy closure, whereas the representation of final demand only has a minor impact on the quantitative results.

The remaining of this paper is structured as follows. Section 2 introduces the core GTAPINGAMS model. Section 3 presents the equilibrium conditions associated with the dual (cost minimization) version of the model, which form the basis for the GAMS software. Section 4 introduces the computer code for the model. It further discusses issues about data aggregation, filtering, and re-balancing, and how GMR and SOE models can be calibrated to obtain empirically consistent trade responses. Section 5 reports some forensic calculations of our illustrative policy example. Concluding comments are provided in Section 6. All the GAMs program files discussed here together with the $\mathrm{LT}_{\mathrm{E} X}$ source for the paper are provided in the supplementary files published with this paper.

\section{Data, Technology and Preferences}

This section introduces the structure of core GMR and SOE models included in the GTAPINGAMS distribution. Both models are static, and track the production and distribution of goods in the global economy. In the GTAP 9 Data Base the world is divided into 140 regions (typically representing individual countries) and 57 commodities (or goods), but computational constraints tend to limit the number 
of regions and goods which can be included in a single model. Datasets are easily aggregated which can be useful for both empirical applications focusing on a subset of regions and for debugging steps at the model formulation stage.

In each region, final demand structure is composed of public and private expenditure across goods. Decisions about the allocation of resources are decentralized, and the representation of behavior by consumers and firms in the model follows the canonical microeconomic optimization framework: (i) consumers maximize welfare subject to a budget constraint with fixed levels of investment and public expenditure; (ii) producers combine intermediate inputs, and primary factors (several categories of labor, land, resources and physical capital) at least cost for given technology. 5

While GMR and SOE models are based on the same data and employ the same representation of production technology and consumer preferences, they of course differ in their representation of trade. The GMR model is based on a standard Armington representation of bilateral trade flows. An implication is that production and consumption decisions in a given country (or group of countries) will affect world prices, and the magnitude of this effect will mainly depend on the elasticity estimates (a measure of country-level market-power). By contrast, the soE model considers the case in which production and consumption decision in a region country (or group of country) do not affect world prices. This is modeled by treating supply and demand by the "rest of the world" (ROw, i.e. countries that are not considered relevant for the soE analysis) as perfectly elastic. Corner solutions are avoided through the assumption that output destined for the domestic and export markets are differentiated products (see De Melo and Robinson, 1989). ${ }^{6}$ Therefore, from the perspective of a given region, the impact of policy evaluated in GMR and sOE models will differ through their impact on the terms of trade.

In the following, we start by describing the basic notation, and then present the structure of the data together with benchmark accounting identities. We then present a "primal" description of agents' optimization problems (i.e. specified in terms of quantity variables), which leads to the equilibrium conditions presented in the subsequent section.

5 Details about GTAP sectors and primary factors are provided in Appendix A. Readers of this paper who are interested in using GTAPINGAMS as a research tool are encouraged to download the supplementary materials for this paper and refer to Appendix B for installation instructions. The computer programs described have been tested using data files from the GTAP 9 Flexagg package, flexagg9aY04.zip, flexagg9aY07.zip and flexagg9aY11.zip. A license for these data files must be purchased separately by the users. In addition, a licensed installation of GAMs (version $24.7 \cdot 3$ or higher) is required.

${ }^{6}$ In the present implementation, international closure between the region of interest and the Row is achieved by fixing the value of the current account at its benchmark level, and permitting the real exchange rate to clear the market. Other assumptions are of course possible and are left for future research. 
Table 1. Definitions of set indices.

Set Definition

$i, j$ Sectors, an aggregation of the 57 sectors in the GTAP 9 Data Base

$g$ Production sectors $i$, plus private consumption "C", public demand "G" and investment "I"

$r, s$ Regions, an aggregation of the 140 regions in the GTAP 9 Data Base

$f \quad$ Factors of production (consisting of mobile factors, $f \in m_{f}$, skilled labor (i. officials, mangers and legislators (ISCO-88 Major Groups 1-2), ii. technicians and associated professionals, iii. clerks, and iv. service and market sales workers), unskilled labor, capital, and sector-specific, $f \in s_{f}$, agricultural land and other resources)

\subsection{Notation}

The notation used in the model is summarized in the Tables $1-3$. Table 1 defines the various dimensions which characterize an instance of the model, including the set of sectors/commodities $(i, j)$, the set of regions $(r, s)$, the set of factors of production $(f)$. Set $g$ combines the production sectors $i$ and private and public consumption demand (indices " $\mathrm{C}$ " and "G") and investment demand (index "I"). It allows for a much tighter formulation of the model as they can all be conceived of "goods" produced in similar fashion. To simplify the exposition of the model, however, we describe private consumption, public consumption and investment demand as stand alone components.

Table 2 defines the primal variables (activity levels) which characterize an equilibrium. The model determines values of all the variables except international capital flows, a parameter which would be determined endogenously in an intertemporal model. Table 2 also displays the concordance between the variables and their GAMs equivalents.

Table 3 defines the relative price variables for goods and factors in the model. As is the case in any Shoven-Whalley CGE model, the equilibrium conditions determine relative rather than nominal prices.

While the core GTAPINGAMS model is base on Cobb-Douglas final demand, the canonical models incorporate logic for two additional demand systems: the LES and the CDE demand system. In particular, the LES representation distinguishes between subsistence demand and discretionary demand, and we define the additional variables in Table 4. Similarly, we define an Armington composite price index for products entering CDE final demand. (Details of these demand systems are provided in Appendices D and C.)

Finally, Table 5 reports the definition of tax and subsidy rates applied in the 
Table 2. Definitions of activity levels (quantity variables).

\begin{tabular}{|c|c|c|c|}
\hline Variable & Definition & GAMS variable & Benchmark (GTAP) value \\
\hline$Y_{i r}$ & Production & $Y(i, r)$ & $\operatorname{vom}(i, r)$ \\
\hline$C_{r}$ & Discretionary consumption & $Y(" C ", r)$ & $\operatorname{vom}(" \mathrm{C} ", r)$ \\
\hline$G_{r}$ & Aggregate public & $Y(" g ", r)$ & $\operatorname{vom}(" g ", r)$ \\
\hline$I_{r}$ & Aggregate investment & $Y(" i ", r)$ & $\operatorname{vom}(" i ", r)$ \\
\hline$M_{i r}$ & Aggregate imports & $M(i, r)$ & $\operatorname{vim}(i, r)$ \\
\hline$X_{i r}$ & Trade flows with rest of world regions & $X(i, r)$ & $\operatorname{vem}(i, r)$ \\
\hline$F T_{f r}$ & Factor transformation & $\mathrm{FT}(f, r)$ & $\operatorname{evom}(f, r)$ \\
\hline$Y T_{j}$ & International transport services & $\mathrm{YT}(j)$ & $\operatorname{vtw}(j)$ \\
\hline
\end{tabular}

model, both in terms of the notation employed to describe the model and that used in the GAMs code. Note that revenues from taxes and subsidy expenditures do not appear as explicit variables in the GTAP Data Base and are defined on the basis of expenditures and tax rates. We come back to this below.

\subsection{Benchmark data structure and accounting identities}

The economic structure underlying the GTAP dataset and model is illustrated in Figure 1. Symbols in this flow chart correspond to variables in the economic model (see Table 2): $Y_{i r}$ is the production of good $i$ in region $r, C_{r}, I_{r}$ and $G_{r}$ portray private consumption, investment and public demand, respectively, $M_{i r}$ portrays the import of good $i$ into region $r, R A_{r}$ stand for representative consumers, and $F T_{S_{f} r}$ is the activity through which the set of sector-specific factors of production $\left(s_{f}\right)$ are allocated to individual sectors. Further, solid lines represent commodity and factor market flows, while dotted lines indicate tax revenues and transfers.

Domestic and imported goods markets are represented by horizontal lines at the top of the figure. Domestic production $\left(v o m_{i r}\right)$ is distributed to exports $\left(v x m d_{i r s}\right)$, international transportation services $\left(v s t_{i r}\right)$, intermediate demand $\left(v d f m_{i j r}\right)$, household consumption $\left(v d f m_{i C r}\right)$, investment $\left(v d f m_{i I r}\right)$, and government consump- 
Journal of Global Economic Analysis, Volume 1 (2016), No. 2, pp. 1-77.

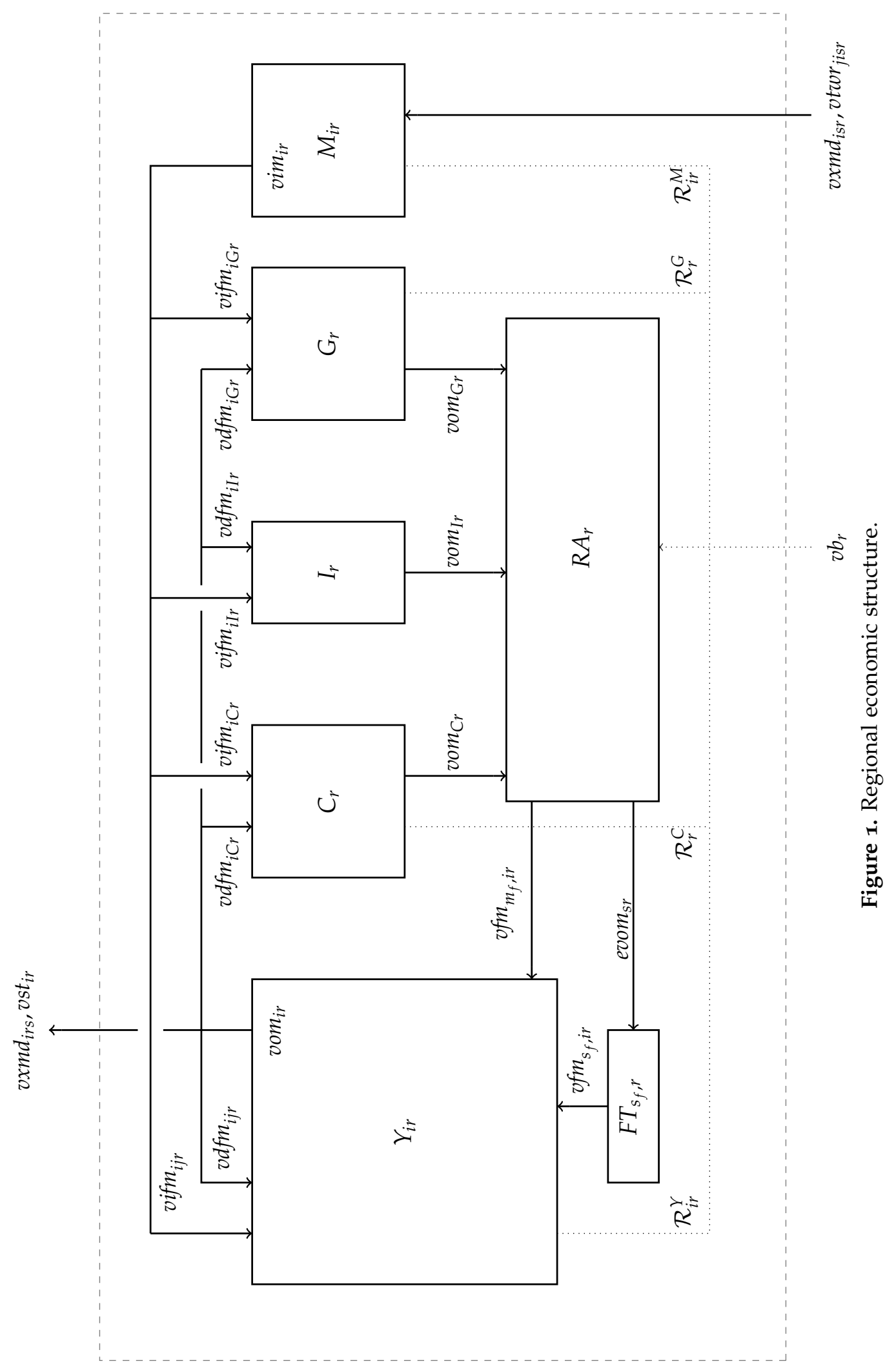


Table 3. Definitions of price variables.

\begin{tabular}{|c|c|c|}
\hline Variable & Definition & GAMS variable \\
\hline$p_{r}^{C}$ & $\begin{array}{l}\text { Final demand price index for the Cobb-Douglas } \\
\text { demand system }\end{array}$ & $P(" C ", r)$ \\
\hline$p_{r}^{G}$ & Public provision price index & $P(" G ", r)$ \\
\hline$p_{r}^{I}$ & Investment price index & $P(" I ", r)$ \\
\hline$p_{i r}^{Y}$ & $\begin{array}{l}\text { Supply price, gross of indirect producer taxes } \\
\text { (when } \eta_{i}^{D X}<\infty \text {, the supply price is replaced by } \\
\text { and export price, } p_{i r}^{X} \text { and domestic supply price, } \\
p_{i r}^{D} \text { ) }\end{array}$ & $P(i, r)$ \\
\hline$p_{i r}^{M}$ & Import price, gross of export taxes and tariffs. & $\mathrm{PM}(i, r)$ \\
\hline$p_{i r}^{E}$ & $\begin{array}{l}\text { Export price from endogenous or exogenous re- } \\
\text { gions. }\end{array}$ & $\mathrm{PE}(i, r)$ \\
\hline$p_{j}^{T}$ & Marginal cost of transport services & $\mathrm{PT}(j)$ \\
\hline$p_{f, r}^{F}$ & $\begin{array}{l}\text { Price of mobile primary factors ( } m_{f} \text { include labor, } \\
\text { land and resources) }\end{array}$ & $P F(f, r)$ \\
\hline$p_{s_{f}, i r}^{S}$ & Price of sector-specific primary factors & $\operatorname{PS}(s f, i, j)$ \\
\hline
\end{tabular}

tion $\left(v d f m_{i G r}\right) .7$ The accounting identity in the GTAP 9 dataset is thus:

$$
v o m_{i r}=\sum_{s} v x m d_{i r s}+v s t_{i r}+\sum_{j} v d f m_{i j r}+v d f m_{i C r}+v d f m_{i I r}+v d f m_{i G r},
$$

where $j$ indexes all goods. Similarly, imported goods (with aggregate value vim ${ }_{i r}$ ) enter intermediate demand $\left(v i f m_{i j r}\right)$, private consumption $\left(v i f m_{i C r}+v i f m_{i S D r}\right)$ and public consumption (vifm $m_{i G r}$ ). The accounting identity for these flows is thus:

$$
v_{i m}=\sum_{j} v i f m_{i j r}+v i f m_{i C r}+v i f m_{i S D r}+v i f m_{i G r} .
$$

7 Recall that in the GAMs implementation of the model the index " $\mathrm{g}$ " includes all sectors represented in the model plus private consumption " $\mathrm{C}$ ", public demand "G" and investment "I". (See Table 1.) For the LES demand representation, it also includes price indices for discretionary demand "dd" and subsistence demand "sd". 
Table 4. Additional variables for LES and CDE demand systems.

\begin{tabular}{llr}
\hline Variable & Definition & GAMS variable \\
\hline$S D_{r}$ & Subsistence demand & $\mathrm{Y}(" \mathrm{sd}, \mathrm{r})$ \\
$D D_{r}$ & Discretionary demand & $\mathrm{Y}(" \mathrm{dd} ", r)$ \\
$p_{r}^{D D}$ & Discretionary demand price index & $\mathrm{P}(" \mathrm{dd} ", r)$ \\
$p_{r}^{S D}$ & Subsistence demand price index & $\mathrm{P}(" \mathrm{sd},, \mathrm{r})$ \\
$p_{i C r}^{A}$ & $\begin{array}{l}\text { Armington composite price representing the } \\
\text { market price of goods entering cDE demand. }\end{array}$ & $\mathrm{PA}(\mathrm{i}, \mathrm{r})$ \\
\hline
\end{tabular}

Inputs to production of good $i\left(Y_{i r}\right)$ include intermediate inputs (domestic $v d f m_{i j r}$ and imported $\left.v i f m_{i j r}\right)$, mobile factors of production $\left(v f m_{m_{f}, i r}\right.$, where $m_{f}$ is a subset of the set $f$ designating all factors of production), and sector-specific factors of production $\left(v f m_{s_{f}, i r}, s_{f} \subset f\right)$. Factor market equilibrium is given by an identity relating the value of factor payments to factor income:

$$
\sum_{i} v f m_{f i r}=\operatorname{evom}_{f r}
$$

and factor earnings accrue to households.

International market clearance conditions require that region $r$ exports of good $i$ (vxmd ir at the top of the figure) equal the imports of the same good from the same region summed across all trading partners $\left(v x m d_{i s r}\right.$ at the bottom of the figure):

$$
v x m_{i r}=\sum_{s} v x m d_{i r s}
$$

where $s$, an alias for $r$, indexes regions. Likewise, market clearance conditions apply for international transportation services. The supply-demand balance in the market for transportation service $j$ requires that the sum across all regions of service exports (vstir, at the top of the figure) equals the sum across all bilateral trade flows of service inputs (vtwr jisr at the bottom of the figure):

$$
\sum_{r} v s t_{j r}=\sum_{i s r} v t w r_{j i s r}
$$

Turning to tax revenues and transfers, shown as dotted lines in figure 1 , flows labeled with $\mathcal{R}$ correspond to tax revenues. For each country, tax flows consist of indirect taxes on production/ exports of each good $\left(\mathcal{R}_{i r}^{Y}\right)$, on consumption $\left(\mathcal{R}_{r}^{C}\right)$, on public demand $\left(\mathcal{R}_{r}^{G}\right)$ and on imports $\left(\mathcal{R}_{i r}^{M}\right)$. The regional budget constraint thus relates tax payments $\left(\mathcal{R}_{i r}^{Y}, \mathcal{R}_{r}^{C}, \mathcal{R}_{r}^{G}, \mathcal{R}_{i r}^{M}\right)$, factor income $\left(\right.$ evom $\left._{f r}\right)$, and the current 
Table 5. Tax and subsidy rates (net basis unless noted).

\begin{tabular}{|c|c|c|c|}
\hline Parameter & Definition & & GAMS Parameter \\
\hline$t_{i r}^{o}$ & Output taxes (gross basis) & & $\operatorname{rto}(i, r)$ \\
\hline$t_{f i r}^{f}$ & Factor taxes & & $\operatorname{rtf}(f, i, r)$ \\
\hline$t_{i j r}^{f d}$ & Intermediate input taxes & Domestic & $\operatorname{rtfd}(i, j, r)$ \\
\hline$t_{i j r}^{f i}$ & & Imported & $\operatorname{rtfi}(i, j, r)$ \\
\hline$t_{i r}^{p d}$ & Consumption taxes & Domestic & rtfd $(i, " C ", r)$ \\
\hline$t_{i r}^{p i}$ & & Imported & $\operatorname{rtfi}\left(i,{ }^{\prime} ", r\right)$ \\
\hline$t_{i r}^{g d}$ & Public demand taxes & Domestic & $\operatorname{rtfd}(i, " G ", r)$ \\
\hline$t_{i r}^{g i}$ & & Imported & $\operatorname{rtfi}(i, " G ", r)$ \\
\hline$t_{i r}^{g d}$ & Investment demand taxes & Domestic & $\operatorname{rtfd}(i, " I ", r)$ \\
\hline$t_{i r}^{g i}$ & & Imported & rtfi(i,"I",r) \\
\hline$t_{i s r}^{x S}$ & Export subsidies & & $\operatorname{rtxs}(i, s, r)$ \\
\hline$t_{i s r}^{m s}$ & Import tariffs & & $\operatorname{rtms}(i, s, r)$ \\
\hline
\end{tabular}

account deficit (i.e., net transfers from abroad, $v b_{r}$ ) to total private consumption expenditure $v o m_{C r}$, total public consumption expenditure $v o m_{G r}$, and total investment vom Ir, yielding:

$$
\text { vom }_{C r}+\text { vom }_{G r}+\text { vom }_{I r}=\sum_{f} \text { evom }_{f r}+\sum_{i} \mathcal{R}_{i r}^{Y}+\mathcal{R}_{r}^{C}+\mathcal{R}_{r}^{G}+\sum_{i} \mathcal{R}_{i r}^{M}+v b_{r} .
$$

To this point we have outlined two types of consistency conditions which are part of any GTAP Data Base: market clearance (supply = demand for all goods and factors), and income balance (net income = net expenditure). A third set of identities involve net operating profits by all sectors in the economy. In the core GTAP model "production" takes place under conditions of perfect competition with constant returns to scale, hence there are no excess profits, and the cost of inputs must equal the value of outputs. This condition applies for each production sector:

$$
\begin{aligned}
Y_{i r}: & \sum_{f} v f m_{f i r}+\sum_{j}\left(v d f m_{i j r}+v i f m_{i j r}\right)+\mathcal{R}_{i r}^{Y}=v o m_{i r}, \\
C_{r}: & \sum_{i}\left(v d f m_{i C r}+v i f m_{i C r}\right)+\mathcal{R}_{i r}^{C}=v o m_{C r}, \\
I_{r}: & \sum_{i} v d f m_{i I r}=v o m_{I r}
\end{aligned}
$$




$$
\begin{aligned}
G_{r}: & \sum_{i}\left(v d f m_{i G r}+v i f m_{i G r}\right)+\mathcal{R}_{i r}^{G}=v o m_{G r}, \\
M_{i r}: & \sum_{s}\left(v x m d_{i s r}+\sum_{j} v t w r_{j i s r}\right)+\mathcal{R}_{i r}^{M}=v i m_{i r} \\
F T_{f r}: & \operatorname{evom}_{f r}=\sum_{i} v f m_{f i r}
\end{aligned}
$$

\subsection{Decentralized optimization problems}

The benchmark identities presented in the previous section indicate the market clearance, zero profit and income balance conditions which define the GTAP model. The displayed equations do not, however, characterize the behavior of agents in the model. In a competitive equilibrium setting, the standard assumption of optimizing atomistic agents applies for both producers and consumers. This section lays out the optimization problem of each component in the model, and thereby provides the structure of production technology (production functions) and preferences (characterizing final demand), as well as the representation of trade. We also highlight where conceptual differences between GMR and SOE models intervene.

Note that in order to simplify notation, we denote decision variables corresponding to the benchmark data structures with the initial " $\mathrm{v}$ " replaced by " $\mathrm{d}$." Hence, while $v d f m_{j i r}$ represents benchmark data on intermediate demand for good $j$ in the production of good $i$ in region $r, d d f m_{j i r}$ represents the corresponding decision variable in the equilibrium model. This approach to the scaling of variables is consistent with the GAMs code, and it provides a flexible and transparent approach with respect to the calibration of activity variables.

\subsubsection{Production technology}

Starting with producers, profit maximization in the constant returns to scale setting is equivalent to cost minimization subject to technical constraints. For sector $Y_{i r}$ we characterize input choices as though they arose from minimization of unit costs:

$$
\begin{array}{ll}
\min _{d d f m, d f m, d i f m} c_{i r}^{D}+c_{i r}^{M}+c_{i r}^{F} & \\
\text { s.t. } \quad & c_{i r}^{D}=\sum_{j} p_{j r}^{Y}\left(1+t_{j i r}^{f d}\right) d d f m_{j i r} \\
c_{i r}^{M} & =\sum_{j} p_{j r}^{M}\left(1+t_{j i r}^{f i}\right) d i f m_{j i r} \\
c_{i r}^{F} & =\sum_{f}\left(\left.p_{f r}^{F}\right|_{f \in m_{f}}+\left.p_{f i r}^{S}\right|_{f \in s_{f}}\right)\left(1+t_{f i r}^{f}\right) d f m_{f i r} \\
& F_{i r}(d d f m, d i f m, d f m)=Y_{i r}
\end{array}
$$

where $F(\cdot)$ represents the production function, which is described by a nested constant-elasticity-of-substitution (CES) form, with structure displayed in Figure 2. 


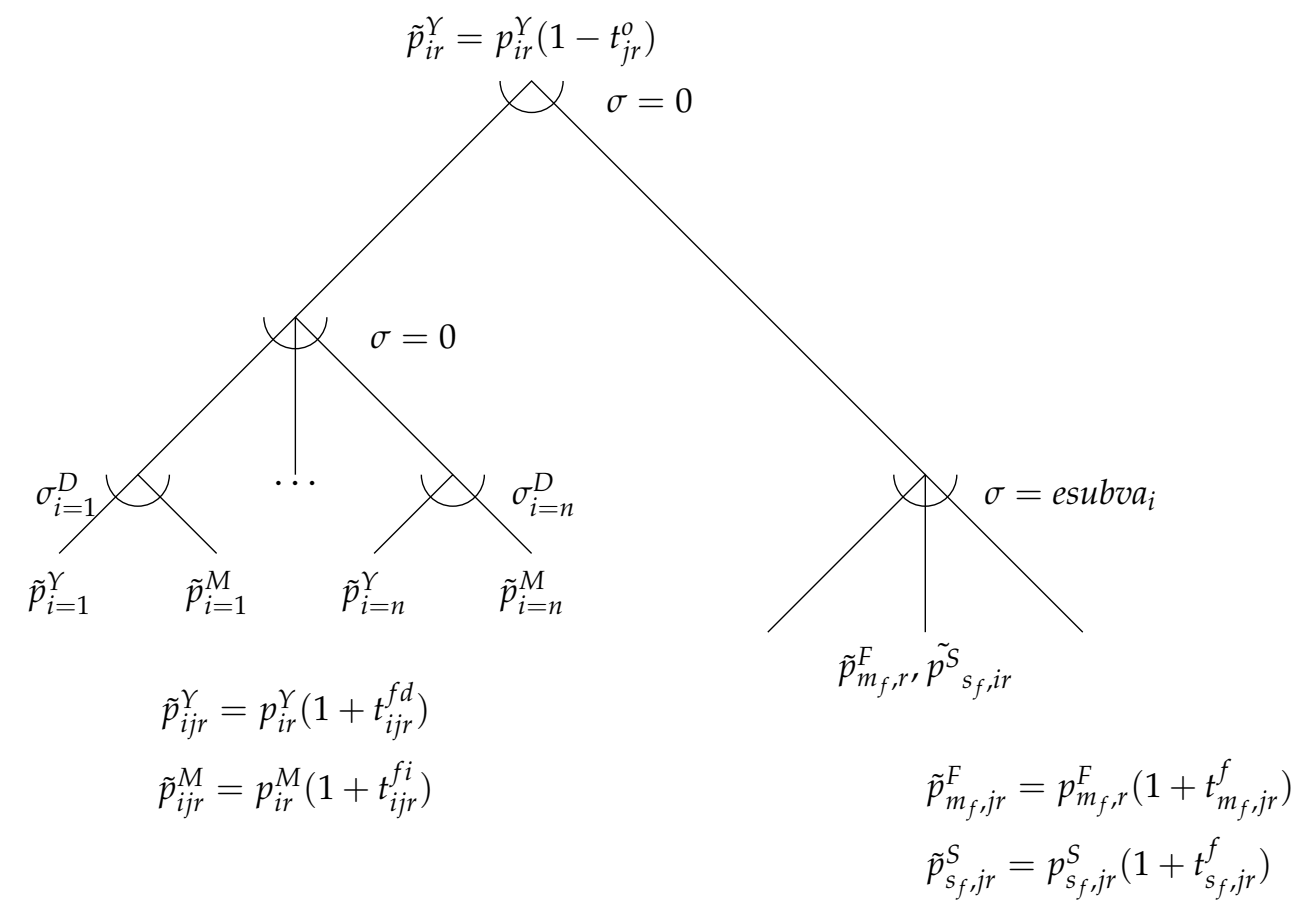

Figure 2. CES nesting structure for production function $Y_{i r}=F_{i r}(d d f m$, difm, dfm $)$.

In the figure, $\sigma$ values in different nests represent substitution elasticities between inputs, with $\sigma_{i}^{D}=e s u b d_{i}$ measuring substitution possibility between intermediate inputs produced domestically and imported from abroad which are similarly a composite of imports from varieties from different regions. esubva $a_{i}$ represents the elasticity of substitution between primary inputs in the value added nest. (Both of these parameters are provided in the GTAP 9 Data Base (see Hertel and van der Mensbrugghe, 2016).) Note further that the specific source of tax revenue is indicated in this figure, consisting of output taxes, taxes on intermediate inputs and taxes on factor demands, all of which are applied on an ad-valorem basis.

One important difference between GMR and SOE models occurs in the differentiation of output for domestic and export markets. In particular, the supply of goods to domestic and export markets are portrayed as arising from the following profit-maximization problem:

$$
\begin{array}{ll}
\max _{d x m, d d m} & p_{i r}^{D} d d m_{i r}+p_{i r}^{X} d x m_{i r} \\
\text { s.t. } & G_{i r}\left(d d m_{i r}, d x m_{i r}\right)=Y_{i r}
\end{array}
$$

where $G$ is the CET function with structure illustrated in Figure 3. In the GMR model, transformation elasticities $\eta_{i r}^{D X}=e t r n d x_{i}$ are set to infinity, which is the default value in the GTAP 9 Data Base. This implies that the supply price of output 


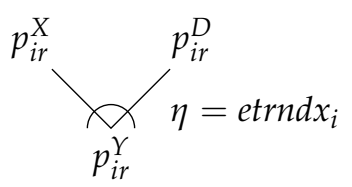

Figure 3. CET transformation between domestic and export markets $Y_{i r}=G_{i r}(d x m, d d m)$.

$p_{j r}^{Y}$ is the same if output is used locally or in a different region. By contrast, in the SOE model we have that etrnd $x_{i}<\infty$, which implies that output price may differ when supplied domestically or abroad. In this case, $p_{j r}^{Y}$ in equation (1) is replaced by $p_{j r}^{D}$. We come back to the choice of etrnd $x_{i}$ in the soE model when we present our illustrative calculations.

\subsubsection{Preferences and final demand}

Private consumption consistent with utility maximization is portrayed by minimization of the cost of a given level of aggregate consumption:

$$
\begin{array}{ll}
\min _{d d f m_{i C r}, d i f m_{i C r}} & \sum_{i} p_{i r}^{Y}\left(1+t_{i r}^{p d}\right) d d f m_{i C r}+p_{i r}^{M}\left(1+t_{i r}^{p i}\right) d i f m_{i C r} \\
\text { s.t. } & H_{r}\left(d d f m_{i C r}, d i f m_{i C r}\right)=C_{i r}
\end{array}
$$

where $H_{r}$ represents final demand from the representative consumer.

Final demand in the core model is characterized by Cobb-Douglas preferences. Alternative specifications included in the model logic include both the LES and CDE expenditure. ${ }^{8}$ The nested discretionary and subsistence demand functions are is displayed in Figure 4.

\subsubsection{Government and public consumption}

Public consumption in the model is represented as a fixed coefficient (Leontief) aggregation of domestic-import composites. This formulation introduces substitution at the second level between domestic and imported inputs while holding sectoral commodity aggregates constant. Figure 5 illustrates the functional form.

\subsubsection{International trade}

The choice among imports from different trading partners is based on Armington's idea of regionally differentiated products. The following cost minimization

8 The LES model involves subsistence and discretionary expenditure, which are represented through composite price indices representing CES aggregates of both domestic and imported inputs, $P(" D D ", r)$ and $P(" S D ", r)$, respectively. The CDE model requires the introduction of trade aggregation activities $(A(i, r))$ and associated Armington composite price indices, $\mathrm{PA}(i, r)$. 


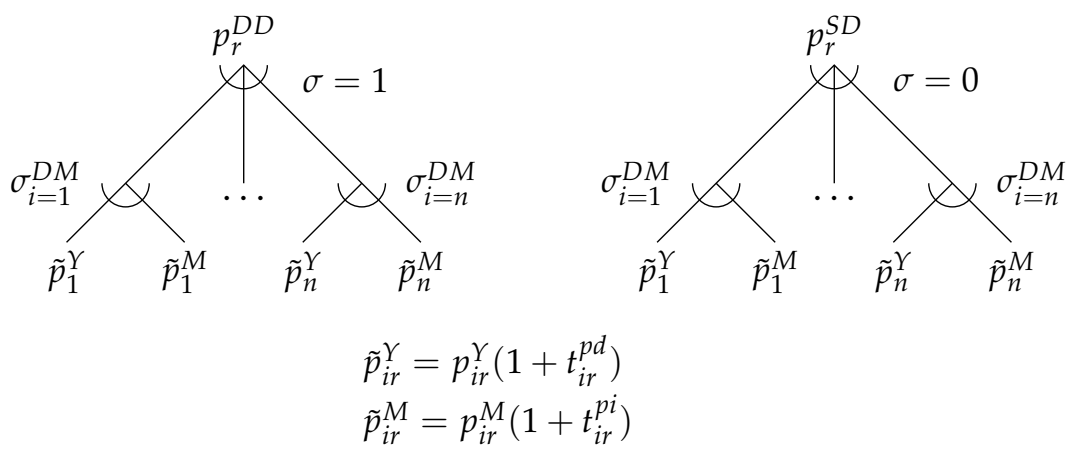

Figure 4. LES nesting for discretionary and subsistence consumption.

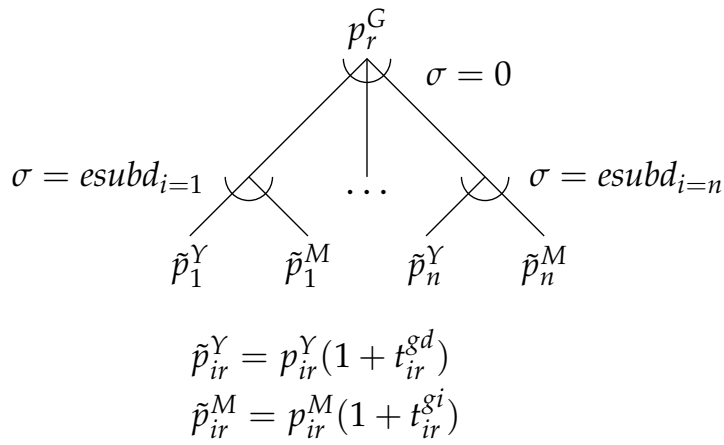

Figure 5. Nesting structure for public consumption $G_{r}=G_{r}\left(d d f m_{i G r}, d i f m_{i G r}\right)$.

problem formalizes this choice:

$$
\begin{aligned}
\min _{d x m d, d t w r} & \sum_{s}\left(1+t_{i s r}^{m s}\right)\left(p_{i s}^{Y}\left(1-t_{i s r}^{x s}\right) d x m d_{i s r}+\sum_{j} p_{j}^{T} d t w r_{j i s r}\right) \\
\text { s.t. } \quad & A_{i r}(d x m d, d t w r)=M_{i r}
\end{aligned}
$$

where $A$ is the import aggregation function, described by the nested cEs-Leontief function shown in Figure 6. In the case of the soE model, in which etrnd $x_{i}<\infty$, $p_{i s}^{Y}$ in (5) is replaced by $p_{i s}^{X}$.

Note that transportation services enter on a proportional basis with imports from different countries, reflecting differences in unit transportation margins across different goods and trading partners. Therefore, substitution at the top level in an Armington composite involves trading off of both imported goods and associated transportation services. Trade flows are subject to export subsidies and import tariffs, with subsidies paid by government in the exporting region, and tariffs collected by government in the importing region.

The provision of international transportation services is modeled through an 


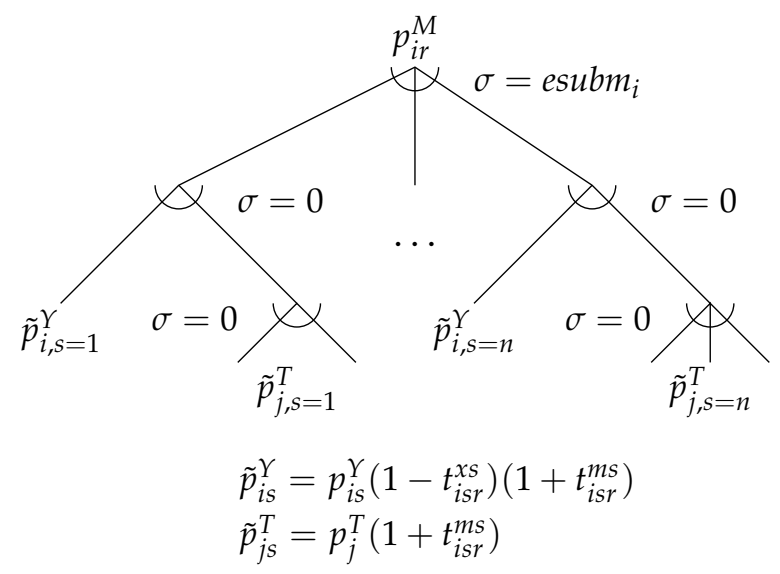

Figure 6. Armington aggregation of traded goods $M_{i r}=A_{i r}(d x m d, d t w r)$.

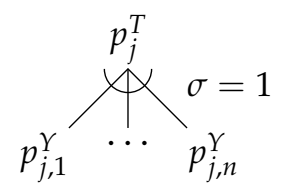

Figure 7. International transportation services aggregator $Y T_{j}=T_{j}(d s t)$.

aggregation of transportation services exported from countries throughout the world. More specifically, we consider the following cost minimization problem for the aggregation of transportation services:

$$
\min _{d s t} \sum_{r} p_{i r}^{Y} d s t_{i r} \quad \text { s.t. } \quad T_{i}(d s t)=Y T_{i}
$$

where the aggregation function $T_{i}$ combines transport service exports from multiple regions. The functional form which aggregates services from different regions is illustrated in Figure 7 .

\subsubsection{Supply of sector-specific factors}

Land and natural resources are portrayed as sector-specific factors of production. These are supplied through constant-elasticity-of-transformation (CET) production function which allocates composite factors to sectoral markets. Formally, the supply of sectoral factors of production is modeled through the following profit-maximization problem:

$$
\begin{array}{ll}
\max _{d f m} & \sum_{j} d f m_{s_{f}, j r} p_{s_{f}, j r}^{S} \\
\text { s.t. } & \Gamma_{s_{f}, r}(d f m)=\text { evom }_{s_{f}, r}
\end{array}
$$




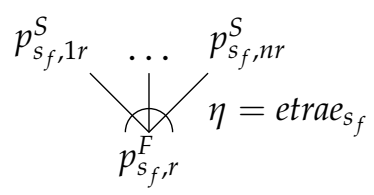

Figure 8. Sector-specific factor CET transformation function $F T_{s_{f}}=\Gamma_{s_{f}}(d f m)$.

where $\Gamma$ is the CET function with structure illustrated in Figure 8. Note that in the figure $\eta$ represents transformation elasticities provided in the GTAP 9 Data Base.

\section{Equilibrium Conditions}

An Arrow-Debreu model concerns itself with the interactions of decentralized decisions by consumers and producers in markets. Mathiesen (1985) proposed a representation of this class of models in which two types of equations define an equilibrium: zero profit and market clearance. The corresponding variables defining an equilibrium are activity levels (for constant-returns-to-scale firms) and commodity prices. ${ }^{9}$ Here we extend Mathiesen's framework with a third class of variables corresponding to consumer income levels. Commodity markets encompass primary endowments of households with producer outputs. In equilibrium the aggregate supply of each good must be at least as great as total intermediate and final demand. Initial endowments are exogenous. Producer supplies and demands are defined by producer activity levels and relative prices. Final demands are determined by market prices.

Economists who have worked with conventional textbook equilibrium models can find Mathiesen's framework to be somewhat opaque because many quantity variables need not be explicitly specified in the model. Variables such as final demand by consumers, factor demands by producers and commodity supplies by producers, are defined implicitly in Mathiesen's model. For example, given equilibrium prices for primary factors, consumer incomes can be computed, and given income and goods prices, consumers' demands can then be determined. The consumer demand functions are written down in order to define an equilibrium, but quantities demanded need not appear in the model as separate variables. The same is true of inputs or outputs from the production process: relative prices determine conditional demand, and conditional demand times the activity level represents market demand. Omitting decisions variables and suppressing

9 Under a maintained assumption of perfect competition, Mathiesen (1985) may characterize technology as constant-returns-to-scale without loss of generality. Specifically, decreasing returns are accommodated through introduction of a specific factor, while increasing returns are inconsistent with the assumption of perfect competition. Note that in this environment zero excess profit is consistent with free entry for atomistic firms producing an identical product. 
definitional equations corresponding to intermediate and final demand provides significant computational advantages at the cost of a somewhat more complicated model statement.

In the following, we detail (i) zero profit conditions, (ii) market clearance conditions, and (iii) income balance conditions, which in the present case is equivalent to the regional budget constraint. These three sets of conditions form the basic system of equation to be solved. Note that the actual code for the model is implemented both in the algebraic mixed complementarity format (GAMs/MCP, see Rutherford, 1995) and through the more compact formulation afforded by the Mathematical Programming System for General Equilibruim (MPSGE) syntax (Rutherford, 1999).

\subsection{Zero profit (arbitrage) conditions}

All production activities in the model are represented by constant-returns-toscale technologies, and markets are assumed to operate competitively with free entry and exit. As a consequence, equilibrium profits are driven to zero and the price of output reflects the cost of inputs. The following sets of equations relating output price to marginal cost are part of the definition of an equilibrium. ${ }^{10}$

The calculation of unit cost and unit revenue functions involves the definition of a number of ancillary variables (that do not appear in the GAMs code as explicit choice variables). In the following we define ancillary variables in un-numbered equations, indicating that these variables are "optional" in the sense that they may be substituted out of the non-linear system of equations. Moreover, we use the symbol $\theta$ to portray value shares from the base year data. In most cases subscripts on these value shares are omitted in order to economize on notation. Finally, to denote benchmark values we use an overline, so that $\bar{t}_{i r}^{p d}$ represents the benchmark value of $t_{i r}^{p d}$.

\subsubsection{Sectoral production $(Y(j, r))$}

Sectoral production combines intermediate inputs with a value-added nest combining primary inputs (see Figure 2). The unit cost of value-added is a CES composite of skilled and unskilled labor, land, resources and capital inputs to production, gross of taxes. Factor inputs may be sector-specific or mobile across sectors:

$$
p_{f j r}^{p f}= \begin{cases}p_{f r}^{F} \frac{\left(1+t_{f j r}^{f}\right)}{1+\bar{t}_{f j r}^{f}} & f \in m_{f} \\ p_{f j r}^{S} \frac{\left(1+t_{f j r}^{f}\right)}{1+\bar{t}_{f j r}^{f}} & f \in s_{f}\end{cases}
$$

10 To retain consistency with the MCP format, we express zero profit conditions as "oriented equations," with marginal (=average) cost on the LHS and marginal (=average) revenue on the RHS. 
and the unit cost function is given by:

$$
c_{j r}^{f}=\left(\sum_{f} \theta_{f}\left(p_{f j r}^{p f}\right)^{1-\sigma}\right)^{1 /(1-\sigma)},
$$

in which $\theta_{f}$ represents the factor share of value added [theta_vfm $\left.(f, g, r)\right]$.

The user cost of intermediate inputs differs from the market price due to the presence of taxes on intermediate inputs:

$$
\begin{aligned}
& p_{i j r}^{d}=p_{i r}^{Y} \frac{1+t_{i j r}^{f d}}{1+\bar{t}_{i j r}^{f d}} \\
& p_{i j r}^{i}=p_{i r}^{M} \frac{1+t_{i j r}^{f i}}{1+\bar{t}_{i j r}^{f i}}
\end{aligned}
$$

A CES cost function describes the minimum cost of a bundle of domestic and imported inputs to production, based on benchmark value shares and an elasticity of substitution $\sigma$ [esubd (i) ]:

$$
c_{i j r}^{i}=\left(\theta\left(p_{i j r}^{d}\right)^{1-\sigma}+(1-\theta)\left(p_{i j r}^{i}\right)^{1-\sigma}\right)^{1 /(1-\sigma)},
$$

in which $\theta$ represents the domestic share of the Armington composite [theta_vdfm $(i, j, r)]$.

Unit cost of sectoral output is then a Leontief (linear) composite of the costs of intermediate and value-added composite inputs, based on base-year value shares:

$$
c_{j r}^{Y}=\sum_{i} \theta_{i} c_{i j r}^{i}+\theta^{f} c_{j r}^{f}
$$

in which $\theta_{i}$ represents the cost share of intermediate input $i$ [theta_cmo $\left.(i, j, r)\right]$; and $\theta^{f}$ represents the cost share of value added in sectoral output [theta_cf $0(j, r)$ ].

Having formulated the unit cost function, it is possible to compactly portray the zero profit condition for $y_{j r}$. In equilibrium, the marginal cost of supply equals the market price, net of taxes:

$$
c_{j r}^{Y}=p_{j r}^{Y} \frac{1-t_{j r}^{o}}{1-\bar{t}_{j r}^{o}}
$$

In the soe model production for domestic and export markets are differentiated, and we replace $p_{j r}^{Y}$ by a unit revenue function,

$$
r_{j r}^{Y}=\left(\theta\left(p_{j r}^{D}\right)^{1+\eta}+(1-\theta)\left(p_{j r}^{X}\right)^{1+\eta}\right)^{1 /(1+\eta)},
$$

in which $\theta$ represents the export share of output [theta_vxm $(j, r)]$. 


\subsubsection{Consumer demand (Y ( " C", r ) )}

In previous versions of GTAPINGAMS the consumer price index represented a Cobb-Douglas demand system with an Armington substitution between domestic and imported goods prices gross of tax. This model is retained as one option in the new model, price indices for domestic and imported goods are given by:

$$
p_{i r}^{d c}=p_{i r}^{Y} \frac{1+t_{i r}^{p d}}{1+\bar{t}_{i r}^{p d}},
$$

and

$$
p_{i r}^{i c}=p_{i r}^{M} \frac{1+t_{i r}^{p i}}{1+\bar{t}_{i r}^{p i}},
$$

and the Armington composite price of good $i$ is a CES composite price defined over these indices:

$$
p_{i r}^{c}=\left(\theta\left(p_{i r}^{d c}\right)^{1-\sigma}+(1-\theta)\left(p_{i r}^{i c}\right)^{1-\sigma}\right)^{1 /(1-\sigma)},
$$

in which $\theta$ represents the domestic demand share [theta_vdfm $(i, " c ", r)]$.

In addition to the Cobb-Douglas representation of the final demand system, our core model includes a LES, which combines a Cobb-Douglas discretionary demand with a Leontief subsistence demand activity. The added complexity of the LES specification permits the model to be calibrated both to the income and average price elasticities of demand. (See Appendix C for details.) The price indices for discretionary and subsistence demand are defined by:

$$
p_{r}^{D D}=\prod_{i}\left(p_{i r}^{c}\right)^{\theta_{i}}
$$

in which $\theta_{i}$ represents the discretionary value share [theta_cm0 ( $\left.i, " d d ", r\right)$ ].

The price index for subsistence demand is defined by a Leontief cost function:

$$
p_{r}^{S D}=\sum_{i} \theta_{i} p_{i r}^{c}
$$

in which $\theta_{i}$ represents the commodity $i$ share of subsistence demand

[theta_cm0 (i, "sd", r)].

Finally, GAMs code includes a third representation of final demand in the form of the CDE demand system (Hanoch, 1975). This representation, details of which are presented in Appendix D, has been part of the GTAP model in GEMPACK for many years, and our implementation follows those of Hertel and van der Mensbrugghe (2016) and Chen (2015). Similar to the LES demand system, this approach permits calibrating empirical evidence on both own-price and income elasticities. 


\subsubsection{Government demand ( $(" g ", r)$ )}

Public expenditure is a fixed-coefficient aggregate of Armington composite goods. Within each composite domestic and imported goods trade off with a constant elasticity of substitution. The unit price indices for domestic and imported goods are given by:

$$
p_{i r}^{d g}=p_{i r}^{Y} \frac{1+t_{i r}^{d g}}{1+\bar{t}_{i r}^{g d}}
$$

and

$$
p_{i r}^{i g}=p_{i r}^{M} \frac{1+t_{i r}^{i g}}{1+\bar{t}_{i r}^{i g}}
$$

The composite price of the $i$ th good is then:

$$
p g_{i r}=\left(\theta\left(p_{i r}^{d g}\right)^{1-\sigma}+(1-\theta)\left(p_{i r}^{i g}\right)^{1-\sigma}\right)^{1 /(1-\sigma)},
$$

in which $\theta$ represents the domestic share of public demand [theta_vdfm $(i, " g ", r)$ ].

The unit cost of public services $\left(G_{r}\right)$ is defined by the Leontief cost coefficients:

$$
\sum_{i} \theta_{i} p g_{i r}=p_{r}^{G},
$$

in which $\theta_{i}$ represents the value share of commodity $i$ in public expenditure [theta_cmo $(i, " g ", r)]$.

\subsubsection{Aggregate imports (M (i, r ) )}

An import cost index applies export taxes, trade and transport margins and import tariffs to the producer supply prices in exporting regions:

$$
p y_{i s r}^{m}=p_{i s}^{Y} \frac{\left(1-t_{i s r}^{x s}\right)\left(1+t_{i s r}^{m s}\right)}{\left(1-\bar{t}_{i s r}^{x s}\right)\left(1+\bar{t}_{i s r}^{m s}\right)} .
$$

In the case of the soe model, the supply price $p_{i s}^{Y}$ is replaced by export price $p_{i s}^{X}$. The unit price of transportation services is given by:

$$
p t_{j i s r}^{m}=p_{j}^{T} \frac{1+t_{i s r}^{m s}}{1+\bar{t}_{i s r}^{m s}} .
$$

Transportation margins enter as fixed coefficients with bilateral trade flows, so the unit delivered price is a convex combination of the unit prices with weights corresponding to base year value shares:

$$
p y t_{i s r}^{m}=\theta p y_{i s r}^{m}+\sum_{j} \theta_{j}^{T} p t_{j i s r}^{m}
$$

in which $\theta$ represents good $i$ share of imports [theta_vxmd (i,s, r) ]; and $\theta_{j}^{T}$ represents the value share of transportation service $j$ in the import price 
[theta_vtwr $(j, i, s, r)]$.

Having formed a price index for bilateral imports from region $s$ to region $r$, the CEs cost index can be defined on the basis of value shares and the elasticity of substitution across imports from different regions, $\sigma=$ esubm $_{i}$ :

$$
\operatorname{cim}_{i r}=\left(\sum_{s} \theta_{s}\left(p y t_{i s r}^{m}\right)^{1-\sigma)}\right)^{1 /(1-\sigma)},
$$

in which $\theta_{s}$ is the value share of bilateral imports from region $s$ [theta_m (i, $\left.s, r\right)$ ].

The import activity $\left(m_{i r}\right)$ has a zero profit condition which relates the unit cost of imports to the market price of the import aggregate:

$$
\operatorname{cim}_{i r}=p_{i r}^{M} .
$$

3.1.5 International transportation services (YT ( $j)$ )

For simplicity, the unit cost of a transportation service depends on the benchmark value shares of region-specific services through a Cobb-Douglas cost function. Under perfect competition with free entry, the unit cost of international transport services equals the equilibrium market price:

$$
\prod_{r}\left(p_{j r}^{Y}\right)^{\theta_{r}}=p_{j}^{T}
$$

in which $\theta_{r}$ represents the region $r$ share of transportation service $j$ [theta_vst $(j, r)$ ]. In the soe model, the supply price $p_{i s}^{Y}$ in equation is replaced by export price $p_{i s}^{X}$.

3.1.6 Sector-specific factor transformation ( $F T(f, r)$ )

The unit value of sector-specific factors is defined as a CET aggregate of returns to factor $f$ across sectors $j$ :

$$
p v f m_{f r}=\left(\sum_{j} \theta_{j} p s_{f j r}^{1+\eta}\right)^{1 /(1+\eta)} \quad f \in s_{f} .
$$

in which $\theta_{j}$ is the sector $j$ share of earnings for factor $f$ [theta_evom $\left.(f, j, r)\right]$.

The constant elasticity of transformation frontier defines the profit-maximizing allocation of factors to individual sectors. In equilibrium, the unit value of the aggregate factor is equal to the maximum unit earnings:

$$
p_{f r}^{S}=p v f m_{f r} \quad f \in s_{f}
$$

\subsection{Market clearance}

Supply-demand conditions apply to all goods and factors. Benchmark demand and supply quantities appear as scale factors in many of these equations, typically multiplied by activity levels which are equal to unity in the reference 
equilibrium. ${ }^{11}$

\subsubsection{Firm output $(P(i, r))$}

Aggregate output of good $i$ in region $r$ in the reference equilibrium is vom $(i, r)$ :

$$
Y_{i r} v_{0 m} m_{i r}=\sum_{j} d d f m_{i j r}+d d f m_{i C r}+d d f m_{i I r}+d d f m_{i G r}+\sum_{s} d x m d_{i r s}+d s t_{i r}
$$

where the compensated demand functions can be obtained by differentiating the unit cost functions:

$$
\begin{aligned}
d d f m_{i j r} & =Y_{j r} v d f m_{i j r}\left(\frac{c i_{i j r}}{p_{i j r}^{d}}\right)^{\sigma} \\
d d f m_{i C r} & =C_{r}\left(v d f m_{i C r} \frac{p_{r}^{C}}{p c_{i r}}\right)\left(\frac{p_{i r}^{C}}{p_{i r}^{d c}}\right)^{\sigma} \\
d d f m_{i I r} & =I_{r} v d f m_{i I r} \\
d d f m_{i G r} & =G_{r} v d f m_{i G r}\left(\frac{p g_{i r}}{p_{i r}^{d g}}\right)^{\sigma} \\
d x m d_{i s r} & =M_{i r} v x m d_{i s r}\left(\frac{p_{i r}^{M}}{p y t_{i s r}^{m}}\right)^{\sigma} \\
d s t_{j r} & =Y T_{j} v s t_{j r} \frac{p_{j}^{T}}{p_{j r}^{Y}}
\end{aligned}
$$

In the soe model (etrnd $x_{i}<\infty$ ) equation (15) is replaced by two equations, one representing the market for domestic output and another representing the market for exports:

$$
\begin{aligned}
& Y_{i r} d d m_{i r}=\sum_{j} d d f m_{i j r}+d d f m_{i C r}+d d f m_{i I r}+d d f m_{i G r} \\
& Y_{i r} d x m_{i r}=\sum_{s} d x m d_{i r s}+d s t_{i r} .
\end{aligned}
$$

In these expressions, the compensated domestic and export supply coefficients are

\footnotetext{
${ }^{11}$ While not crucial for representation of the model as a nonlinear system of equations, we follow the мсг convention in writing out the market clearance conditions. The equations are "oriented", with supply variables on the LHS and demands on the RHS. Hence, the sense of the equation is supply $\geq$ demand. In the core model equilibrium prices should always be positive, but in extensions of the standard model it might be quite common to introduce inequalities and complementary slackness, in which case the proper orientation of the equations is essential. Hence, in equilibrium should the price of a good be zero, economic equilibrium is then consistent with a market in which supply $>$ demand.
} 
given by:

$$
\begin{aligned}
& d d m_{i r}=v d m_{i r}\left(\frac{r_{i r}^{Y}}{p_{i r}^{D}}\right)^{\eta} \\
& d x m_{i r}=v x m_{i r}\left(\frac{r_{i r}^{Y}}{p_{i r}^{X}}\right)^{\eta} .
\end{aligned}
$$

3.2.2 Private consumption $(\mathrm{P}(\mathrm{C} ", \mathrm{r})$ )

Consumer demand in region $r$ in the reference equilibrium is $v o m_{C r}$ hence:

$$
C_{r} \text { vom }_{C r}=\frac{R A_{r}}{p_{r}^{C}}
$$

3.2.3 Composite imports (PM $(i, r))$

The aggregate value of imports of good $i$ in region $r$ in the reference equilibrium is vimir:

$$
M_{i r} \operatorname{vim}_{i r}=\sum_{j} d i f m_{i j r}+d i f m_{i C r}+d i f m_{i G r}
$$

where compensated demand functions are given by:

$$
\begin{aligned}
\operatorname{difm}_{i j r} & =Y_{j r} v i f m_{i j r}\left(\frac{c i_{i j r}}{p_{i j r}^{i}}\right)^{\sigma} \\
\operatorname{difm} m_{i C r} & =C_{r} v i f m_{i C r}\left(\frac{p c_{i r}}{p_{i r}^{i c}}\right)^{\sigma} \frac{p_{r}^{C}}{p c_{i r}} \\
\operatorname{difm} m_{i G r} & =G_{r} v i f m_{i G r}\left(\frac{p g_{i r}}{p_{i r}^{i g}}\right)^{\sigma}
\end{aligned}
$$

\subsubsection{Transport services $(\mathrm{PT}(j))$}

The aggregate demand (and supply) for transport service $j$ in the benchmark equilibrium is $v t w_{j}$ :

$$
Y T_{j} v t w w_{j}=\sum_{i s r} d t w r_{j i s r}
$$

where

$$
d t w r_{j i s r}=M_{i r} v t w r_{j i s r}\left(\frac{p_{i r}^{M}}{p y t_{i s r}^{m}}\right)^{\sigma} .
$$




\subsubsection{Primary factors $(P F(f, r))$}

The aggregate demand (and supply) of primary factor $f$ in region $r$ is evom $_{f_{r}}$ :

$$
\text { evom }_{f r}= \begin{cases}\sum_{j} d f m_{f j r} & f \in m_{f} \\ \text { evom }_{f r} F T_{f r} & f \in s_{f}\end{cases}
$$

where the demand for primary factor is given by:

$$
d f m_{f j r}=Y_{j r} v f m_{f j r}\left(\frac{c_{j r}^{f}}{p_{f j r}^{p f}}\right)^{\sigma} .
$$

3.2.6 Specific factors $(P S(f, j, r))$

The net value of benchmark payments to factor $f$ in sector $j$ in region $r$ is $\operatorname{vfm}(f, j, r)$ :

$$
v f m_{f j r}\left(\frac{p_{s_{f}, j r}^{S}}{p_{s_{f}, r}^{F}}\right)^{\eta}=d f m_{f j r}
$$

where the demand for primary factor is written above.

\section{$3 \cdot 3$ Regional budget ( $R A(r)$ )}

Private and public incomes are given by :

$$
R A_{r}=\sum_{f} p_{f r}^{F} \text { evom }_{f r}+p_{n}^{C} v b_{r}-p_{r}^{I} v \text { m }_{I r}-p_{r}^{G} v o m_{G r}+\mathcal{R}_{r}
$$

The base year current account deficit in region $r$ is $\mathrm{vb}(r)$, and region $r=n$ corresponds to the "numeraire region" who's consumption prices denominates international capital flows (following conventional static trade theory, we hold the current account deficit fixed in counterfactual analysis). Furthermore, tax revenue in region $r$ consists of output taxes, intermediate demand taxes, factor taxes, final demand taxes, import tariffs and export subsidies:

$$
\begin{aligned}
\mathcal{R}_{r}= & \sum_{j} \mathcal{R}_{j r}^{o}+\sum_{i j}\left(\mathcal{R}_{i j r}^{f d}+\mathcal{R}_{i j r}^{f i}\right)+\sum_{f j} \mathcal{R}_{f j r}^{f} \\
& +\sum_{i}\left(\mathcal{R}_{i r}^{p d}+\mathcal{R}_{i r}^{p i}+\mathcal{R}_{i r}^{g d}+\mathcal{R}_{i r}^{g i}\right)-\sum_{i s} \mathcal{R}_{i r s}^{x s}+\sum_{i s} \mathcal{R}_{i s r}^{m s}
\end{aligned}
$$

Each of these components of tax revenue can be calculated as an ad-valorem or proportional tax rate times a market price times the quantity demanded or produced.

Taxes related to $Y_{j r}$ include output taxes: ${ }^{12}$

$$
\mathcal{R}_{j r}^{o}=t_{j r}^{o} v_{0} m_{j r} p_{j r}^{Y} Y_{j r} \quad\left[\operatorname{REV} \operatorname{RO}_{-}(\mathrm{g}, \mathrm{r})\right],
$$

${ }^{12}$ Tax revenues in the GAMS codes - both MCP and MGE are represented by the macros indicated in square brackets. 
tax revenue from intermediate inputs:

$$
\begin{aligned}
& \mathcal{R}_{i j r}^{f d}=t_{i j r}^{f d} p_{i r}^{Y} d d f m_{i j r} \quad\left[\operatorname{REV} \_\operatorname{TFD}(i, j, r)\right], \\
& \mathcal{R}_{i j r}^{f i}=t_{i j r}^{f i} p_{i r}^{M} d i f m_{i j r}, \quad\left[\operatorname{REV} \_\operatorname{TFI}(i, j, r)\right],
\end{aligned}
$$

and factor tax revenue:

$$
\mathcal{R}_{f j r}^{f}=t_{f j r}^{f} p_{f r}^{F} d f m_{f j r} \quad\left[\operatorname{REV}_{-} \mathrm{TF}(\mathrm{f}, \mathrm{g}, \mathrm{r})\right] .
$$

Taxes on household consumption of domestic and imported goods are:

$$
\mathcal{R}_{i r}^{p d}=t_{i r}^{p d} p_{i r}^{Y} d d f m_{i C_{r}}, \quad\left[\operatorname{REV}_{-} \mathrm{TFD}(\mathrm{i}, \mathrm{C} ", \mathrm{r})\right],
$$

and

$$
\left.\mathcal{R}_{i r}^{p i}=t_{i r}^{p i} p_{i r}^{M} d i f m_{i G r} \quad[\text { REV_TFI (i, "C", r })\right] .
$$

Taxes on public demand for domestic and imported goods are:

$$
\mathcal{R}_{i r}^{g d}=t_{i r}^{g d} p_{i r}^{Y} d d f m_{i G r} \quad\left[\operatorname{REV} \operatorname{TFD}\left(i, \mathrm{GG}^{\prime}, \mathrm{R}\right)\right],
$$

and

$$
\left.\mathcal{R}_{i r}^{g i}=t_{i r}^{g i} p_{i r}^{M} d i f m_{i G r} \quad[\text { REV_TFI (i, "G", r })\right] .
$$

Export subsidies (paid by the government in the exporting region) are:

$$
\mathcal{R}_{i r s}^{x s}=t_{i r s}^{x s} p_{i r}^{Y} d x m d_{i r s} \quad\left[\operatorname{REV}_{\text {IXS }}(i, \mathrm{r}, \mathrm{s})\right],
$$

and import tariff revenues are given by:

$$
\mathcal{R}_{i s r}^{m s}=t_{i s r}^{m s}\left(p_{i s}^{Y}\left(1-t_{i s r}^{x s}\right) d x m d_{i s r}+\sum_{j} p_{j}^{T} d t w r_{j i s r}\right) \quad\left[\operatorname{REV} \_\mathrm{TMS}(\mathrm{i}, \mathrm{s}, \mathrm{r})\right] .
$$

\section{Implementation}

This section describes the implementation of GMR and SOE models in GAMs using the GTAP 9 dataset. We first describe the content of the distribution directory, and provide the logic of the model buildstream. We then discuss a number of issues related to data manipulation, namely aggregation across commodities and regions, data filtering and re-balancing. Finally, we discuss calibration of elasticities for international trade in GMR and SOE models, providing an intuitive (Marshallian) argument on how models can be parametrized in order to approximate the same responsiveness to policy shocks.

\subsection{Distribution Folders}

In this section we overview the structure of the distribution directory. Practicalities on how to run the code is provided in Appendix B. Details of the directories and GAMS programs provided in GTAPINGAMS version 9 are provided in Appendix 
E. More detailed comments may also be found interspersed in the GAMS code presented in Appendix F.

The distribution directory contains seven second-level subdirectories, whose content we now overview in alphabetical sequence:

BUILD contains a command script which automates dataset construction and testing. This script (build.gms) calls programs stored in the CODE subfolder, including FLEX2GDX.GMS, which translates data from .HAR to .GDX format, ${ }^{13}$ FILTER.GMS, a program which filters and then rebalances the core dataset (see data filtering section below), GTAP9DATA.GMS, a program which reads a .GDX GTAPINGAMS dataset, GTAPAGGR.GMS, a program which performs dataset aggregation, and CDECALIB.GMS, a program which computes coefficients of the CDE demand system which are consistent with price and income elasticities of demand.

The distributed copy of build.gms reads, filters and aggregates data files for 2011. At the end of the computational process, listing files can be found in the BuILD directory, while the associated .GDX data files generated by these routines are saved in the GAMSDATA directory.

This directory also contains programs for consistency testing of generated datasets. test.gms runs bmkchk. gms, cdechk.gms and mcpmge.gms. See Appendix E for a description of these programs.

CODE contains the main GAMS program files which are included in this distribution. These files need not reside in this directory, but they are self contained and should always be moved as a collection. Two of the files in this directory contain GAMS code for the canonical static model, both specified as a mixed complementarity problem in two alternative representations:

MGE.GMS The standard model with tabular GAMS/MPSGE representation, and

MCP.GMS The standard model with an algebraic GAMS/MCP representation.

DEFINES contains mapping files for aggregations of GTAP 9 datasets. Files ending with .MAP define an aggregation in terms of the source dataset and mappings from sets in the source to sets in the target. Three single dimensional sets and three two-dimensional tuples are included in each mapping file. The sets and tuples are defined as follows:

13 The .HAR format is used in the original distribution of the GTAP 9 Data Base. These data files need to be obtained separately and stored in the GTAPDATA subdirectory, which is discussed below. 


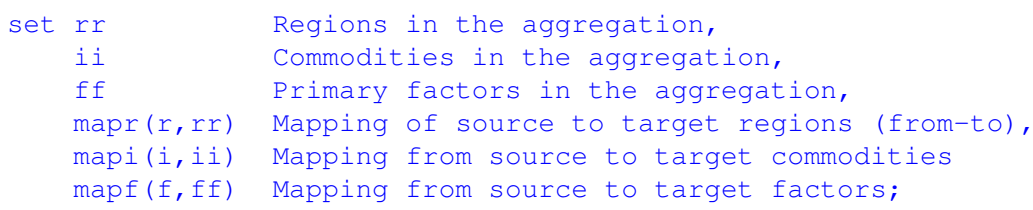

As an example, here is a set and mapping which aggregates skilled labor types:

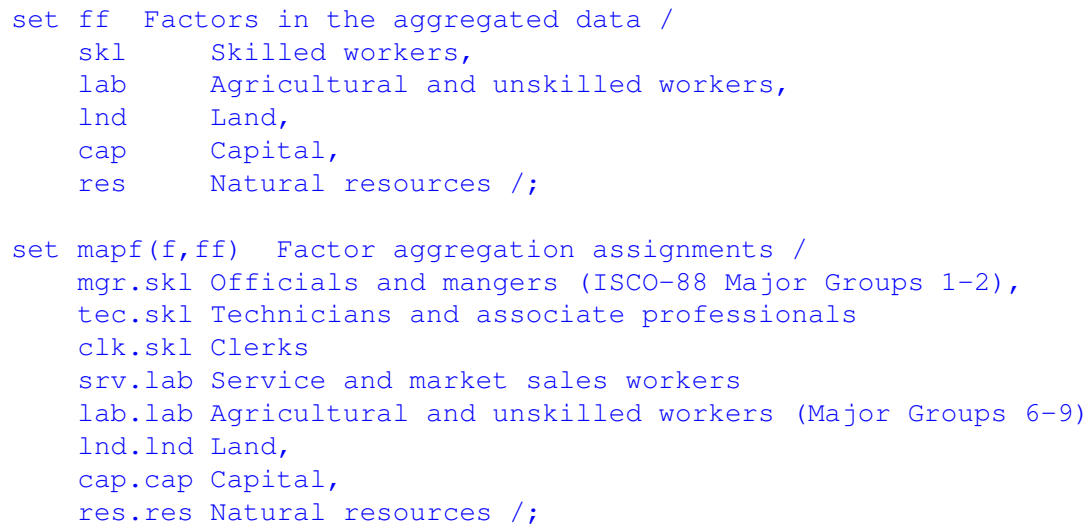

Four alternative regional / commodity aggregation are included in the DEFINES directory to illustrate how aggregation works in GTAPINGAMS. The first is the full disaggregate dataset GTAPINGAMS.MAP which retains all regions and markets from the GTAP 9 Data Base after original data have been filtered and a few sector labels have been changed. ${ }^{14}$

Three aggregated datasets are based on regional disaggregation which distinguishes the G20, other oil exporters, a composite region representing other low income countries and a composite region representing other middle income countries. The G20_IEA aggregates commodities into 23 sectors included in the International Energy Agency energy database, and G2O_MACRO aggregates to a four commodity sectoral mapping distinguishing agriculture, manufacturing, services and energy.

DOC contains the paper you are reading (please check the version).

14 The sectoral identifier which differ from the GEMPACK model are as follows: oIL (crude oil) is relabeled CRU, COA (coal) becomes COL, P_C (petroleum and coal products) becomes OIL, ELY (electricity) becomes ELE, and ELE (electronic equipment) becomes EEQ. 
and $f$ the set of primary factors. Table A.I presents the identifiers for the 57 GTAP 9 sectors (plus CGD investment goods) in their most disaggregate form (see Appendix A). These sectors may be aggregated freely to produce more compact dataset.

Aggregation across commodities involves the reclassification of goods at $a$ benchmark point in the price space. If we index the disaggregate goods using $i, j$ and index the corresponding aggregated goods with $I$, $J$, we can identify commodities combined to form $I$ as $i \in \mathcal{I}_{I}$. Aggregation at reference prices $\bar{p}_{i}$ implies that the value of aggregate demand equals the value of the constituent disaggregate demand: ${ }^{15}$

$$
\bar{p}_{I} C_{I}(\bar{p})=\sum_{i \in \mathcal{I}_{I}} \bar{p}_{i} C_{i}(\bar{p}) .
$$

Furthermore, consistent exact aggregation implies that both demand and the elasticity of demand at the benchmark point in the aggregate model coincides with the demand response in the disaggregate model, taking benchmark prices into account. Formally:

$$
\left.\bar{p}_{J} \frac{\partial C_{I}}{\partial p_{J}}\right|_{\bar{p}}=\left.\sum_{i \in \mathcal{I}_{I}, j \in \mathcal{I}_{J}} \bar{p}_{j} \frac{\partial C_{i}}{\partial p_{j}}\right|_{\bar{p}} .
$$

An implication is that the Allen-Uzawa elasticity of substitution (AUES) matrix of the aggregate model has to correspond to value share-weighted average of terms in the AUES matrix of the disaggregate model:

$$
\hat{\sigma}_{I J}=\sum_{i \in \mathcal{I}_{I}, j \in \mathcal{I}_{J}} \frac{\theta_{i}}{\hat{\theta}_{I}} \frac{\theta_{j}}{\hat{\theta}_{J}} \sigma_{i j}
$$

where $\hat{\theta}_{I}, \hat{\theta}_{J}$ are the value share of inputs $I$ and $J$ in the aggregate cost function, and $\hat{\sigma}$ is the AUES matrix in terms of the aggregate prices. ${ }^{16}$

${ }^{15}$ We use $\bar{p}_{i}$ and $\bar{p}_{I}$ in this expression to emphasize the role of price as an aggregation weight, but without loss of generality, we may assume that the reference price vectors $\bar{p}_{i}=1 \quad \forall i$ and $\bar{p}_{I}=1 \quad \forall I$. This Harberger normalization greatly simplifies notation. When units are scaled so that the unit cost at this point is one, values shares at this point are identically equal to share parameters in the CES function, i.e. $\alpha_{i}=\theta_{i}$, and benchmark demands are equal to value shares, i.e. $\bar{C}_{i}=\theta_{i}$.

${ }^{16}$ Note that exact aggregation based on (27) is only possible when working with a specific functional form, in which case own-price elasticities in the aggregated model are:

$$
\epsilon_{I}=\hat{\theta}_{I} \sigma_{I I}=\hat{\theta}_{I} \sum_{(i j) \in \mathcal{I}_{I}} \frac{\theta_{i}}{\hat{\theta}_{I}} \frac{\theta_{j}}{\hat{\theta}_{I}} \sigma_{i j}
$$

Note also that if we had information about benchmark value shares $\left(\theta_{i}\right)$ and benchmark elasticities of demand $\left(\epsilon_{i}\right)$, but no information regarding off-diagonal terms in the AUES matrix $\sigma_{i j}, i \neq j$, the vectors $\theta_{i}$ and $\epsilon_{i}$ may or may not be consistent with a given cost 
In practice, our aggregation routine proceeds as follows. First, we construct the full AUES matrix from the CDE parameters at the benchmark point (subparir in the GTAP Data Base), using expression (D.4) in Appendix D. Second, to ensure a consistent demand response when the data is aggregated across commodities, we use the aggregated value shares and the diagonal terms of the AUES matrix to recalibrate coefficients of the CDE demand system.

\subsubsection{Aggregation across regions}

Suppose that we aggregate across regions as well as across commodities. ${ }^{17}$ Cost functions in regions $r$ and $r^{\prime}$ are disjoint, so the demand response for $p_{i r}$ does not depend on $p_{i r^{\prime}}$. We therefore begin by calculating price elasticities for the aggregate goods within each region, and then produce a quantity-weighted aggregation of elasticities across regions. Therefore, the own-price elasticity of demand for aggregate commodity $I$ in aggregate region $R$ is given by:

$$
\epsilon_{I R}=\frac{\sum_{r \in \mathcal{R}_{R}} \epsilon_{I r} \bar{C}_{I r}}{\sum_{r \in \mathcal{R}_{R}} \bar{C}_{I r}},
$$

where $\bar{C}_{I r}$ is benchmark consumption. As noted in footnote 15 , because of the Harbgerger normalization, it is also equal to the value shares.

function. In this setting, aggregation can use a simplifying assumption that the average off-diagonal AUES in the aggregation-relevant terms equals the overall average off-diagonal value for each of the constituent goods. From this it follows that average share-weight offdiagonal AUES value associated with input $i$ is given by:

$$
\bar{\sigma}_{i}=\frac{\epsilon_{i}}{\theta_{i}-1}
$$

Substituting $\bar{\sigma}_{i}$ for $\sigma_{i j}$ in (28), we have a formula for an inexact aggregation:

$$
\hat{\epsilon}_{I}=\sum_{i \in \mathcal{I}_{I}}\left(\frac{1-1 / \hat{\theta}_{I}}{1-1 / \theta_{i}}\right) \frac{\theta_{i}}{\theta_{I}} \epsilon_{i}
$$

In either exact aggregation (working from a full AUEs matrix) or inexact aggregation (based on average off-diagonal values), we find that $\theta_{i}<\theta_{I} \quad \forall i \in \mathcal{I}_{i}$, hence the elasticity of demand for composite good $I$ is less than a weighted sum of the elasticities of demand in the constituent goods:

$$
\left|\hat{\epsilon}_{I}\right|<\sum_{i \in \mathcal{I}_{I}} \frac{\theta_{i}}{\hat{\theta}_{I}}\left|\epsilon_{i}\right| .
$$

17 Note that regional identifiers in the full dataset correspond to ISO alpha-3 country codes. Users can define their own aggregations of the GTAP Data Base and use any labels to describe regions. For technical reasons, if a dataset is to be used with MPSGE, then regional identifiers can have at most 4 characters. Table A.2 presents the three-character identifiers which are normally used for primary factors. 
Own-price elasticities together with value shares define diagonal terms in the Allen-Uzawa elasticity matrix. To compute off-diagonal AuEs terms, we use a value-weighted aggregation of cross-price elasticities across regions. In particular, cross-price (compensated) elasticities are given by:

$$
\epsilon_{I J r}=\frac{\sum_{i \in \mathcal{I}_{I}, j \in \mathcal{I}_{J}} \sigma_{i j r} \bar{C}_{i r} \bar{C}_{j r}}{\sum_{i \in \mathcal{I}_{I}, j \in \mathcal{I}_{J}} \bar{C}_{i r} \bar{C}_{j r}} \theta_{J r} .
$$

To ensure that these terms are consistent with the adding up condition of the AUES matrix, we average these terms across constituent regions and scale them appropriately:

$$
\sigma_{I J R}=\lambda_{I R}\left(\frac{\sum_{r \in \mathcal{R}_{R}} \epsilon_{I J r} \psi_{I J r R}}{\theta_{J R}}\right) \quad \forall I \neq J
$$

in which

$$
\psi_{I J r R}=\frac{\bar{C}_{I r} \bar{C}_{J r}}{\sum_{r^{\prime} \in \mathcal{R}_{R}} \bar{C}_{I r^{\prime}} \bar{C}_{I r^{\prime}}},
$$

and the scaling factor $\lambda_{I R}$ is chosen so that $\sum_{J} \sigma_{I J R} \theta_{J R}=0$. Given our somewhat ad-hoc treatment of off-diagonal terms, it seems sensible to define aggregations from the GTAP Data Base with full commodity and regional details rather than from a dataset which has already been aggregated.

\subsection{Data filtering}

The GTAP source data in original form presents substantial challenges for calibrated models processed using direct solution methods (e.g., PATH, CONOPT or IPOPT). In our experience, most numerical problems with GTAPINGAMs models can be traced to density of the source data in which we find large numbers of small coefficients. These coefficients portray economic flows which are a negligible share of overall economic activity, yet impose a significant computational burden during matrix factorization.

In order to "filter" these economically insignificant value and reduce dimensionality of the problem, GTAPINGAMs includes a GAMS program (FILTER.GMS) which removes small values which are smaller than a specified tolerance level. An input to this program (ND) determines the filter tolerance, i.e. the number of decimals for the smallest coefficient to be retained in the data. For example, when $n d=4$, the smallest coefficient in the benchmark social accounting matrix is 0.0001. When $n d=6$, the smallest number is 0.000001 , etc. Larger values of ND retain a larger number of small coefficients in the filtered dataset. Filtering makes a GTAP Data Base smaller, as illustrated in Table 6 in which it can be seen that filtering reduces the size of a GTAP Data Base by somewhere between $20 \%$ and $50 \%$, depending on the filtering tolerance.

Most of the reduction in non-zeros results from the elimination of small intermediate inputs and bilateral trade flows. Importantly, the filtering procedure has 
Table 6. Filtering results for entire dataset (2011 data).

\begin{tabular}{|c|c|c|c|c|c|c|c|}
\hline & \multicolumn{4}{|c|}{ Nonzeros (1000) } & \multirow{2}{*}{\multicolumn{3}{|c|}{ \% Reduction }} \\
\hline & Dataset & Aft & ter Filt & ering & & & \\
\hline & $n d=$ & 4 & 5 & 6 & 4 & 5 & 6 \\
\hline Domestic Intermediate $v d f m$ & 478.8 & $233 \cdot 3$ & 290.7 & 342.2 & 51 & 39 & 29 \\
\hline Imported Intermediate vifm & 478.8 & 186.5 & 5247.6 & 300.3 & 61 & 48 & 37 \\
\hline Bilateral trade $v t w r$ & 776.4 & 175.4 & 314.2 & 463.8 & 77 & 60 & 40 \\
\hline Transport margins vxmd & 109.8 & 400.9 & 591.1 & 766.8 & 63 & 46 & 30 \\
\hline
\end{tabular}

differential impacts on regions and markets in the database, and the choice of a filter tolerance depends to some extent on the size of the countries to be included in a given analysis. For our analysis of the G2o countries in the present paper, a filter tolerance $n d=5$ seems suitable, whereas $n d=7$ leads to numerical problems due to small coefficients. Therefore, depending on the nature of the policy question under investigation, different filtering strategies may be adopted. Individual researchers may have their own opinions about how to select parameter values should be rounded to zero. The version of filter. gms provided with the GTAPINGAMS distribution is intended to provide a starting point for this step in the dataset development process.

Removing small entries from the dataset implies that the resulting filtered dataset no longer represent a micro-consistent matrix. However, unlike earlier versions of GTAPINGAMS, we do not use a nonlinear optimization framework to rebalance the data. Instead, filter.gms moves imbalances resulting from omitted coefficients into either factor supplies or investment demand depending on the sign of imbalance which appears following filtering. This approach to reconciliation is simple to implement provided that the inconsistencies resulting from filtering are small. The reconciliation methodology implemented in filter.gms is perhaps less useful for large scale recalibration exercises such as might arise with a wholesale change in benchmark tax rates or production structure.

In practice, we note that for $n d=5$, the data rebalancing procedure imposes very small changes in the remaining nonzero elements, but it substantially reduces the number of coefficients in the dataset as indicated in Table 6. Nearly half of the trade flow and imported intermediate demand coefficients can be dropped, resulting in a reduction in the size of the dataset from nearly $44 \mathrm{MB}$ to $27 \mathrm{MB}$. More importantly, sparsity tends to improve robustness. Larger models are easier to solve when the underlying datasets have been carefully filtered.

\subsection{Calibration of trade elasticities}

Our sOE model is based on the idea that goods are differentiated both on the basis of origin and destination. In this setting, production supplies goods for the 
domestic and export markets with a technology capturing the idea that the quantities supplied to these submarkets depend on relative prices. Each traded good then has three associated trade elasticities: i) etadx (i), the elasticity of transformation between goods produced for the the domestic and export markets; ii) esubdm (i), the elasticity of substitution between domestic and imported varieties entering intermediate and final demand, and iii) esubm (i), the elasticity of substitution between imports from different countries.

In the GMR model corresponding to the standard GTAP model, $\eta^{D X}=\infty$, so goods produced for the domestic and export markets are perfect substitutes. In the GTAPINGAMS framework, $\eta^{D X}$ can take on any nonnegative value. A finite value is typically specified in the soe model. When doing this, we adjust the domestic-import demand elasticity to maintain consistency with trade responses in the standard GTAP model. We interpret consistency from a Marshallian perspective. In a given market, suppose the import demand elasticity is $\epsilon^{18}$ and benchmark rate of protection is $\bar{t}$. Scaling units so that the FOB supply price is 1 , the demand price is $1+\bar{t}$, and the quantity demanded in the benchmark is 1 .

When the import supply elasticity from partner countries, $\eta$, is infinite, the import supply price is fixed $(p=1)$. Therefore, if the tariff was removed and demand is isoelastic, the new equilibrium quantity and price (in an isoelastic model) are given by:

$$
q^{*}=(1+\bar{t})^{|\epsilon|} .
$$

With a fixed import supply price, the quantity demanded at $p=1$ is the new equilibrium. This outcome is illustrated in Figure 9a, in which benchmark import demand is at price-quantity point $a$, benchmark import supply is at point $b$, and there is a benchmark trade barrier equal to $20 \%$. The free-trade equilibrium is at point $c$, reflecting benchmark import demand elasticity $\epsilon=5$.

Now instead of a perfectly elastic import supply we consider $\eta<\infty$. In this case, removing tariffs implies a new equilibrium supply price $p^{*}$, and the associated equilibrium supply and demand $q^{*}$ from (30) is given by:

$$
q^{*}=\left(\frac{1+\bar{t}}{p^{*}}\right)^{|\epsilon|}=\left(p^{*}\right)^{\eta} \text {. }
$$

The aggregate trade response under $\eta<\infty$ equals the response with $\eta=\infty$ when the demand elasticity $(\epsilon)$ is adjusted upward:

$$
p^{*}=(1+\bar{t})^{|\epsilon| / \eta},
$$

${ }^{18}$ When value shares are small, the price elasticity of demand for imports is approximately equal to -esubdm (i) . 


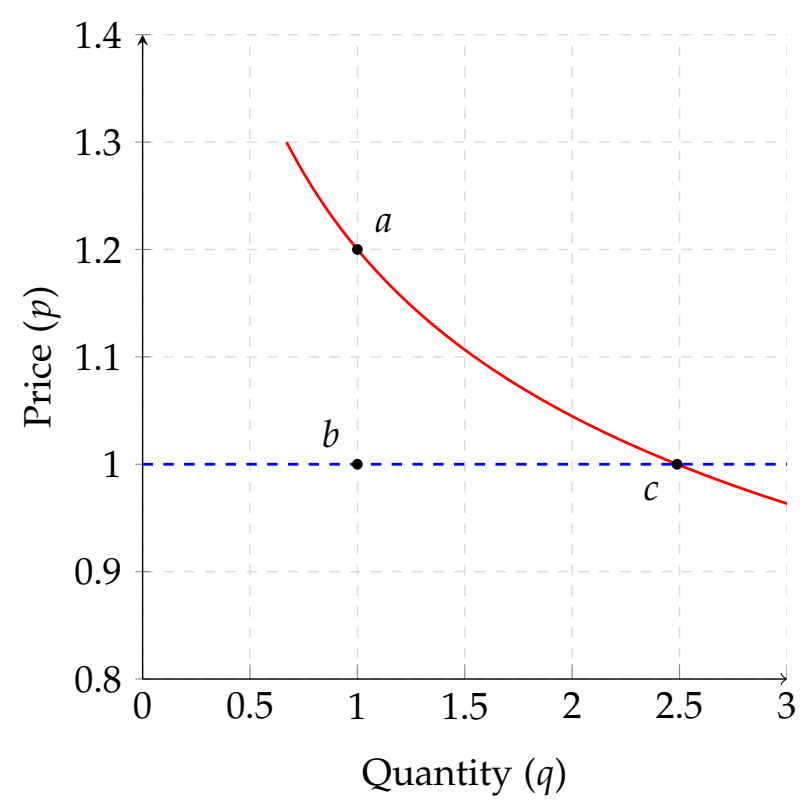

(a) $\epsilon=5, \eta=\infty$.

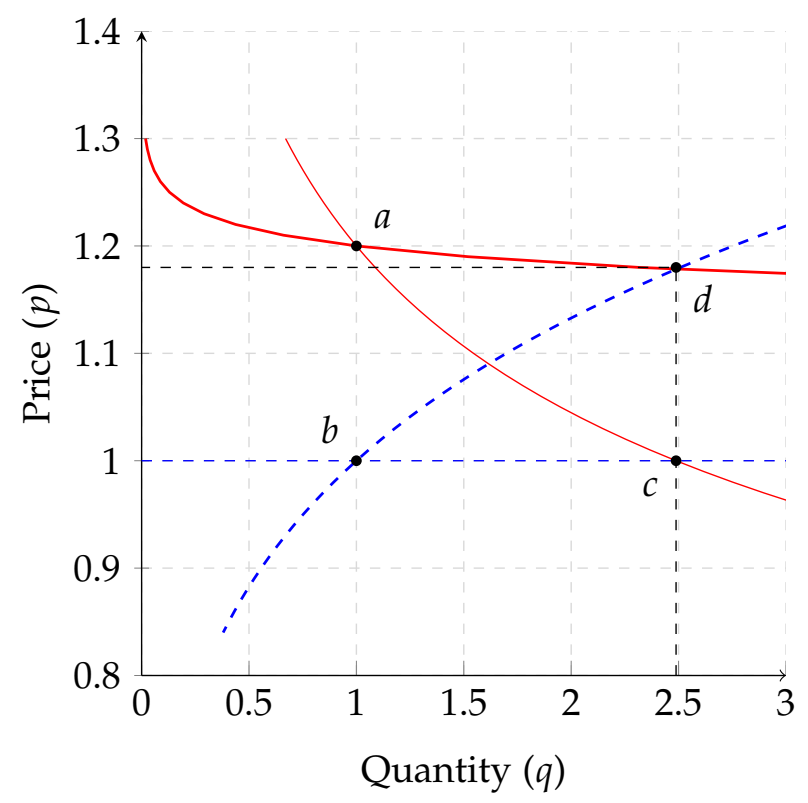

(b) $\epsilon=16.7, \eta=7.1$.

Figure 9. Consistent Calibration of $\epsilon$ and $\eta$. 
the reparametrized elasticity of demand is given by:

$$
|\epsilon|=\frac{|\epsilon|}{1-|\epsilon| / \eta} \text {. }
$$

Let $\theta=1-|\epsilon| / \eta$. Consistency of trade quantity responses in the revised model implies that $\theta \geq 0$. When $\eta=\infty$, then we have the original model with a horizontal import supply curve. Setting $\theta=0.3$, the new Marshallian model appears in Figure $9 \mathrm{~b}$. As in the previous model, $a$ and $b$ are benchmark demand and supply with a $20 \%$ tariff barrier. While free trade in the original model is at point $c$, free trade in the revised model is at point $d$. Supply is less elastic, so social surplus increases are captured by the supply side of the market, and the equilibrium price following tariff removal increases by over $10 \%$ from the benchmark level.

In the GAMs code, this adjustment takes place at the top of gtap9data.gms file. The run-time environment variable thetadx defines how the adjustment of export supply and import demand is to be calibrated to match the GMR model. The associated assignments are reported here.

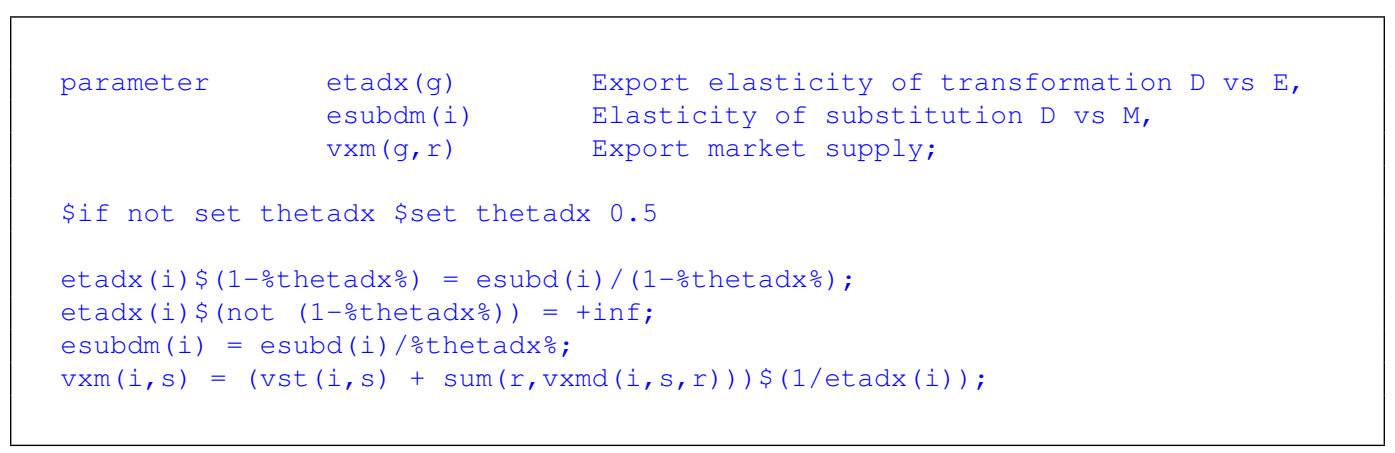

\section{Illustrative Calculations}

We conclude by reporting on a few simulations which illustrate the importance of model closure for assessing the economic effects of policy reform. The GMR and soE models are well suited to help understand the role of terms of trade in policy experiments. In these simulations, we consider on the economic impact of unilateral, proportional adjustment of regional import tariffs and export taxes. Furthermore, as a matter of illustration, we will focus only on results for the United States (USA) and China (CHN). ${ }^{19}$

We start by summarizing the commodity-based and regional structure of taxes on imports to USA and CHN in the 2011 base year database. This is reported in Figures 10 and 11 respectively, with the top panel (a) reporting data for the US,

${ }^{19}$ Region CHN in our G2O aggregation includes GTAP regions CHN and HKG. 


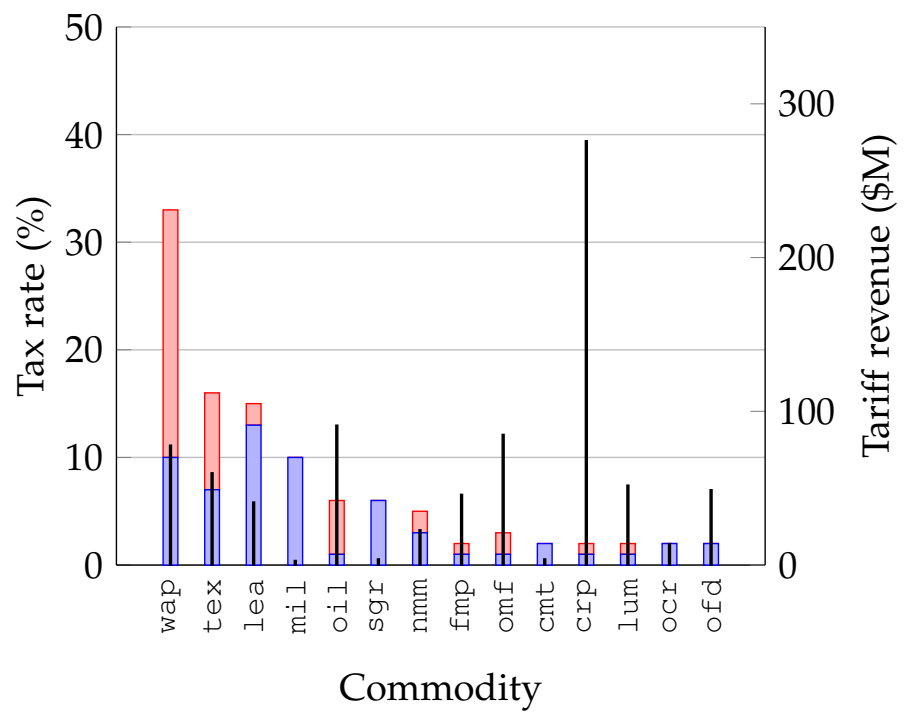

(a) USA imports.

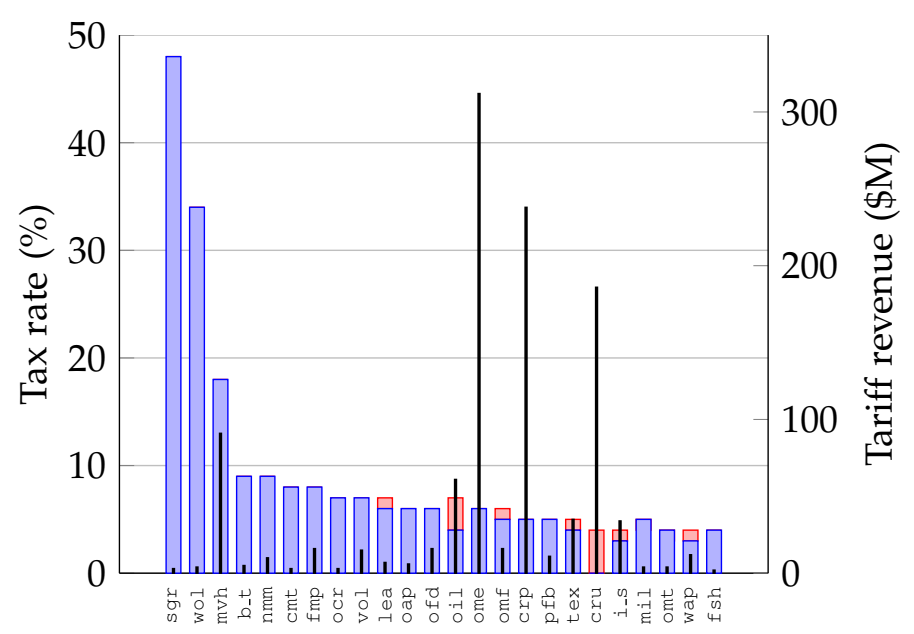

Commodity

(b) China imports.

$\square$ Import tariff rate (left axis)

$\square$ Export tax rate (left axis)

- Tariff revenue (right axis)

Figure 10. Trade taxes and tariff revenue by commodity. 


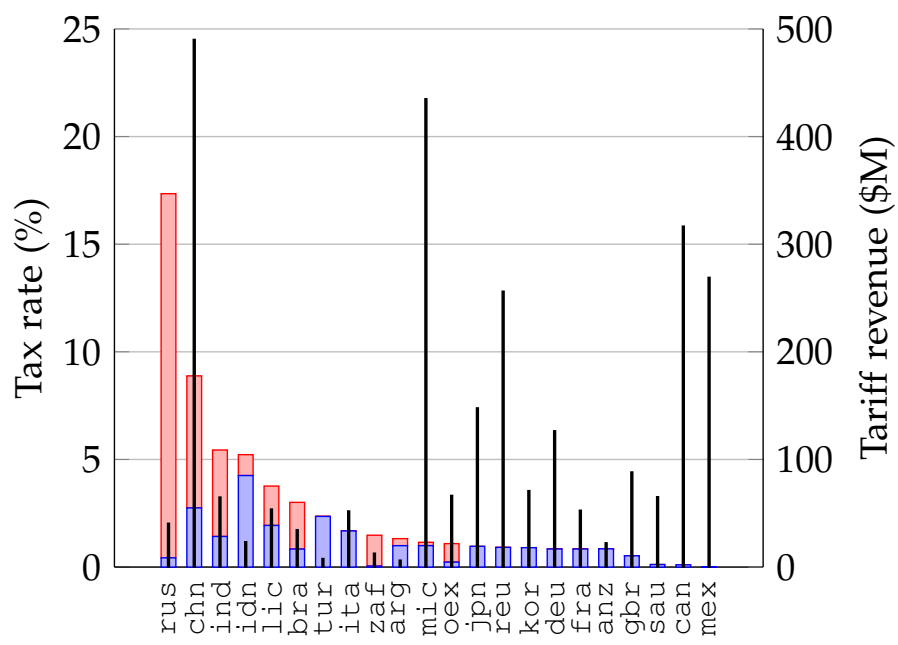

Trading partner

(a) USA imports.

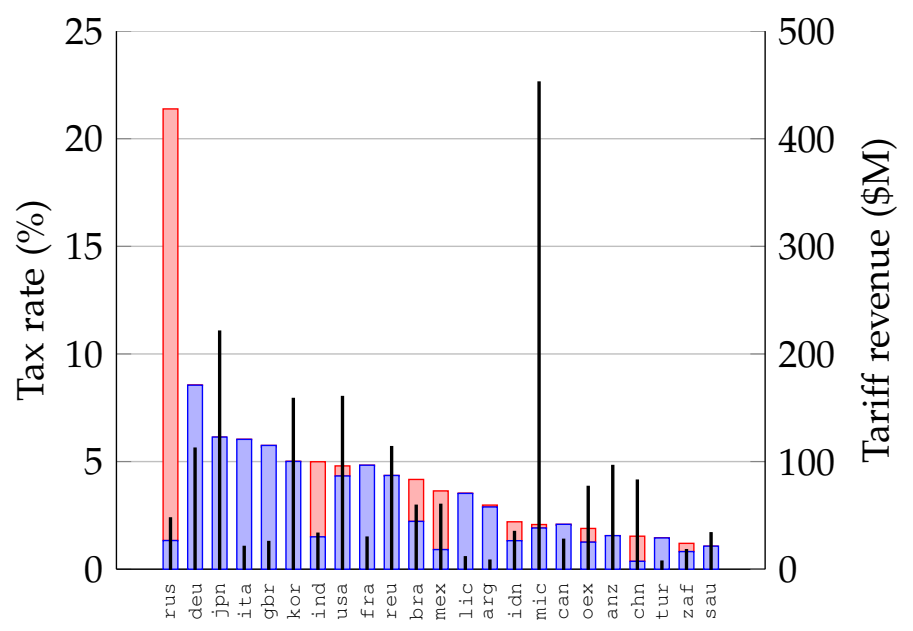

Trading partner

(b) China imports.

$\square$ Import tariff rate (left axis)

$\square$ Export tax rate (left axis)

- Tariff revenue (right axis)

Figure 11. Trade taxes and tariff revenue by partner. 
and the bottom panel (b) for China. In the figures, we report both import tariff rates by the importing country and export taxes applied by the exporting regions. We further report total tariff revenue for each commodity or region in million US\$.

As the top panel of figure 1o shows, taxes applied to USA imports are highest on wearing apparel (WAP), textiles (TEx), and leather (LEA). In the GTAP 9 Data Base, these goods are subject to substantial export taxes. Among the highest taxed goods, the highest tariff revenue is associated with imports of chemicals, rubber and plastic products (CRP). Data for China, reported in the bottom panel of figure 10, shows that imports to China of sugar (SGR), "wool, silk-worm cocoons" (WOL), and "motor vehicles and parts" (MVH) are subject to tariffs of $20 \%$ or more, but the largest tariff revenue (among the highest taxed imports) are on "machinery and equipment" (OME), CRP and crude oil (CRU).

Turning to the regional structure of taxes on imports, data for the US reported in figure 11 suggest that the highest trade taxes are applied on imports from Russia, China, India and Indonesia. Export taxes are the largest fraction of taxes on imports from Russia, China and India. Tariff revenue is concentrated on the countries which have the highest exports to the USA, China, Canada, Mexico and the European Union. Tariff rates are, however, quite low on these imports.

The bottom panel of figure 11 summarizes the regional structure of taxes on imports to CHN in 2011. Taxes on imports to China are highest from Russia, again largely on the basis of export taxes applied by Russia. China's import tariffs average around $5 \%$ on imports from the OECD countries (Japan, European Union, the United States). The largest share of import tariff revenue is associated with imports from middle income countries (MIC).

Overall, average taxes on imports by the US (including both export taxes applied by trade partners and import tariffs collected by USA) are a little less than $2 \%$. Taxes on imports to China average a bit more than $4 \%$. We note that relative to other countries in the database, the United States and China have relatively low trade taxes. Taxes in both countries are far from uniform, hence proportional increases in trade taxes might be expected to increase the distortionary cost of the existing tax system.

The results of our stylized policy experiment, in both the SOE and GMR models, are shown in Figure 12. Unilateral proportional adjustments to the average tax rate vary from $0 \%$ (free trade) to $10 \%$, and we report the Hicksian equivalent variation (EV) as a measure of the welfare change associated with varying tax rates. Furthermore, in the figures the benchmark situation described above is represented by a solid dot. Note also that for both models we use the CDE model to represent final demand, and study the sensitivity of results to final demand specification in Figure 13 below.

In the GMR framework, China increases welfare through a small decrease in trade taxes (to $4 \%$ ) while the US can only slightly increase welfare by increasing trade taxes (to roughly $4.5 \%$ ). In these simulations, the welfare impact depends whether 
Journal of Global Economic Analysis, Volume 1 (2016), No. 2, pp. 1-77.

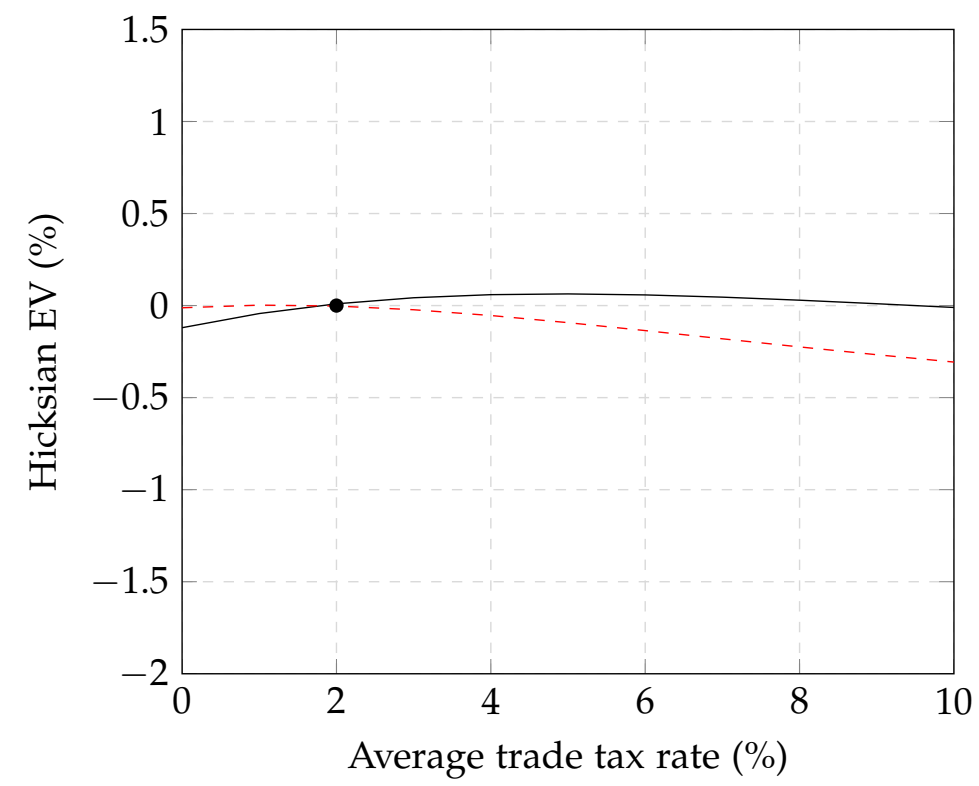

(a) USA.

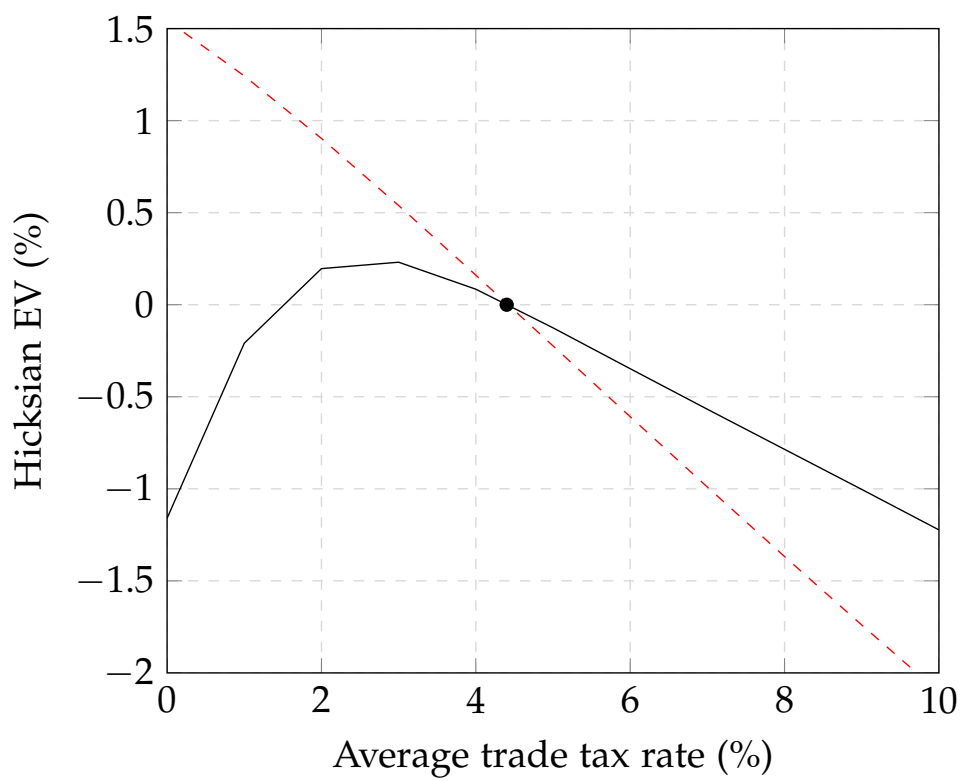

(b) China.

- Global multiregional (GMR) model

- - Small open economy (SOE) model

Figure 12. Welfare effect of unilateral policy. 
Journal of Global Economic Analysis, Volume 1 (2016), No. 2, pp. 1-77.

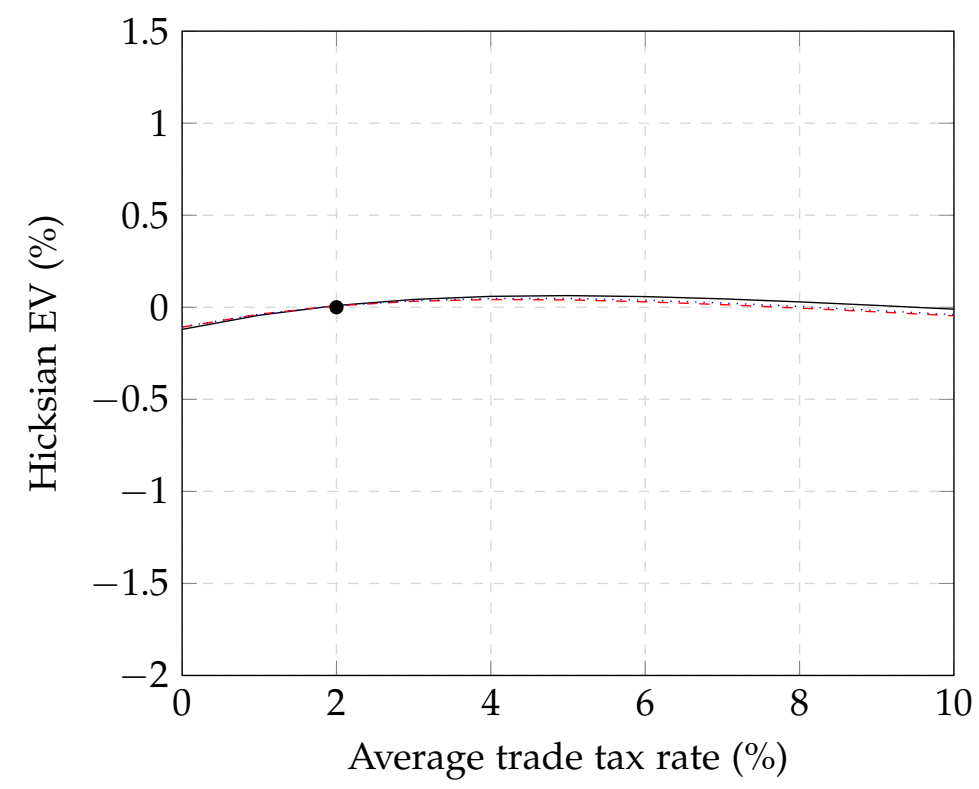

(a) USA.

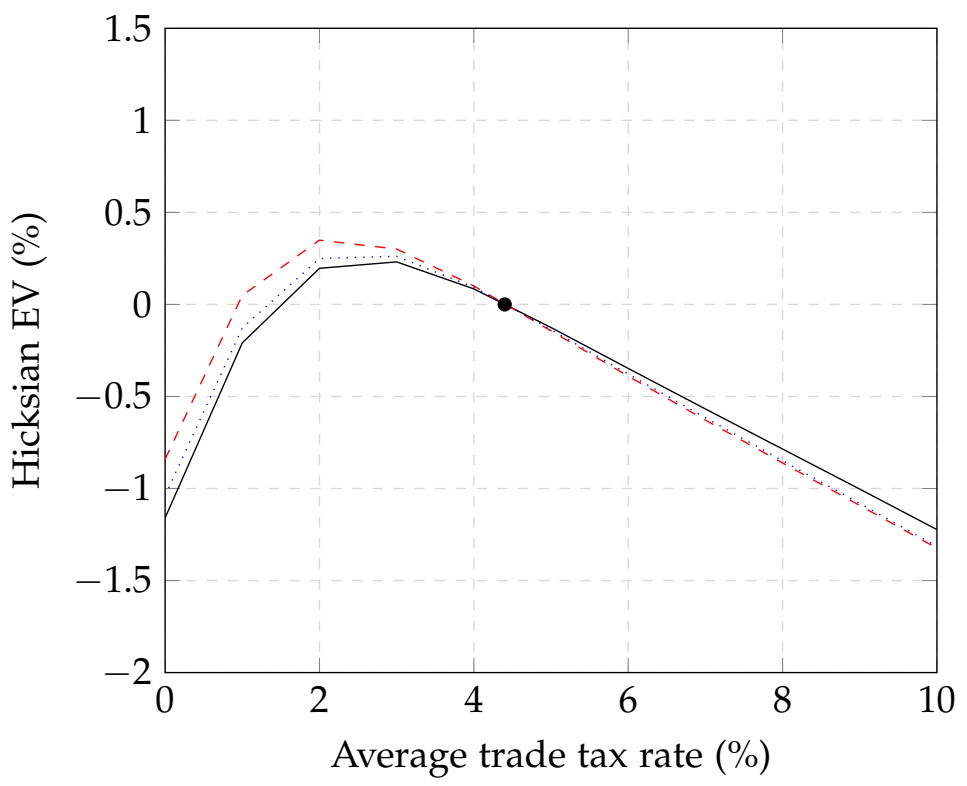

(b) China.

$C D E$ demand system

- - - Cobb Douglas demand system

Linear expenditure system

Figure 13. Demand system sensitivity. 
one works with a multiregional or small open economy closure. Although the GMR and SOE models are based on identical benchmark datasets, the absence of terms of trade effects in the open economy setting has significant implications for the effects of changes in tax policy. In the GMR model, China gains from a small reduction in tariffs, whereas in the soE model, China gains the most from free trade.

Finally, we compare GMR model results across alternative assumptions about final demand. Results from this comparison are reported in figure 13. In contrast to the importance of the model closure, the structure of final demand only modestly influences results for this specific set of simulations. This is especially striking for the US, as the welfare effect of trade taxes is almost identical across alternative final demand specifications. For China, differences are somewhat more pronounced, but they are quantitatively much less important than differences that can be attributed to alternative trade closures.

\section{Concluding Comments}

This paper has documented two general equilibrium models implemented in GAMs based on the GTAP version 9 Data Base. The global multiregional model based on an Armington representation of bilateral trade flows in which terms of trade is endogenous, and a small open economy model, in which relative prices between distinguished regions are endogenous, but rest of world prices and the current account are fixed. These two models represent the "canonical" representations of international trades responses, one in which terms of trade are endogenous and another in which relative prices in rest-of-world are held fixed.

The model features three alternative demand systems: Cobb Douglas, Linear Expenditure and Constant Difference in Elasticities. While the model based on CD preferences is the most parsimonious, it cannot accommodate empirical estimates of own-price and income elasticities. This limitation is addressed by the two other alternatives, the LES and the CDE models. As described in this paper, the CDE model offers sufficient degrees of freedom that it can be calibrated to both income and own-price elasticities whereas the LEs model can be calibrated to match income but only average price elasticities of demand. Calculations focusing on substantial price shocks suggest demonstrate that although the LES is less flexible than the $\mathrm{CDE}$, the welfare effects of unilateral tariff reforms are robust with respect to the structure of final demand.

All in all, the set of models made available through this paper offers an starting point for quantitative study of international trade policy. We believe that evidence based analysis requires that the analyst understand how structural assumption affect the results. For the particular policy illustration considered here, it seems that trade closures matter a lot, whereas the representation of final demand is quantitatively less important. This will, of course, depend on the types of policies considered. 


\section{Acknowledgements}

This paper borrows material from the unpublished manuscripts Rutherford (1998) and Rutherford (2005). GAMs program files are included in the supplementary files published with this paper. A GAMS license (version 24.7.3 or later) including (at least) an NLP and/or MCP solver is required. We would like to thank Christoph Boehringer, Justin Caron, Jan Imhof and four anonymous referees for their contributions to this work. We remain responsible for any remaining error. 


\section{Appendix A. GTAP Sectors and Primary Factors}

Table A.1. Commodities and Industries in the GTAP 9 database

\begin{tabular}{llll}
\hline Identifier & Definition & Identifier & Definition \\
\hline PDR & Paddy rice & LUM & Wood products \\
WHT & Wheat & PPP & Paper products, publishing \\
GRO & Cereal grains nec & P_C & Petroleum, coal products \\
V_F & Vegetables, fruit, nuts & CRP & Chemical,rubber,plastic prods \\
OSD & Oil seeds & NMM & Mineral products nec \\
C_B & Sugar cane, sugar beet & I_S & Ferrous metals \\
PFB & Plant-based fibers & NFM & Metals nec \\
OCR & Crops nec & FMP & Metal products \\
CTL & Cattle,sheep,goats,horses & MVH & Motor vehicles and parts \\
OAP & Animal products nec & OTN & Transport equipment nec \\
RMK & Raw milk & ELE & Electronic equipment \\
WOL & Wool, silk-worm cocoons & OME & Machinery and equipment nec \\
FRS & Forestry & OMF & Manufactures nec \\
FSH & Fishing & ELY & Electricity \\
COA & Coal & GDT & Gas manufacture, distribution \\
OIL & Oil & WTR & Water \\
GAS & Gas & CNS & Construction \\
OMN & Minerals nec & TRD & Trade \\
CMT & Meat: cattle,sheep,goats,horse & OTP & Transport nec \\
OMT & Meat products nec & WTP & Sea transport \\
VOL & Vegetable oils and fats & ATP & Air transport \\
MIL & Dairy products & CMN & Communication \\
PCR & Processed rice & OFI & Financial services nec \\
SGR & Sugar & ISR & Insurance \\
OFD & Food products nec & OBS & Business services nec \\
B_T & Beverages and tobacco products & ROS & Recreation and other services \\
TEX & Textiles & OSG & PubAdmin/Defence/Health/Educat \\
WAP & Wearing apparel & DWE & Dwellings \\
LEA & Leather products & CGD & Aggregate investment \\
& & & \\
\hline
\end{tabular}


Journal of Global Economic Analysis, Volume 1 (2016), No. 2, pp. 1-77.

Table A.2. Primary Factors in the GTAP 9 database

\begin{tabular}{lll}
\hline \multicolumn{2}{c}{ Identifier } & Definition \\
\hline Mobile factors: & & \\
& MGR & Officials and Managers legislators (ISCO-88 Major Groups 1-2), \\
& TEC & Technicians and associate professionals \\
& CLK & Clerks \\
& SRV & Service and market sales workers \\
& LAB & Agricultural and unskilled workers (Major Groups 6-9) \\
CAP & Capital \\
Sluggish factors: & & \\
& LND & Land \\
& RES & Natural resources \\
\hline
\end{tabular}




\section{Appendix B. Practicalities}

System Requirements

You will need to have the following:

- A computer.

- A gtap 9 license and data file.

- A gams system, Version 24.7.1 or newer.

- A nonlinear solver (PATH, IPOPT or CONOPT).

- The MPSGE subsystem (optional)

\section{Getting Started}

The GTAPINGAMS package is distributed as a zip file containing the directory structure and GAMS programs which can be unzipped into a clean working directory. GTAP source data are not distributed with the GTAPINGAMS system. In order to generate models with the GTAPINGAMs tools, it is necessary to obtain the GTAP 9 distribution archives.

Here are the steps involved in installing GTAPINGAMS:

1) Create an empty root directory for GTAP.

2) Unzip gtap9ingams.zip in this directory.

3) Install the GTAP data file flexagg 9 aY11. zip into the gtapdata subdirectory. ${ }^{20}$

4) Connect to the build directory and execute gams build.gms This will take some time to complete. The batch file is set up to begin with the 2011 base year data. Choose a different year if you wish.

5) Run test.gms in the build directory to evaluate benchmark consistency of the generated datasets.

6) The GAMs programs in the forensics directory provide a template for how to conduct counterfactual policy simulations, using Excel PivotTables and PivotCharts to synthesize model output.

${ }^{20}$ You need only one data files, but these data are provided for three different years in the GTAP "flexhar" distribution. 


\section{Appendix C. The Linear Expenditure System}

The linear expenditure system (LES or Stone-Geary) utility function was invented by Roy Geary and first estimated by Richard Stone. An early analysis by Frisch (1959) calibrated the functional form using a parameter named the 'money flexibility'. Subsequently, Sato (1972) and Powell (1992) pointed out the correspondence between Frisch's money flexibility and the elasticity of substitution among commodities. Here we employ Powell's insight to calibrate the linear expenditure demand system to benchmark data consisting of expenditure shares, income elasticities of demand and the share-weighted compensated elasticity of demand.

Let $x_{i}$ denote aggregate demand for good $i$. In the LEs demand system, $x_{i}$ is the sum of subsistence demand $\left(s_{i}\right)$ and discretionary demand $\left(d_{i}\right)$. Subsistence demand remains fixed on a per-capita basis while discretionary demand depends on commodity prices and income.

Given homogeneity of prices we may assume that the benchmark expenditure and prices of all goods equal unity, and the benchmark demand for commodity $i$ equals $\theta_{i}$, the benchmark value share of commodity $i$ in final demand. Demand for $i$ resulting from LES utility maximization can be written:

$$
x_{i}=s_{i}+\bar{d}_{i} \frac{1-\sum_{j} p_{j} s_{j}}{\beta p_{i}}=s_{i}+\bar{d}_{i} \frac{c(p)}{p_{i}} u
$$

where

$M$ indicates income (equal to unity at the benchmark point), $p_{i}$ is the price of good $i$ (equal to unity at the benchmark point),

$\beta$ is the benchmark value share of discretionary demand $\left(=\sum_{i} \bar{d}_{i}\right)$,

$\alpha_{i}$ is the value share of good $i$ in discretionary demand $\left(=\frac{\bar{d}_{i}}{\beta}\right)$

$c(p)$ is the price index of discretionary demand $\left(=\prod_{i} p_{i}^{\alpha_{i}}\right)$, and

$u$ is an indirect utility index for discretionary $\operatorname{demand}^{21}\left(=\frac{M-\sum_{j} p_{j} s_{j}}{\beta c(p)}\right)$

Utility maximization provides a demand function $x_{i}(p, M)$. In the GTAP setting, inputs to the demand system calibration are:

$\theta_{i} \quad$ The expenditure share of good $i$

${ }^{21}$ The money-metric utility index for aggregate utility is $U=1+\beta(u-1)$ 
$\epsilon_{i}$ The compensated own-price elasticity of demand:

$$
\epsilon_{i}=\left.\frac{\partial x_{i}(p, M(U))}{\partial p_{i}}\right|_{U=\bar{U}} \frac{p_{i}}{x_{i}}
$$

$\eta_{i} \quad$ The income elasticity of demand for good $i$

$$
\eta_{i}=\frac{\partial x_{i}(p, M)}{\partial M} \frac{M}{x_{i}}
$$

Calibration of the LEs to $\theta_{i}, \epsilon_{i}$ and $\eta_{i}$ involves allocating budget shares across subsistence and discretionary demand, subject to the constraint:

$$
\theta_{i}=s_{i}+\bar{d}_{i}
$$

Differentiating (C.I) with respect to $M$, the income elasticity of demand is given by:

$$
\eta_{i}^{\mathrm{LES}}=\frac{1}{\beta}\left(1-\frac{s_{i}}{\theta_{i}}\right)
$$

This expression permits us to calibrate $s_{i}$ and $\bar{d}_{i}$ in terms of $\theta_{i}, \beta$ and $\eta_{i}$ :

$$
s_{i}=\theta_{i}\left(1-\beta \eta_{i}\right)
$$

and

$$
\bar{d}_{i}=\theta_{i}-s_{i}=\beta \eta_{i} \theta_{i}
$$

and hence $\alpha_{i}=\eta_{i} \theta_{i}$.

Diagonal terms in the Slutsky matrix of the compensated demand function at the benchmark point can be found by differentiating (C.1), holding $u=1$ :

$$
\frac{\partial x_{i}}{\partial p_{i}}=\bar{d}_{i}\left(\alpha_{i}-1\right)
$$

hence

$$
\epsilon_{i}^{\mathrm{LES}}=\beta \eta_{i}\left(\alpha_{i}-1\right)=\beta \eta_{i}\left(\eta_{i} \theta_{i}-1\right)
$$

The discretionary expenditure share, $\beta$, is a free parameter which can be calibrated to target average compensated price elasticities, i.e.

$$
\min _{\beta} \sum_{i} \theta_{i}\left(\epsilon_{i}-\beta \eta_{i}\left(\eta_{i} \theta_{i}-1\right)\right)^{2}
$$



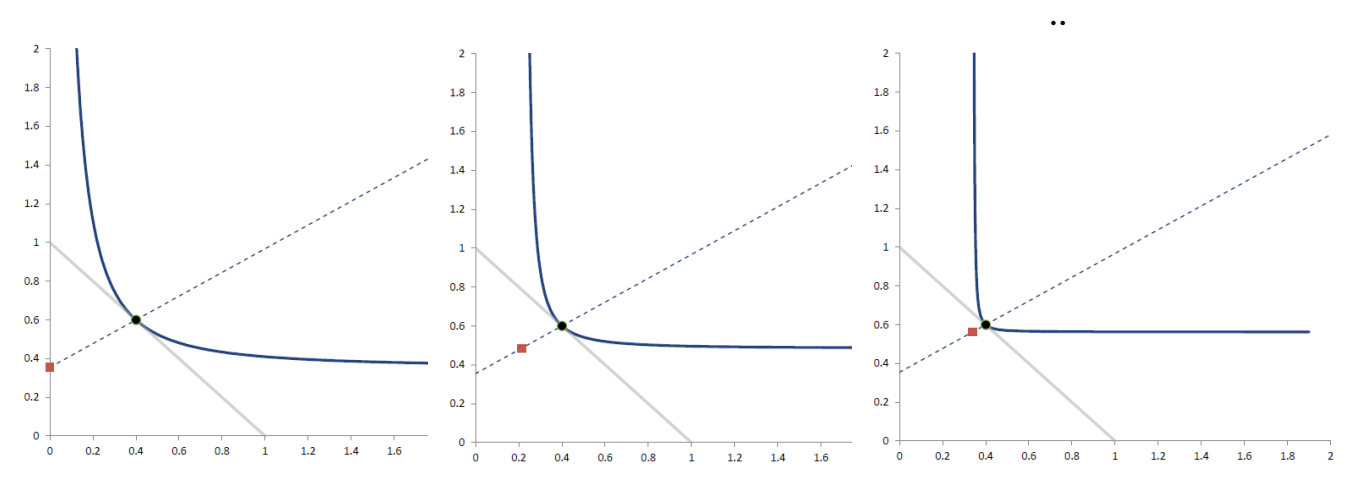
(a) $\beta=0.65, \bar{\epsilon}=-0.28$
(b) $\beta=0.30, \bar{\epsilon}=-0.14$
(c) $\beta=0.10, \bar{\epsilon}=-0.05$

Figure C.1. Calibration with Alterative Price Elasticities

hence, if we calibrate $\beta$ from to match average own-price elasticities, we have:

$$
\beta=\frac{\sum_{i} \theta_{i} \epsilon_{i}}{\sum_{i} \eta_{i} \theta_{i}\left(\eta_{i} \theta_{i}-1\right)}
$$

One consequence of this calibration is that when elasticities are high, subsistence demands may be negative, producing some difficulty in interpretation. An alternative approach is to fix $\beta$ at maximum value for which subsistence demands are non-negative:

$$
\beta=\min _{i} \frac{1}{\eta_{i}}=\frac{1}{\eta_{\max }}
$$

and then replace the Cobb-Douglas utility function over discretionary demand with a constant-elasticity-of-sustitution (CES) utility function. The unit cost function is then

$$
c^{\mathrm{CES}}(p)=\left(\sum_{i} \eta_{i} \theta_{i} p_{i}^{1-\sigma}\right)^{1 /(1-\sigma)}
$$

and the demand function is

$$
x_{i}=s_{i}+\bar{d}_{i}\left(\frac{c^{\mathrm{CES}}(p)}{p_{i}}\right)^{\sigma} u .
$$

Given any value of $\beta$, the elasticity of substitution in discretionary demand can then be calibrated to match the average own-price elasticity:

$$
\sigma=\frac{\sum_{i} \theta_{i} \epsilon_{i}}{\beta \sum_{i} \eta_{i} \theta_{i}\left(\eta_{i} \theta_{i}-1\right)} .
$$




\section{Appendix D. The CDE Demand System}

\section{Theory and Analytics}

Our implementation of the CDE model follows Chen (2015). In the CDE model, the utility index $U$ for a given region (subscript $r$ suppressed) is defined implicitly by the following equation:

$$
\sum_{i} \theta_{i} U^{e_{i}\left(1-\alpha_{i}\right)}\left(\frac{P_{i}}{C}\right)^{1-\alpha_{i}}=1
$$

where $C$ is the shadow price on the budget constraint, $\alpha_{i}$ is the substitution parameter ( subpar $_{i}$ in the GTAP database), and $e_{i}$ is the income parameter (incpar ${ }_{i}$ ).

In the CDE model $C$ is dual to the budget constraint,

$$
\sum_{i} P_{i} x_{i}=M
$$

and demand functions can be derived using Roy's identify: ${ }^{22}$

$$
x_{i}=\frac{\partial C / \partial P_{i}}{\partial C / \partial M}=\theta_{i} \frac{U^{\left(1-\alpha_{i}\right) e_{i}}\left(P_{i} / C\right)^{-\alpha_{i}}}{\sum_{j}, U^{\left(1-\alpha_{j}\right) e_{j}}\left(P_{j} / C\right)^{-\alpha_{j}}}
$$

While $U$ may be interpreted as a utility index, it does not correspond to a money-metric measure. The corresponding Hicksian welfare index $(W)$ corresponds to the cost index $C$ which solves (D.1) with commodity prices equal to unity, i.e. $W$ solves

$$
\sum_{i} \theta_{i} U^{e_{i}\left(1-\alpha_{i}\right)}\left(\frac{1}{W}\right)^{1-\alpha_{i}}=1
$$

Here is a GAMS model which evaluates CDE demand across commodities $i$ and regions $r \in$ rc. We have $n+3$ variables $\left(x_{i}, C, U\right.$ and $W$ ) determined by $n+3$ equations. While the CDE model is essentially a nonlinear system of equations, we write down the model using mixed complementarity syntax so as to associate equations with variables. ${ }^{23}$

${ }^{22}$ The partial derivatives $\partial C / \partial P_{i}$ and $\partial C / \partial M$ are obtained by differentiating (D.1).

${ }^{23}$ If $U(r)$ is fixed prior to a CDE solve, the corresponding budget $(r)$ constraint is automatically dropped thereby providing the compensated demand response. 


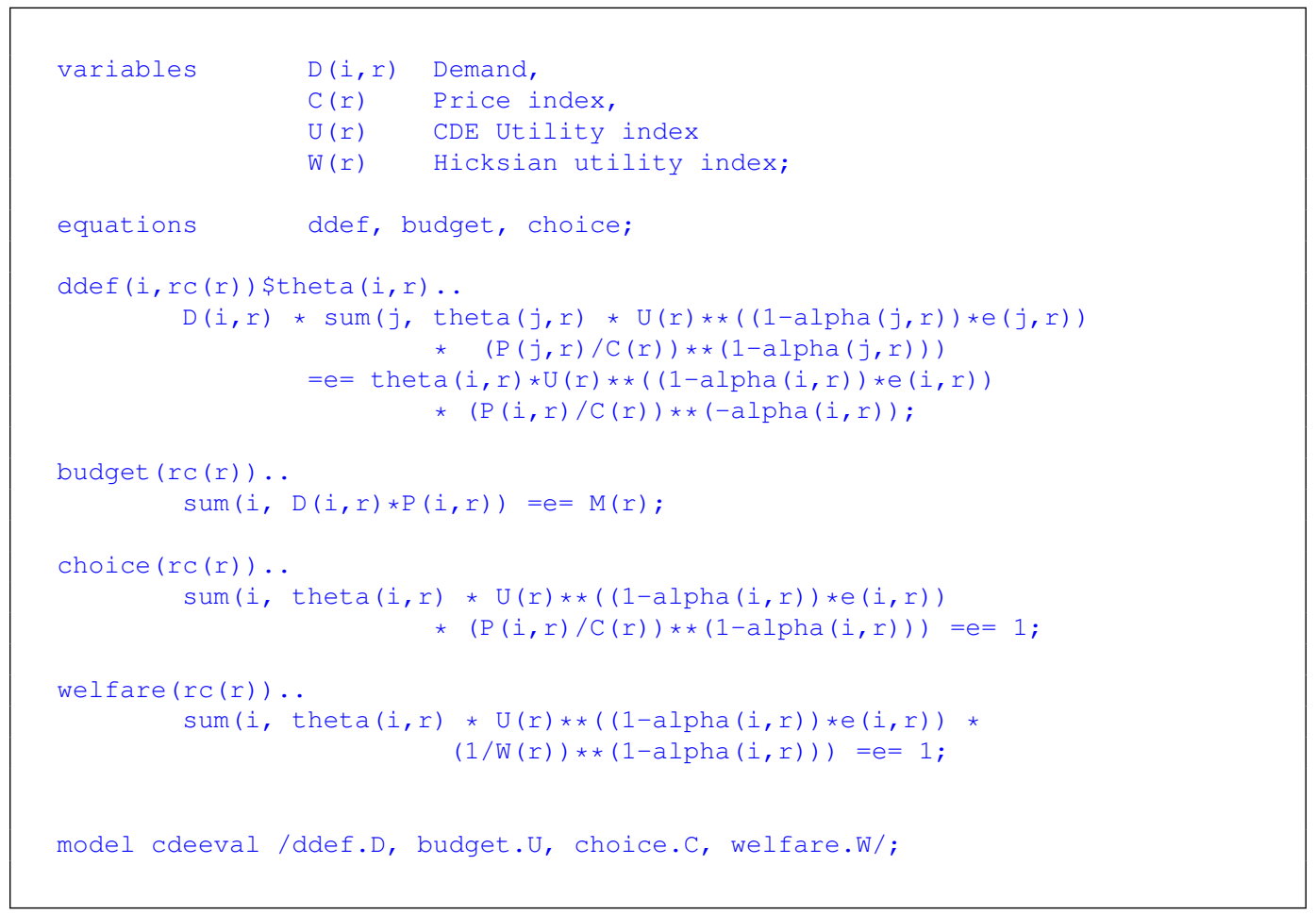

The price elasticity of demand in this model is given by:

$$
\epsilon_{i}^{C D E}=\theta_{i}\left(2 \alpha_{i}-\left(\sum_{k} \theta_{k} \alpha_{k}\right)\right)-\alpha_{i}
$$

and the income elasticity of demand is given by:

$$
\eta_{i}^{C D E}=\frac{e_{i}\left(1-\alpha_{i}\right)+\sum_{k} \theta_{k} e_{k} \alpha_{k}}{\sum_{k} \theta_{k} e_{k}}+\alpha_{i}-\sum_{k} \theta_{k} \alpha_{k}
$$

\section{Calibration}

Calibration of the CDE parameters involves a least squares optimization model of the form:

$$
\min _{\alpha, e} \sum_{i} \theta_{i}\left(\left(\epsilon_{i}^{C D E}-\epsilon_{i}\right)^{2}+\left(\eta_{i}^{C D E}-\eta_{i}\right)^{2}\right)
$$

Here is a GAMS model which calibrates CDE demand across commodities $i$ and regions $r \in \mathrm{rc}$ : 


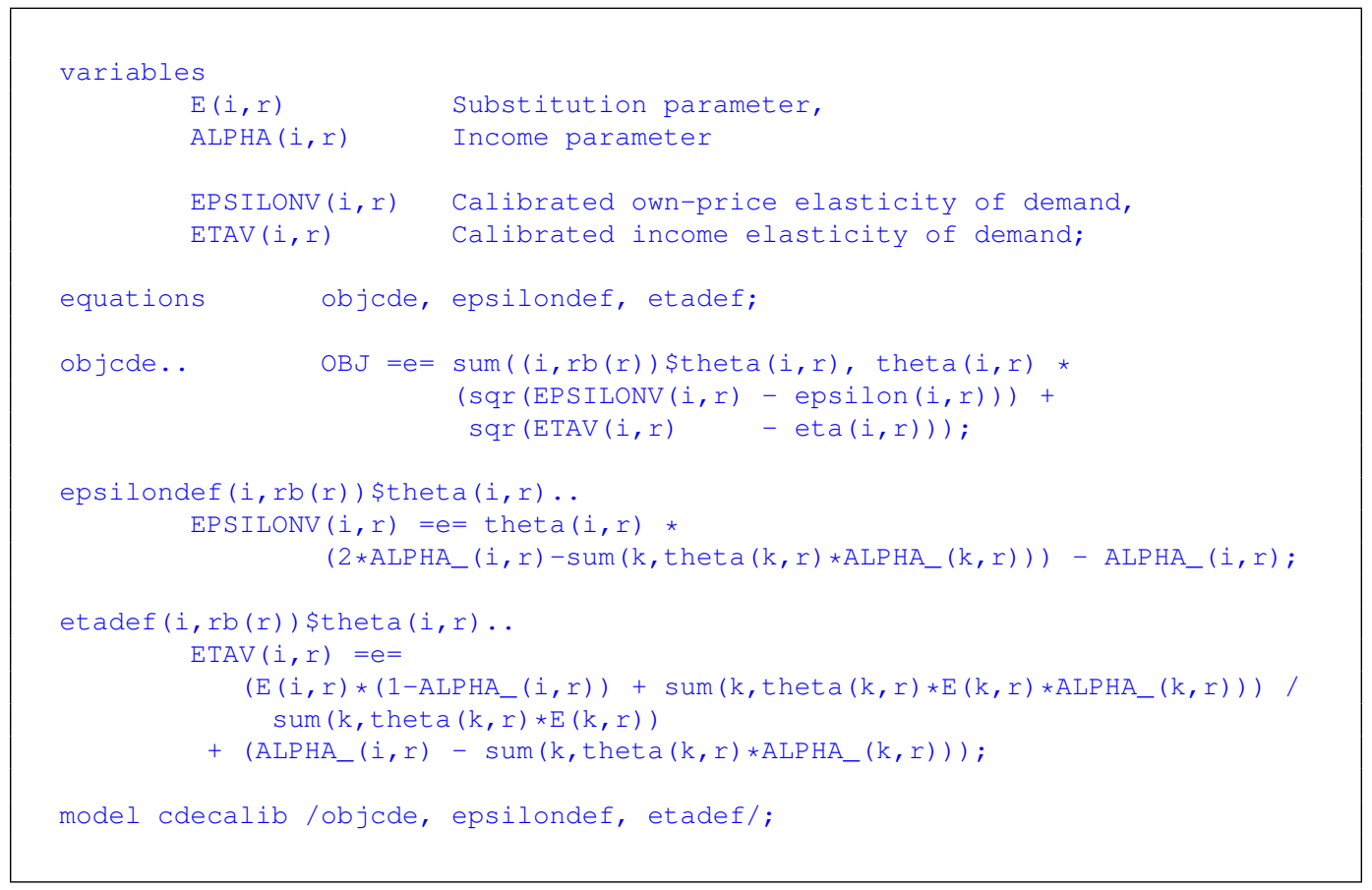

Finally, we note that in the CDE model the Allen-Uzawa elasticities of substitution for compensated demand are given by:

$$
\sigma_{i j}^{C D E}= \begin{cases}\alpha_{i}+\alpha_{j}-\left(\sum_{k} \theta_{k} \alpha_{k}\right) & i \neq j \\ 2 \alpha_{i}-\left(\sum_{k} \theta_{k} \alpha_{k}\right)-\frac{\alpha_{i}}{\theta_{i}} & i=j\end{cases}
$$

The "constant difference of elasticities" feature of the CDE demand system is evident through the calculation based on the AUES elasticities of sustitution:

$$
\sigma_{i k}-\sigma_{j k}=\alpha_{i}-\alpha_{j}
$$

\section{Parallel Processing}

The GAMs program cdecalib.gms has a runtime environment variable named maxthreads. This variable determines whether the CDE calibration is executed one region at a time or, taking advantage of multi-core processors, several regions at a time. When threads $=1$, the program runs in serial model and solutions listings are generated for each calibration. Otherwise, solution listings are suppressed and multiple (typically 8 ) demand system calibrations are solved at once.

The grid computing facilities are a relative new and evolving feature in GAMS 
programming, and they are very useful for applied general equilibrium modeling, so we provide some annotated GAMs code which describes how jobs are submitted and collected:

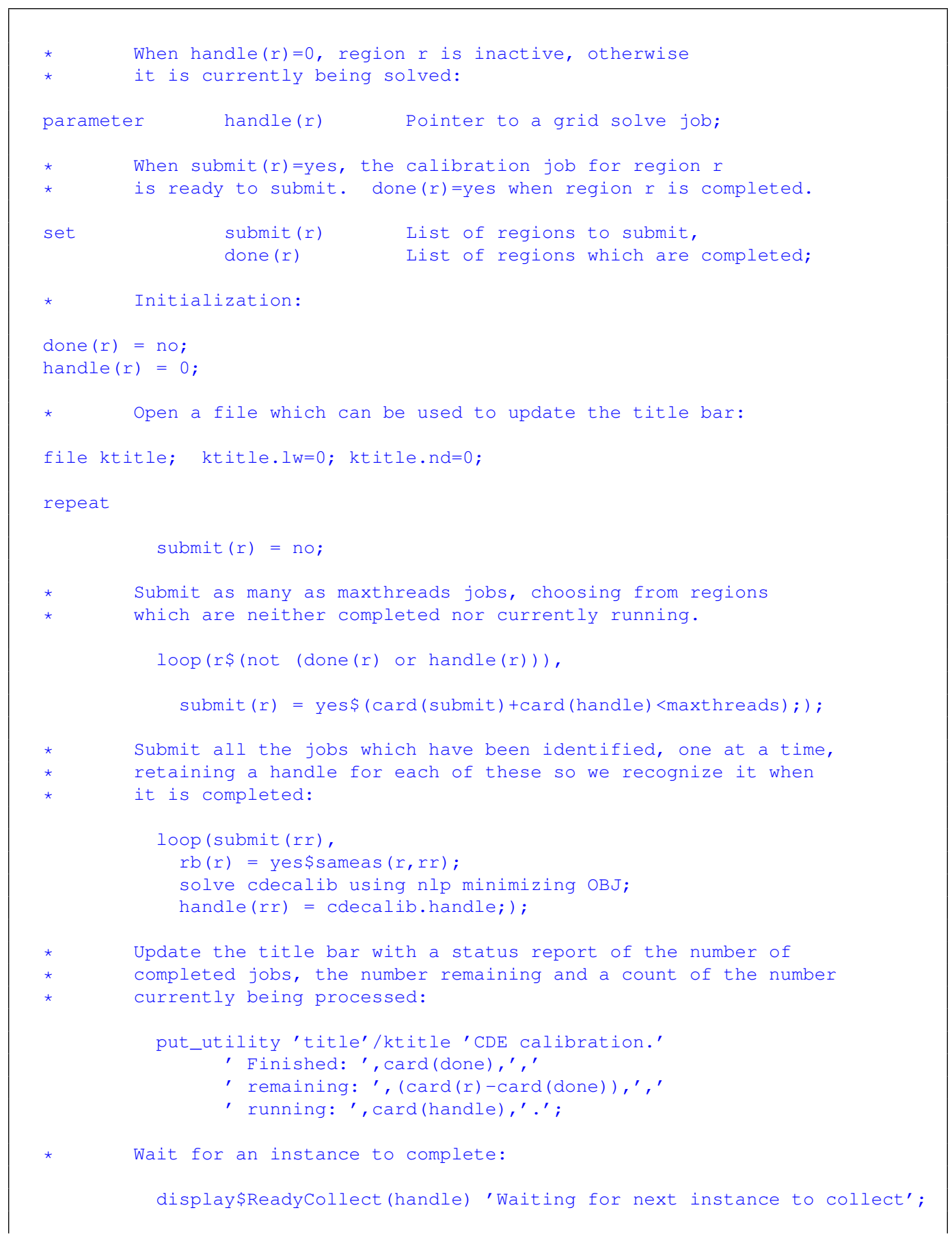


Journal of Global Economic Analysis, Volume 1 (2016), No. 2, pp. 1-77.

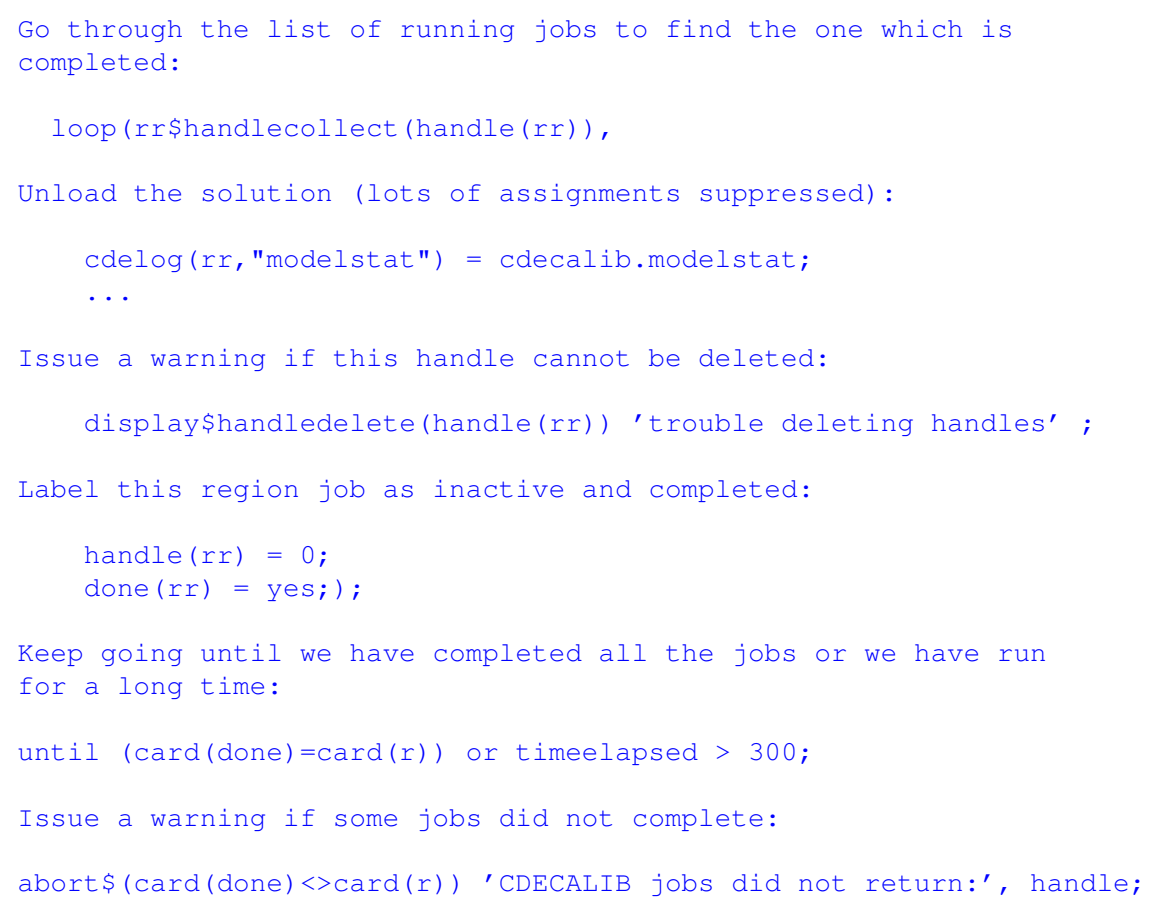

Integrating CDE Demand in MPSGE

The integration of CDE demand in the MPSGE model is subtle. To begin with, we need to introduce an Armington composite price for final demand. This is done with the $A(i, r)$ activity which converts domestic and imported goods into the PA $(i, r)$ commodity:

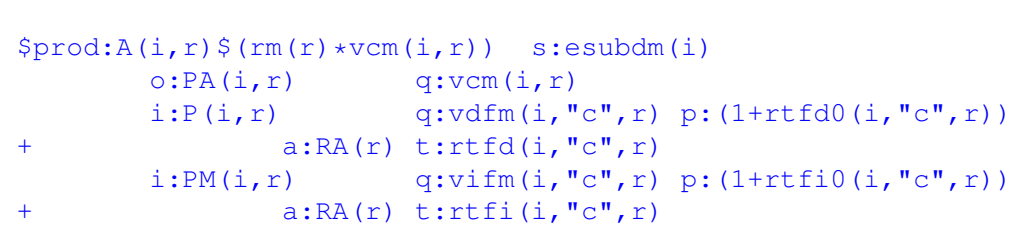

The CDE demand functions are represented by auxiliary variables, and they enter the MPSGE model as rationing multipliers on regional endowments. The assigned set $c$ de $(r)$ is used to indicate whether region $r$ has a CDE demand system. 
Here is the tricky business: MPSGE insists that all consumers entering the model demand something. We therefore need to include "phantom" demand and endowment entries which will offset one another in equilibrium. The budget balance condition in the CDE model (the constraint associated with $U(r)$ imposes that in equilibrium the value of expenditure for region $r(\mathrm{RA}(r))$ equal to the value of the phantom factor endowment vector.

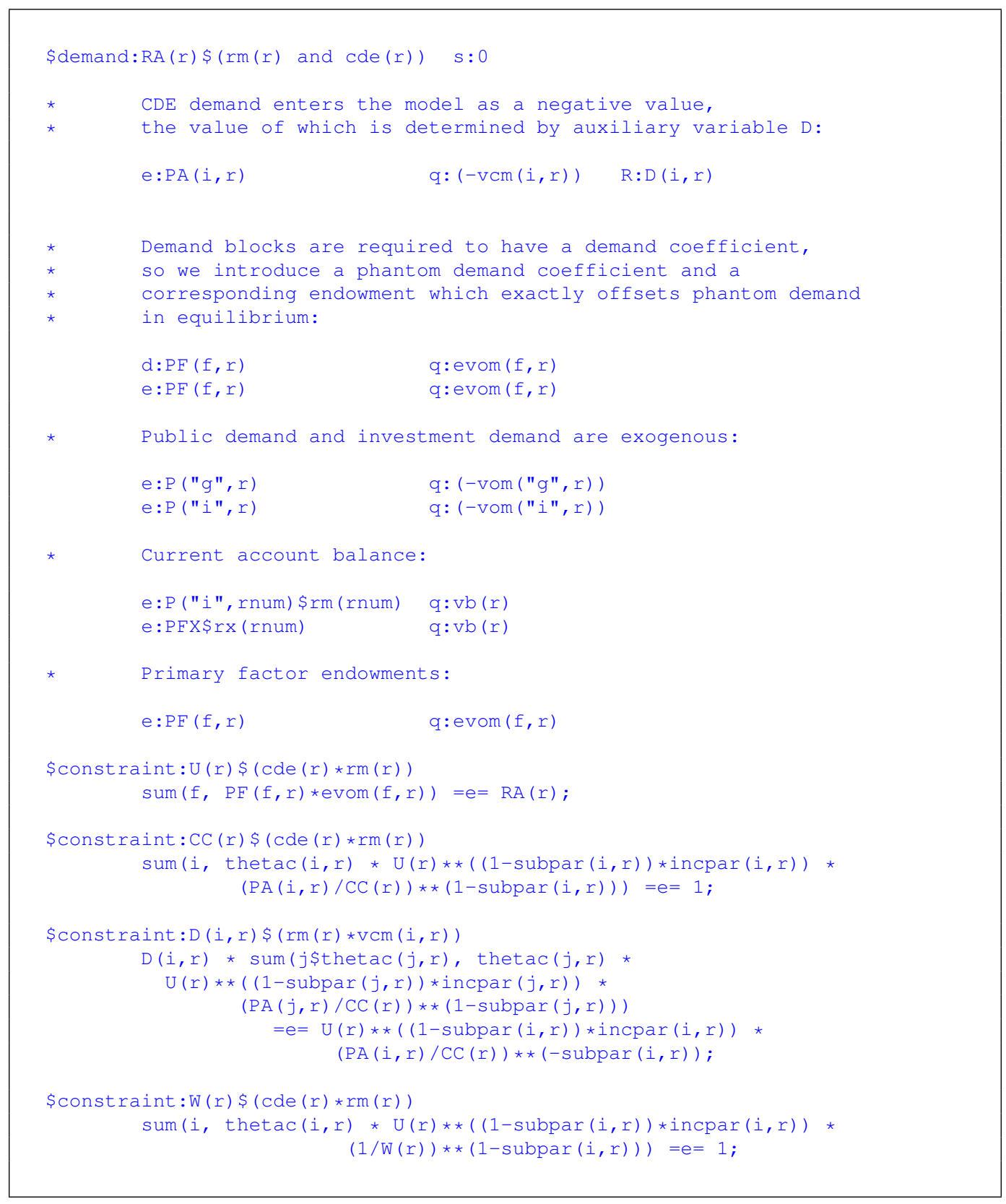




\section{Appendix E. Subdirectories and GAMS Programs}

\begin{tabular}{|c|c|c|}
\hline build/ & & g directory for dataset construction. \\
\hline & build.gms & $\begin{array}{l}\text { Command script to read, filter and aggregate a set of } \\
\text { GTAP datasets. Default configuration: produces datasets } \\
\text { gtapingams.gdx, g20.gdx, g20_macro.gdx and } \\
\text { g20_iea.gdx for 2011. Calls code/flex2gdx.gms, } \\
\text { code/filter.gms, code/gtapaggr.gms and } \\
\text { code/cdecalib.gms. }\end{array}$ \\
\hline & filterchk.gms & $\begin{array}{l}\text { Command script to generate data for Table 6: } \\
\text { Filtering results. Calls code/flex2gdx.gms, } \\
\text { code/filter.gms. Results are written to a PivotData } \\
\text { sheet in filterchk. xlsx. } \\
\text { Command script which calls bmkchk.gms for dataset } \\
\text { g20_macro, mcpmge.gms for dataset } 920 \text { and } \\
\text { cdechk.gms for dataset } 920 \text {. }\end{array}$ \\
\hline & bmkchk.gms & $\begin{array}{l}\text { Benchmark consistency is a necessary, but not a sufficient } \\
\text { condition that the model is properly specified. This routine } \\
\text { checks for the g20 macro dataset in both MGE and MCP for- } \\
\text { mats. This routine produces a replication check for the GMR } \\
\text { model and all the single region soE models. }\end{array}$ \\
\hline & mcpmge.gms & $\begin{array}{l}\text { Is designed to perform a check of consistency for the MCP } \\
\text { and MGE models at a point away from the benchmark equi- } \\
\text { librium. It can be used to verify that a solution computed } \\
\text { with mge.gms also solves mcp.gms, and that a solution } \\
\text { computed with mcp.gms solves mge.gms. The GAMs save- } \\
\text { point and loadpoint commands are used for this purpose. }\end{array}$ \\
\hline & cdechk.gms & $\begin{array}{l}\text { Verifies that the CDE demand system reproduces the ex- } \\
\text { ogenous own-price and income demand elasticities at the } \\
\text { benchmark point. }\end{array}$ \\
\hline
\end{tabular}

\begin{tabular}{l|l|l} 
code/ & \multicolumn{1}{|l}{ Code repository - not a working directory. } \\
\hline flex2gdx.gms & $\begin{array}{l}\text { Routine which translates the HAR files from a GTAP .zip } \\
\text { archive into GAMS . gdx files. The routine produces an } \\
\text { echoprint report of benchmark consistency of the database. } \\
\text { filter.gms }\end{array}$ & $\begin{array}{l}\text { Filter routine, based on environment parameter -nd, the } \\
\text { number of decimal points in the filter. }\end{array}$
\end{tabular}




\begin{tabular}{|c|c|}
\hline gtap 9data.gms & Utility routine for read a GTAPINGAMS version 9 dataset. \\
\hline gtapaggr.gms & $\begin{array}{l}\text { Dataset aggregation routine (call to cdecalib. gms follow- } \\
\text { ing aggregation must be made by user). }\end{array}$ \\
\hline $\begin{array}{l}\text { aggr.gms } \\
\text { chktarget.gms } \\
\text { checkset.gms }\end{array}$ & Utility routines called by gtapaggr.gms. \\
\hline domain.gms & $\begin{array}{l}\text { Standard purpose libinclude routine for extracting the } \\
\text { nonzero domain of a parameter, using the mysterious } \\
\text { "option pd_1<p_1;" syntax. }\end{array}$ \\
\hline cdecalib.gms & $\begin{array}{l}\text { Utility routine to recalibrate CDE demand following dataset } \\
\text { aggregation. }\end{array}$ \\
\hline $\mathrm{mcp} \cdot \mathrm{gms}$ & The canonical static GTAPINGAMS model in algebraic format. \\
\hline mge.gms & $\begin{array}{l}\text { The canonical static GTAPINGAMS model in tabular MPSGE } \\
\text { format. }\end{array}$ \\
\hline gdpcalc.gms & $\begin{array}{l}\text { Utility routine for reporting GDP on the basis of income, fi- } \\
\text { nal demand or sectoral value-added, compatible with either } \\
\text { the mcp. gms or mge.gms models. First call declares report } \\
\text { parameters. }\end{array}$ \\
\hline loadmdl.gms & $\begin{array}{l}\text { Utility routines for switching demand systems (between } \\
\text { Cobb-Douglas, LES and CDE) and model closures (GMR ver- } \\
\text { sus SOE). The macros included here are described below. }\end{array}$ \\
\hline
\end{tabular}

\begin{tabular}{|c|c|c|}
\hline forensics/ & & $\begin{array}{l}\text { Produces some calculations assessing the economic conse- } \\
\text { quences of proportional unilateral changes in trade taxes. }\end{array}$ \\
\hline & $\begin{array}{l}\text { run.gms } \\
\text { ssagen.gms } \\
\text { ssasolve.gms } \\
\text { ssamerge.gms }\end{array}$ & $\begin{array}{l}\text { This GAMS script which execute ssagen.gms, } \\
\text { ssasolve.gms and ssamerge.gms. } \\
\text { This GAMs script produces ssasolve.gms and } \\
\text { ssamerge.gms } \\
\text { is a GAMs programs written by ssagen.gms which pro- } \\
\text { cesses tgrid.gms for several alternative model closures } \\
\text { and demand system specifications. } \\
\text { is a GAMs programs written by ssagen.gms which com- } \\
\text { bines model results into a format suitable for generating an } \\
\text { Excel pivot report. }\end{array}$ \\
\hline
\end{tabular}




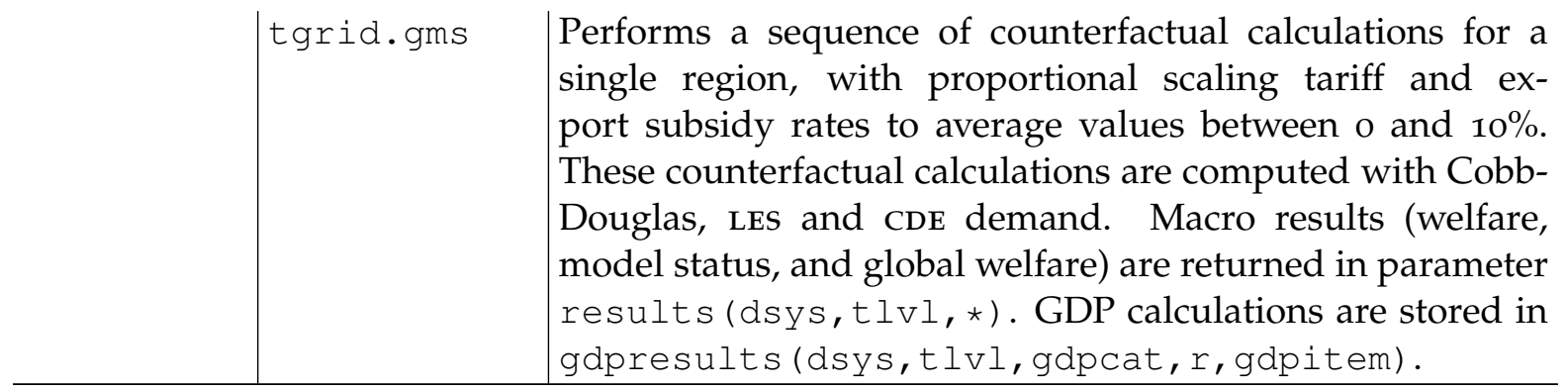

Macros for model configuration

Two user-callable macros provided in loadmdl . gms:

\$macro loaddsys $(f f, r$ ) Loads demand system $f f$ for region $r$ where $f f$ is one of LES, CD or CDE and $r$ is a region identifier, either a quoted set element or a subset of the regions $r$. This function alters:

cd $(r)$ Cobb Douglas demand system flag for model regions

les $(r)$ LES demand system flag for model regions

cde $(r)$ CDE demand system flag

$\operatorname{vdfm}(), \operatorname{vifm}() \quad$ Levels of subsistence and discretionary demand

vom() Output level which activate aggregate consumer demand, subsistence and discretionary demand.

\$macro loadrm ( $r r$ ) Load regions $r r(r)$ as endogenous elements of the current model. If $r r$ is a set which includes all regions in $r$, then a global multiregional model is produced. If $r r$ is singleton or a subset of regions in $r$, then a small open economy closure is provided. This routine alters:

$r m(r)$ Set of regions in the model,

$r \times(r)$ Set of regions in rest of world,

rnum $(r)$ Set defining the numeraire region - the region in the model with the largest consumption.

$\operatorname{vem}(i, r)$ Exports to ROW regions by regions in the model,

rtxs_row $(i, r)$ Average subsidy rates on exports to ROW regions.

rowp fx Current account balance for the rest of world regions. 
The user-callable macros provided in loadmdl.gms are invoked as follows in the tgrid.gms program:

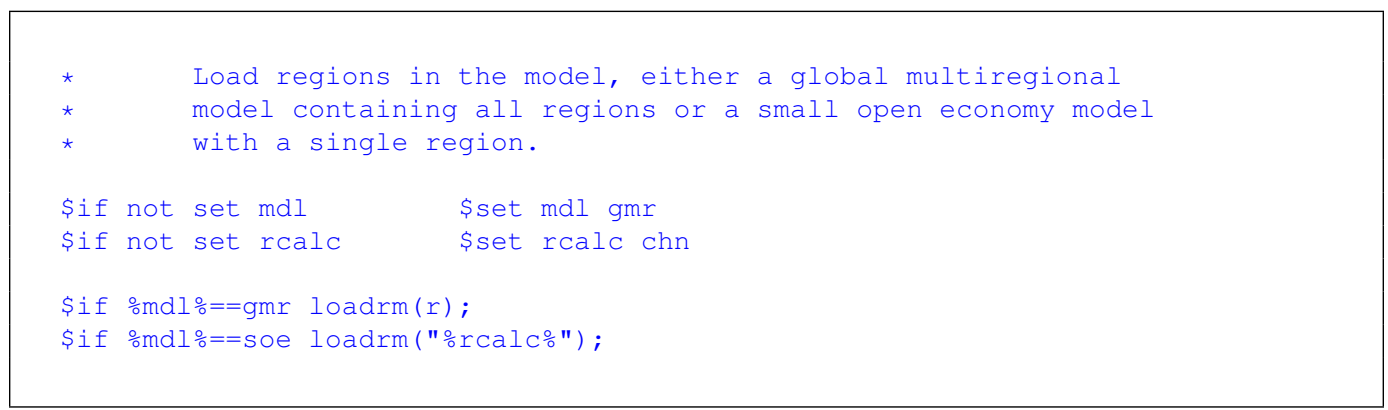

In the same program, a loop over functional forms is used to calculate scenario results for three different demand systems, as shown below.

GDP reporting

gdpcalc.gms declares the following identifiers: ${ }^{24}$

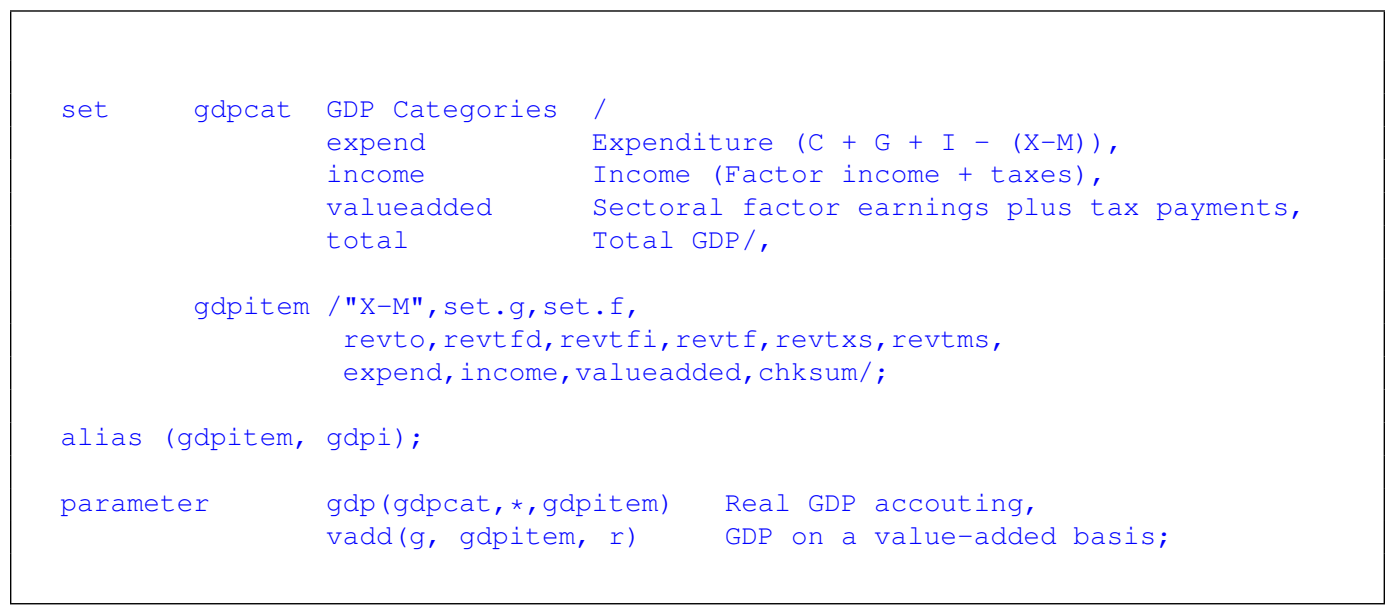

GDP reporting in tgrid.gms consists of an include statement at the beginning of the program, just after having read mge.gms, in a context permitting declarations:

24 These names may not be used in the calling program. 
* Read the model and calculate GDP at the benchmark point:

\$include ocodeㅇge

\$include \%code\%gdpcalc

The GDP routine is included following scenarios solutions inside the loop over alternative demand systems:

loop (dsys,

* Load the demand system:

loaddsys (dsys, r) ;

* Initialize tax instruments at benchmark values:

$\operatorname{rtms}(i, s, r)=\operatorname{rtms} 0(i, s, r) ;$

$\operatorname{rtxs}(i, s, r)=\operatorname{rtxs} 0(i, s, r) ;$

loop (tlvl,

* Assign tax rates for the counterfactual simulation:

$\operatorname{rtms}(i, s, \operatorname{rcalc}) \$ \max (\operatorname{rtms} 0(i, s, \operatorname{rcalc}), 0)=$

rtms0 (i,s,rcalc) * tlvi.val/averate;

$\operatorname{rtxs}(i, \operatorname{rcalc}, s) \$ \max (-\operatorname{rtxs} 0(i, \operatorname{rcalc}, \mathrm{s}), 0)=$

rtxs0 (i,rcalc,s) * tlvl.val/averate;

* Compute the equilibrium values:

\$include gtap9.gen

solve gtap9 using mcp;

abort\$(gtap9.objval>1e-3) "Simulation fails: gtap9.";

* Store the GDP results for this simulation:

\$include \%code\%gdpcalc

gdpresults (dsys, tlvl, gdpcat, r, gdpitem) = gdp (gdpcat, r, gdpitem) ;

$\cdots$

)) 


\section{Appendix F. GAMS Code}

\section{Declarations}

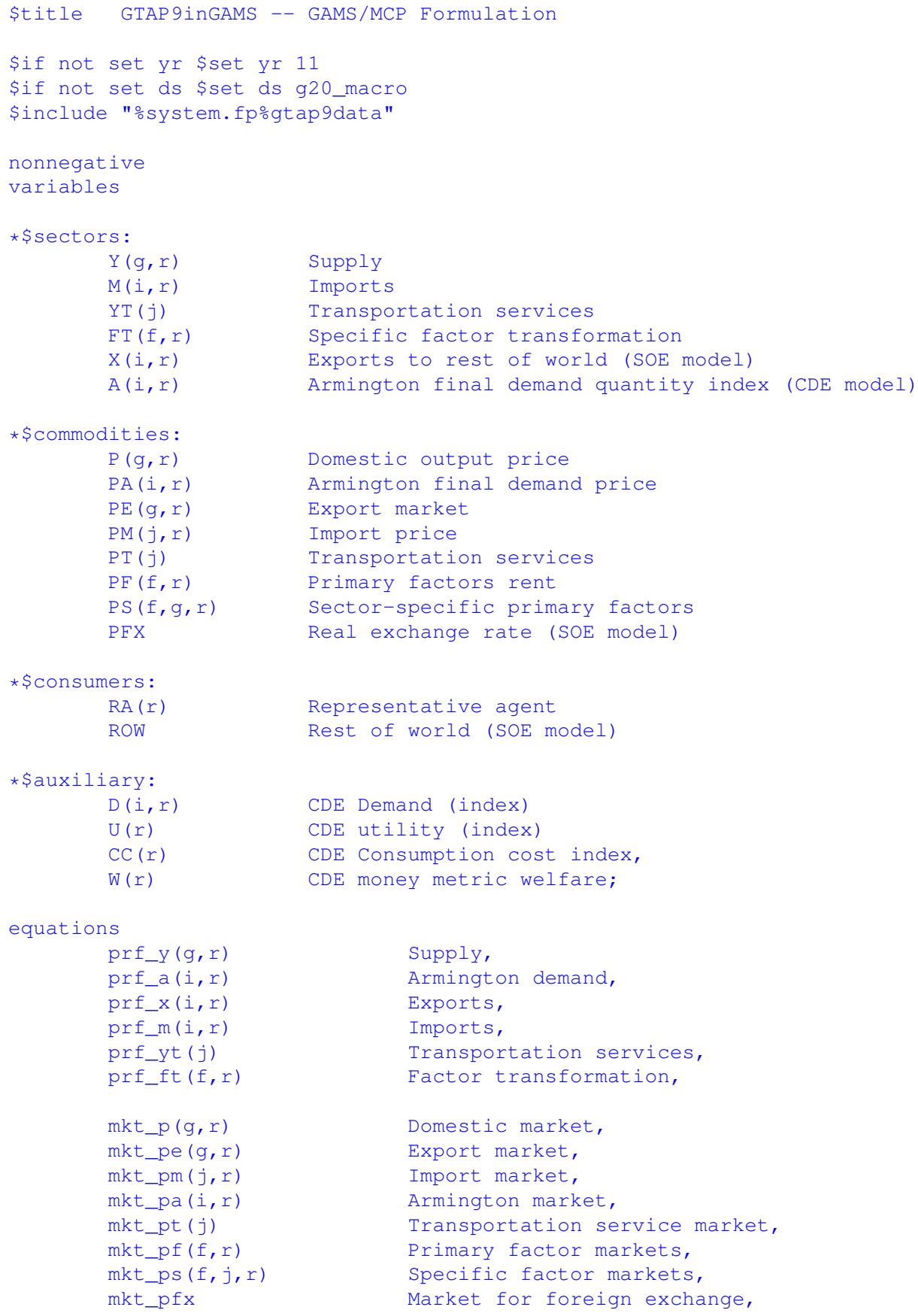




$\begin{array}{ll}\text { inc_ra }(r) & \begin{array}{l}\text { Representative agent } \\ \text { Rest of world agent }\end{array} \\ \text { constraint_D } & \text { Defines D (CDE model) } \\ \text { constraint_U } & \text { Defines U (CDE model) } \\ \text { constraint_CC } & \text { Defines CC (CDE model), } \\ \text { constraint_W } & \text { Defines W (CDE model); }\end{array}$

\section{Zero profit (arbitrage) conditions}

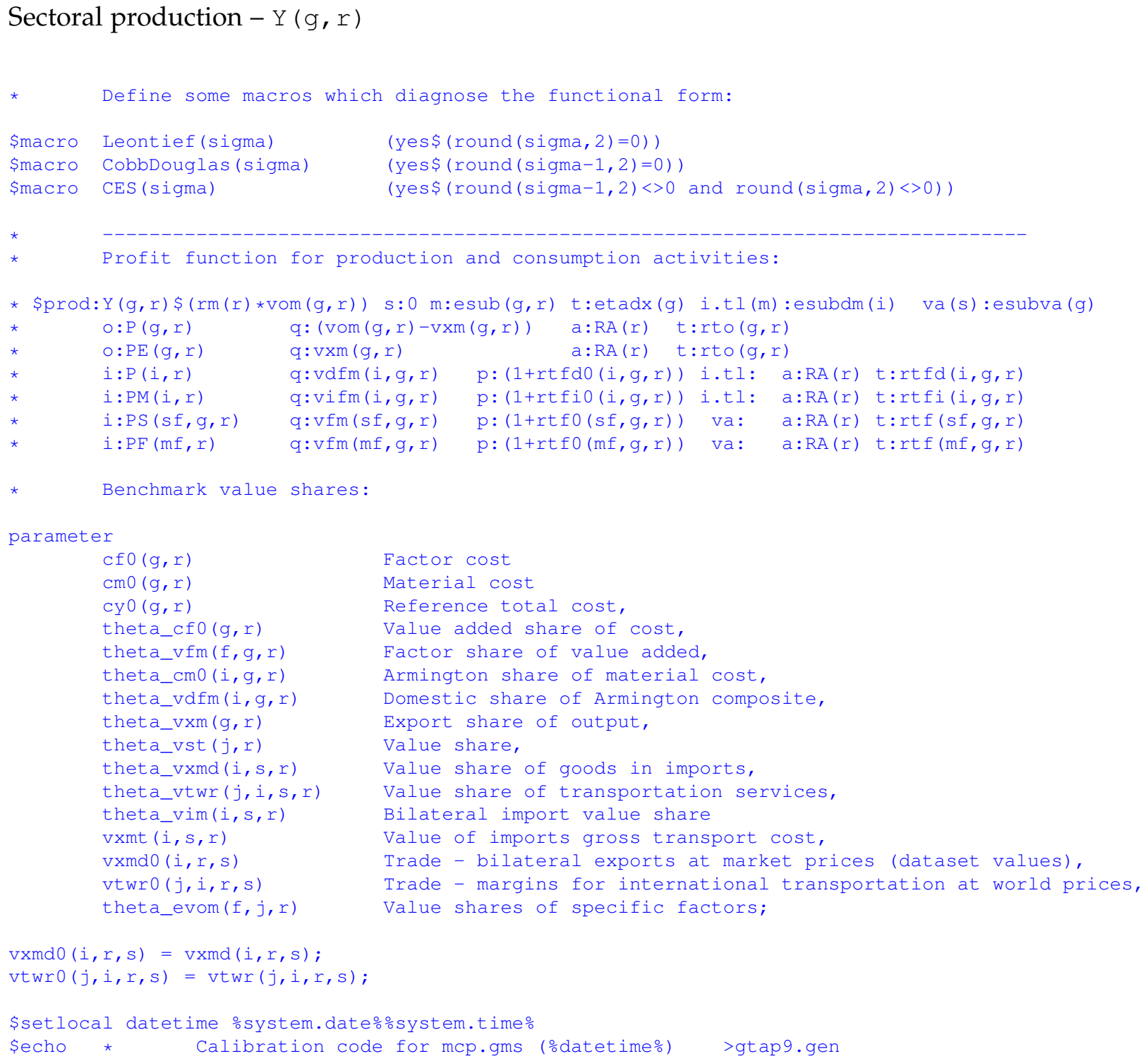




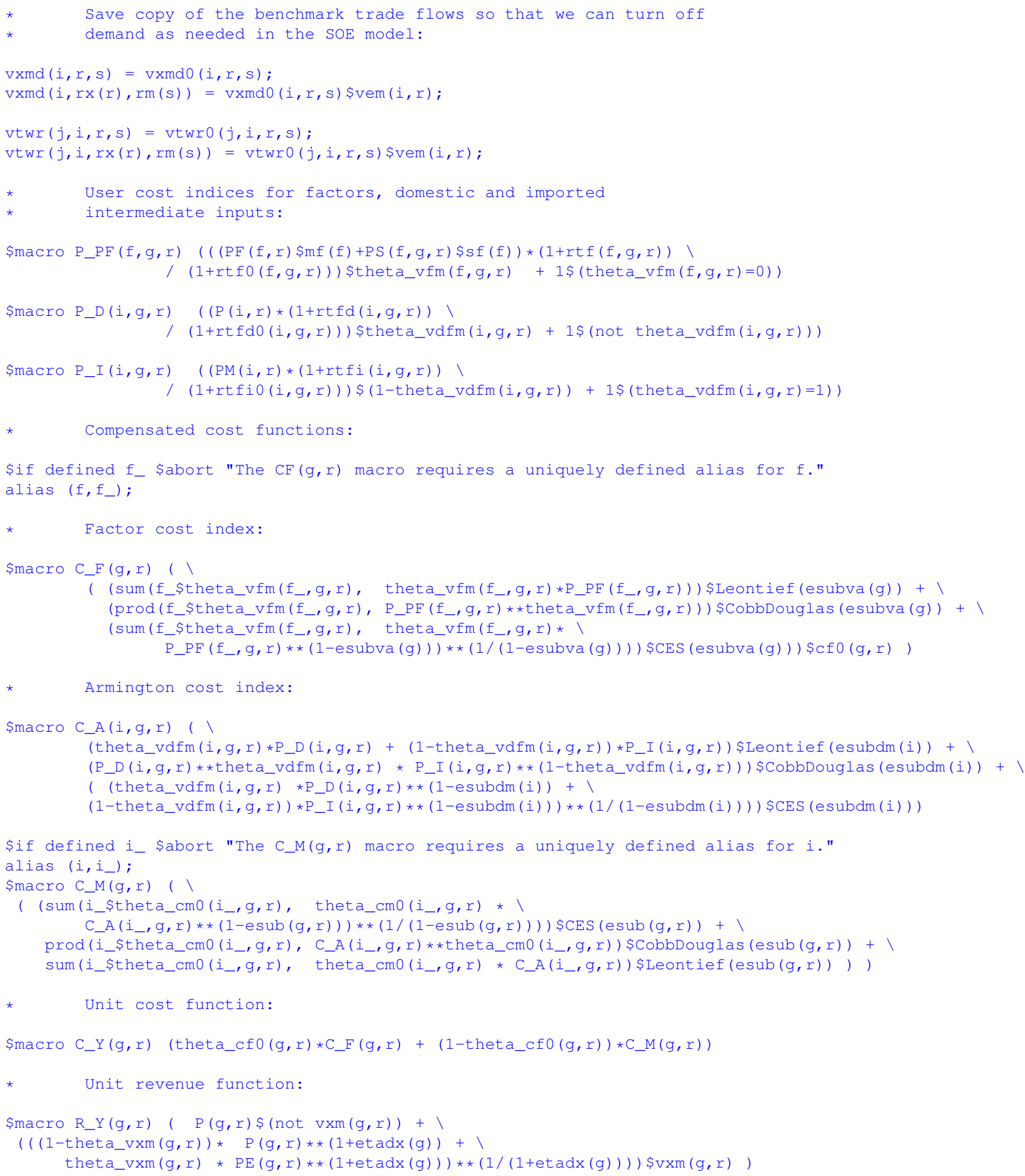




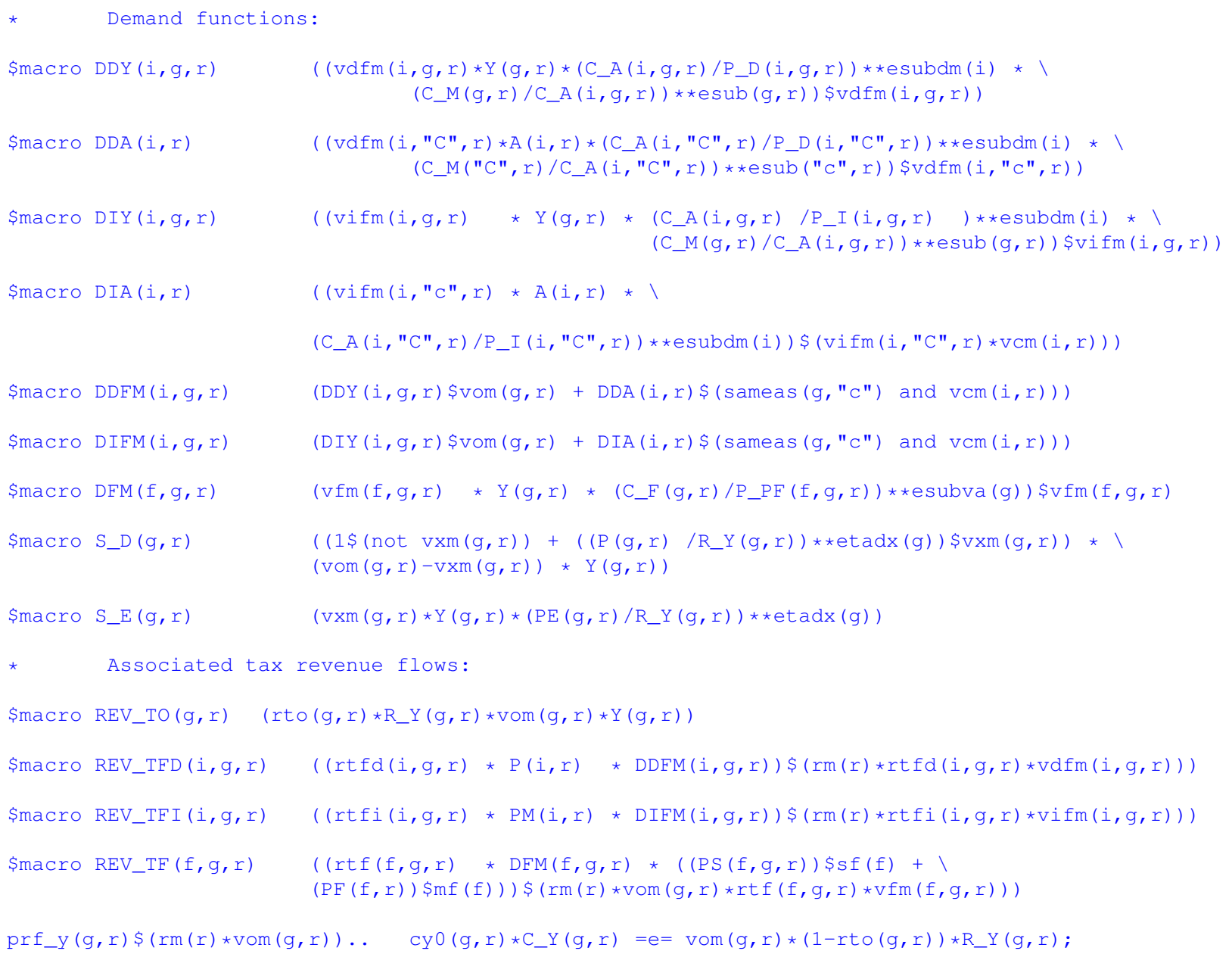

\section{International transportation services $-\mathrm{YT}(j)$}

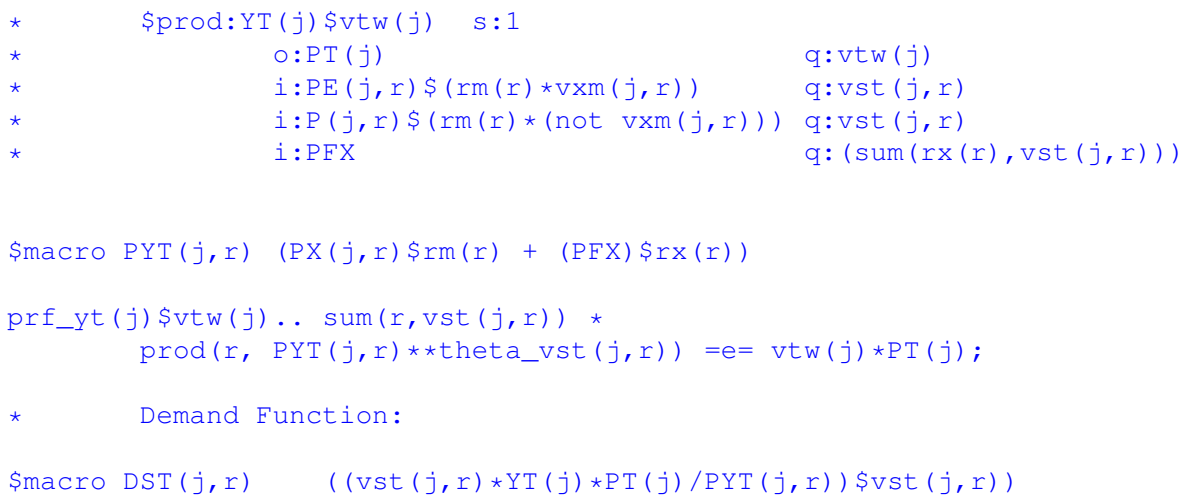




\section{Aggregate imports - M (i, r )}

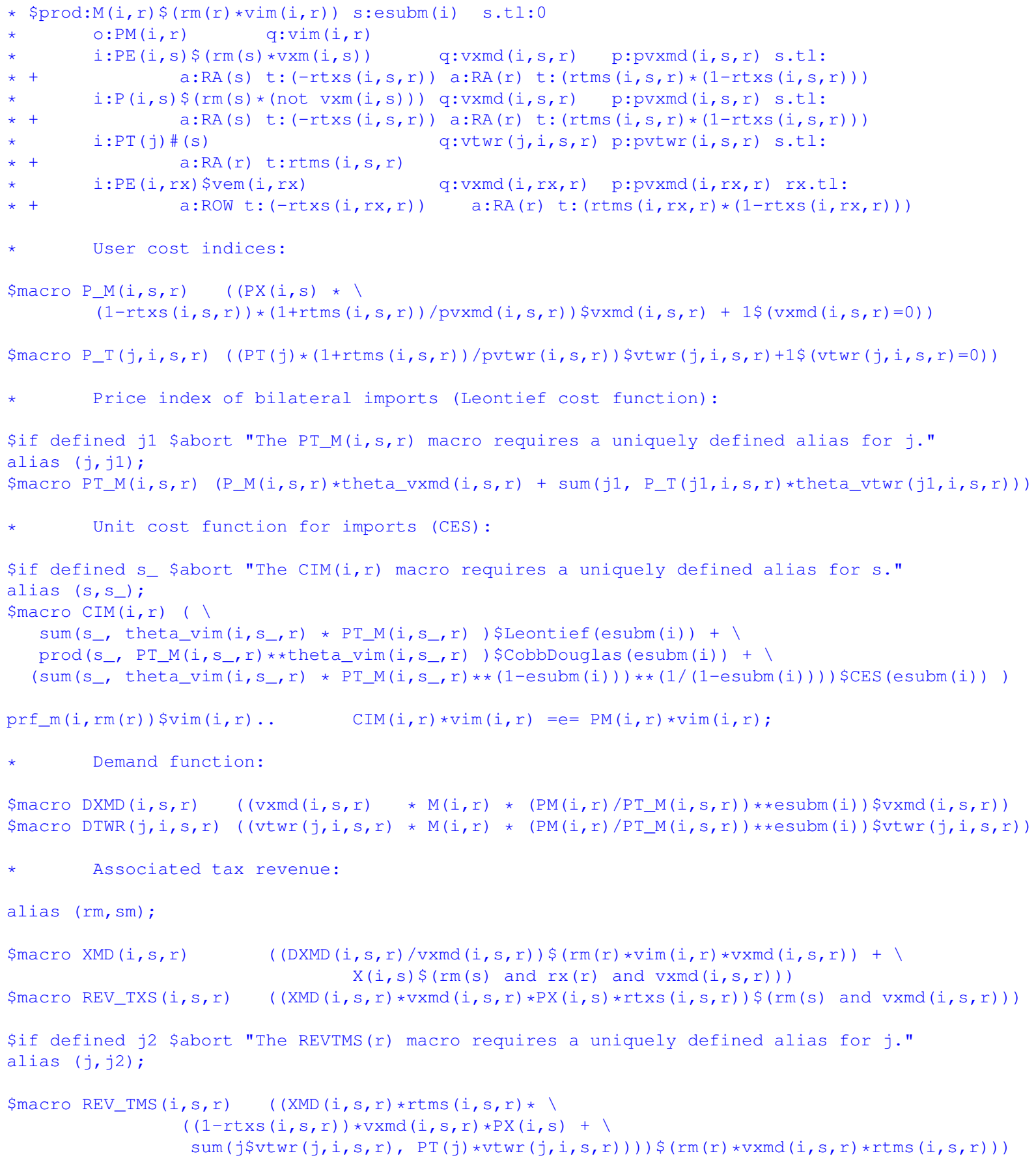


Sector-specific factor transformation $-\mathrm{FT}(\mathrm{f}, \mathrm{r})$

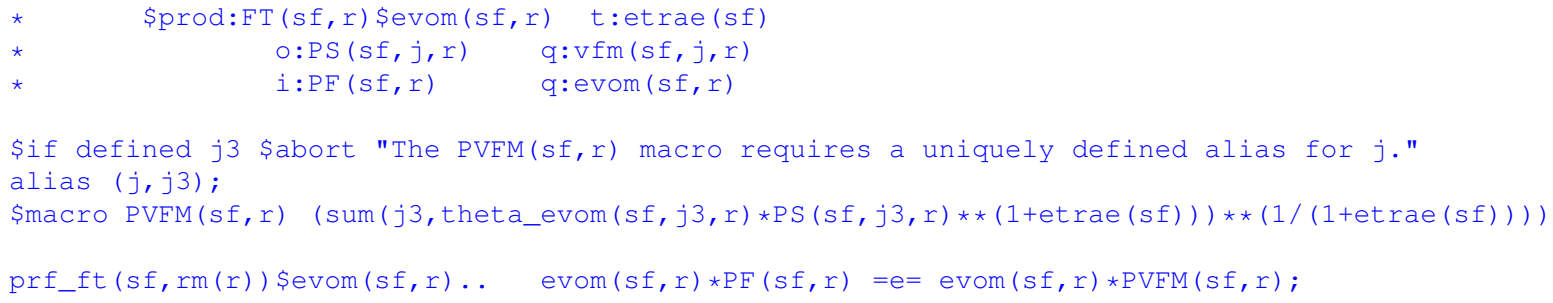

Market clearance

These equations do not appear explicitly in the MPSGE model, as they are generated automatically on the basis of the production function information provided above.

Domestic production and final demand - PY $(g, r)$

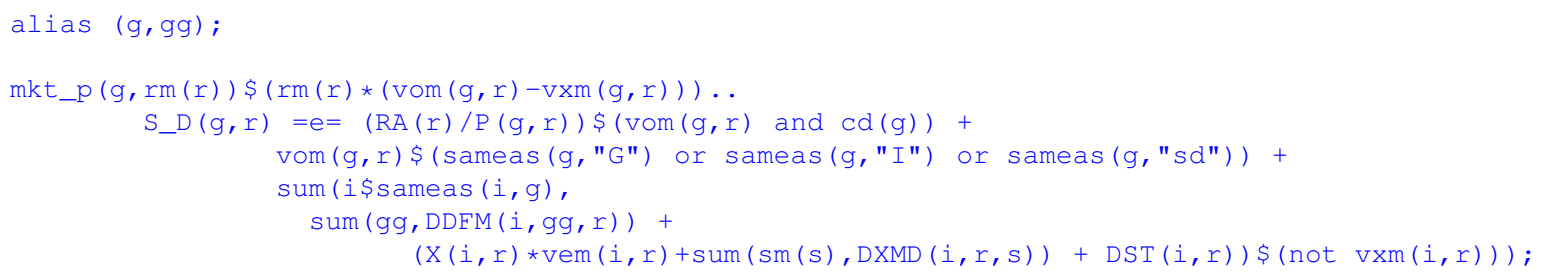

Export supply and demand - PE $(i, r)$

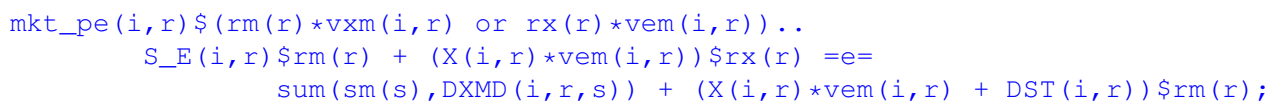

Composite imports - PM $(i, r)$

mkt_pm(i,rm(r)) \$vim(i,r) . $\quad M(i, r) * \operatorname{vim}(i, r)=e=\operatorname{sum}(g, \operatorname{DIFM}(i, g, r))$; 

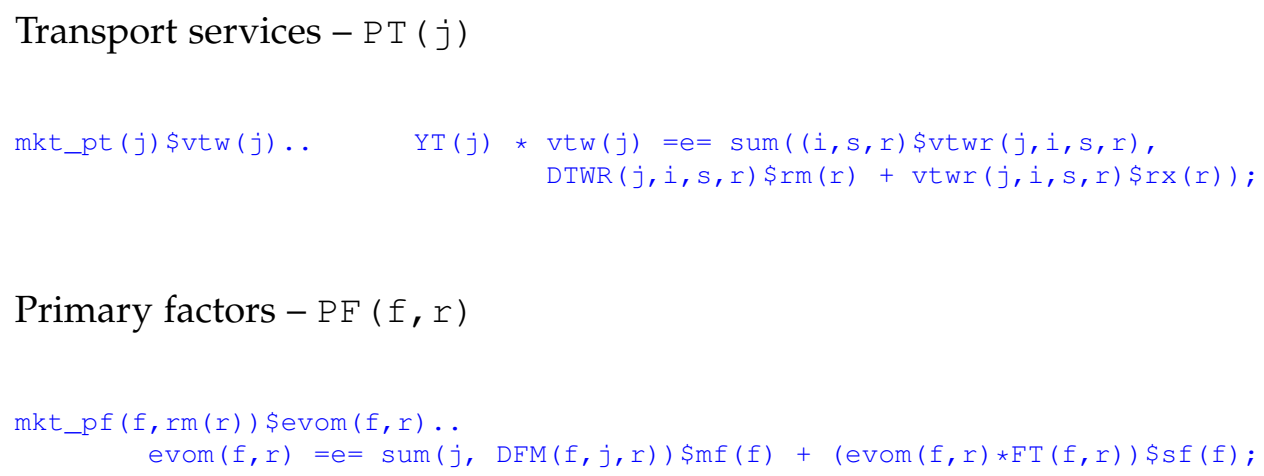

Specific factors - PS $(f, j, r)$

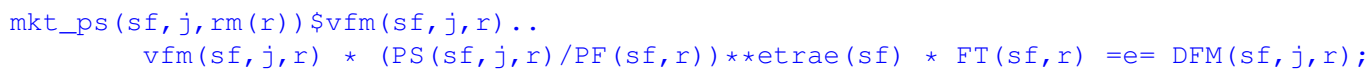

Model Declaration 


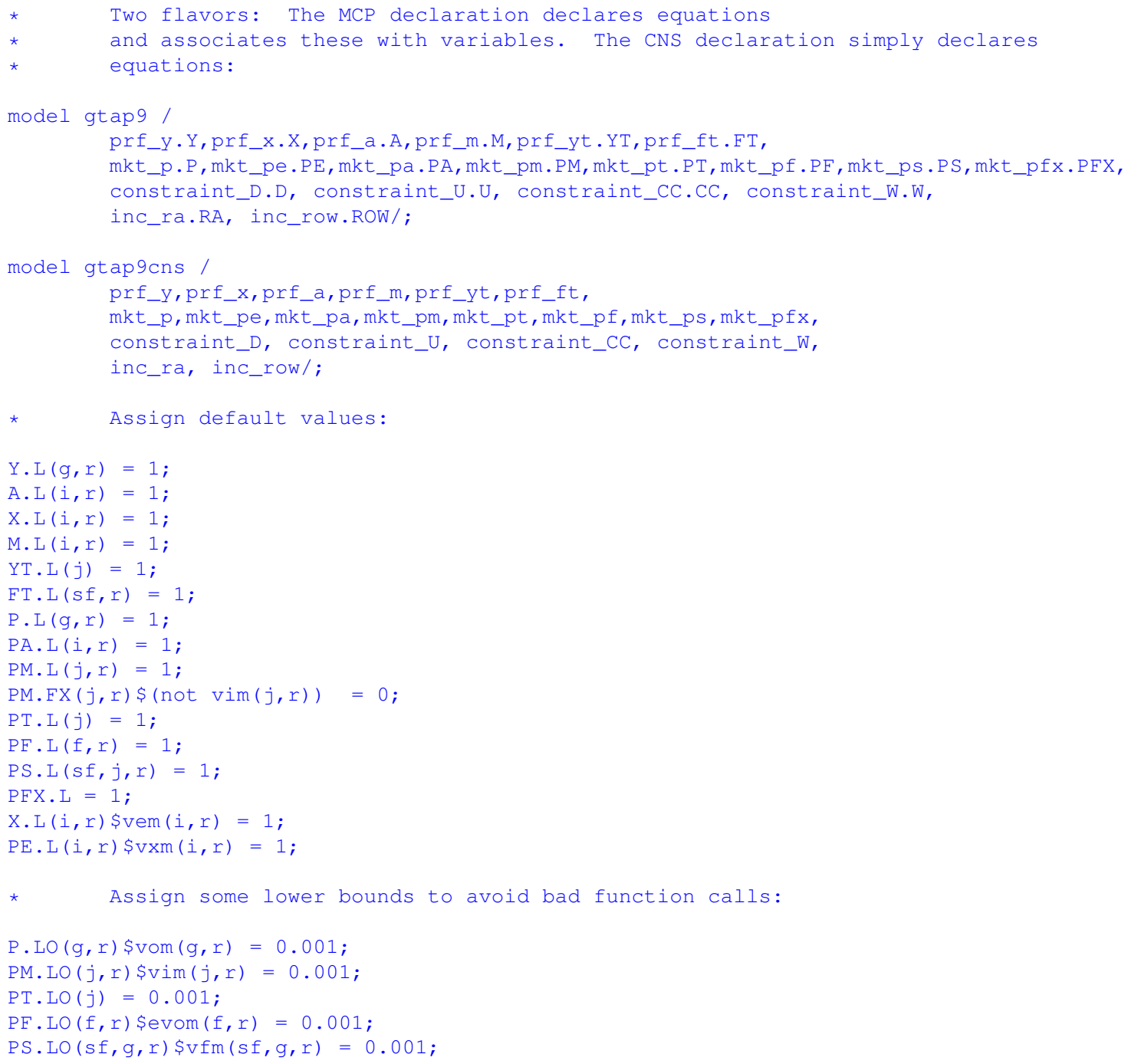

\section{Calibration algebra executed before model solution:}

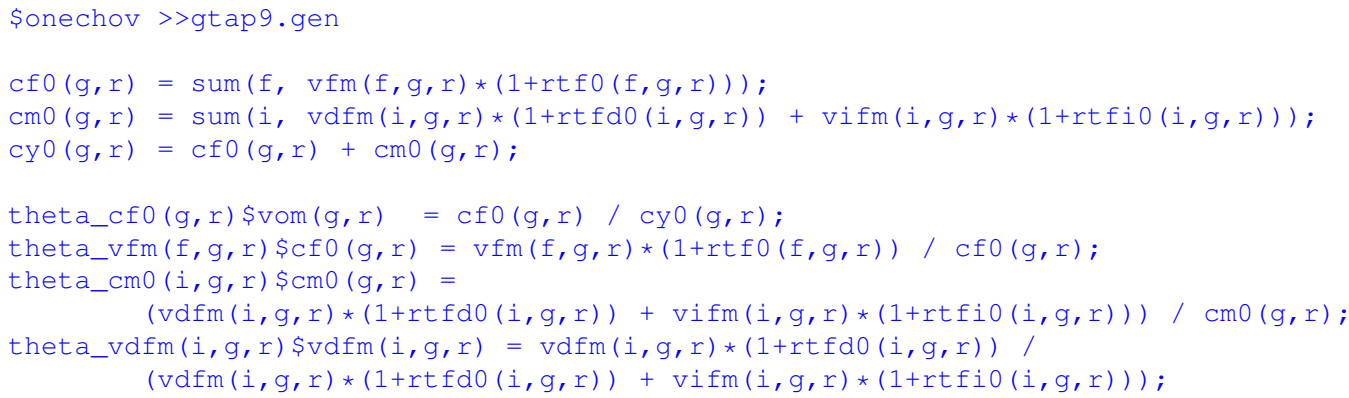




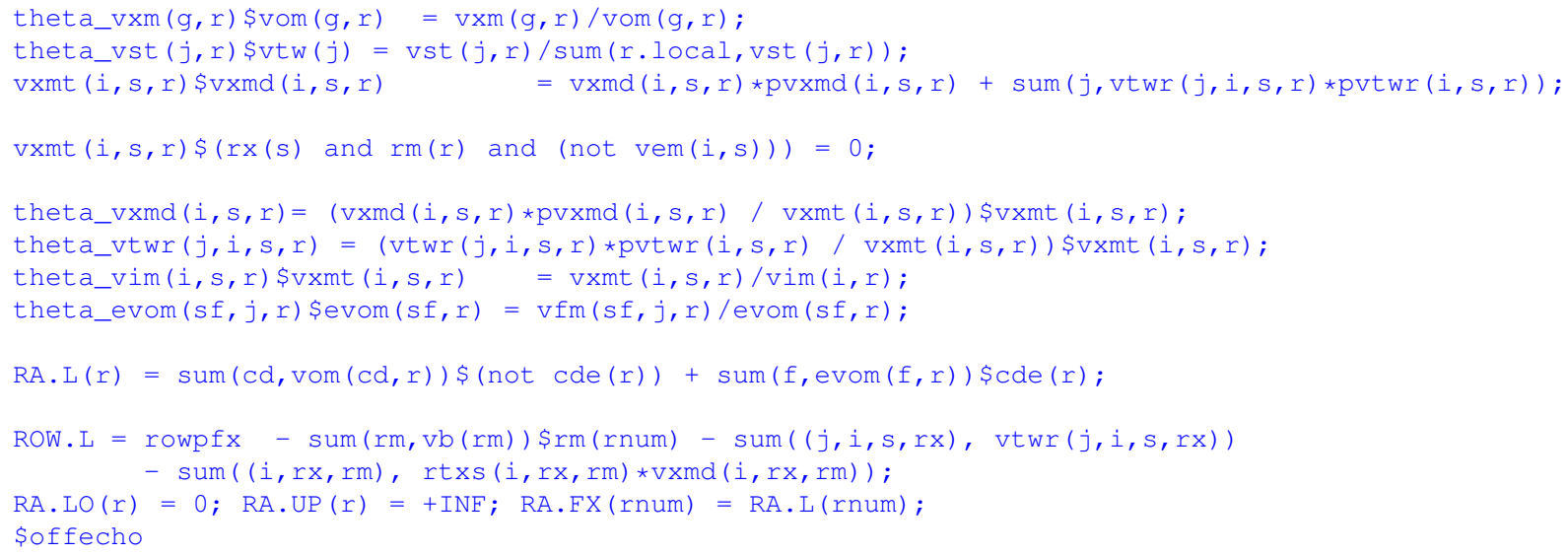

\section{Macros to Move Between Closures and Demand Systems}

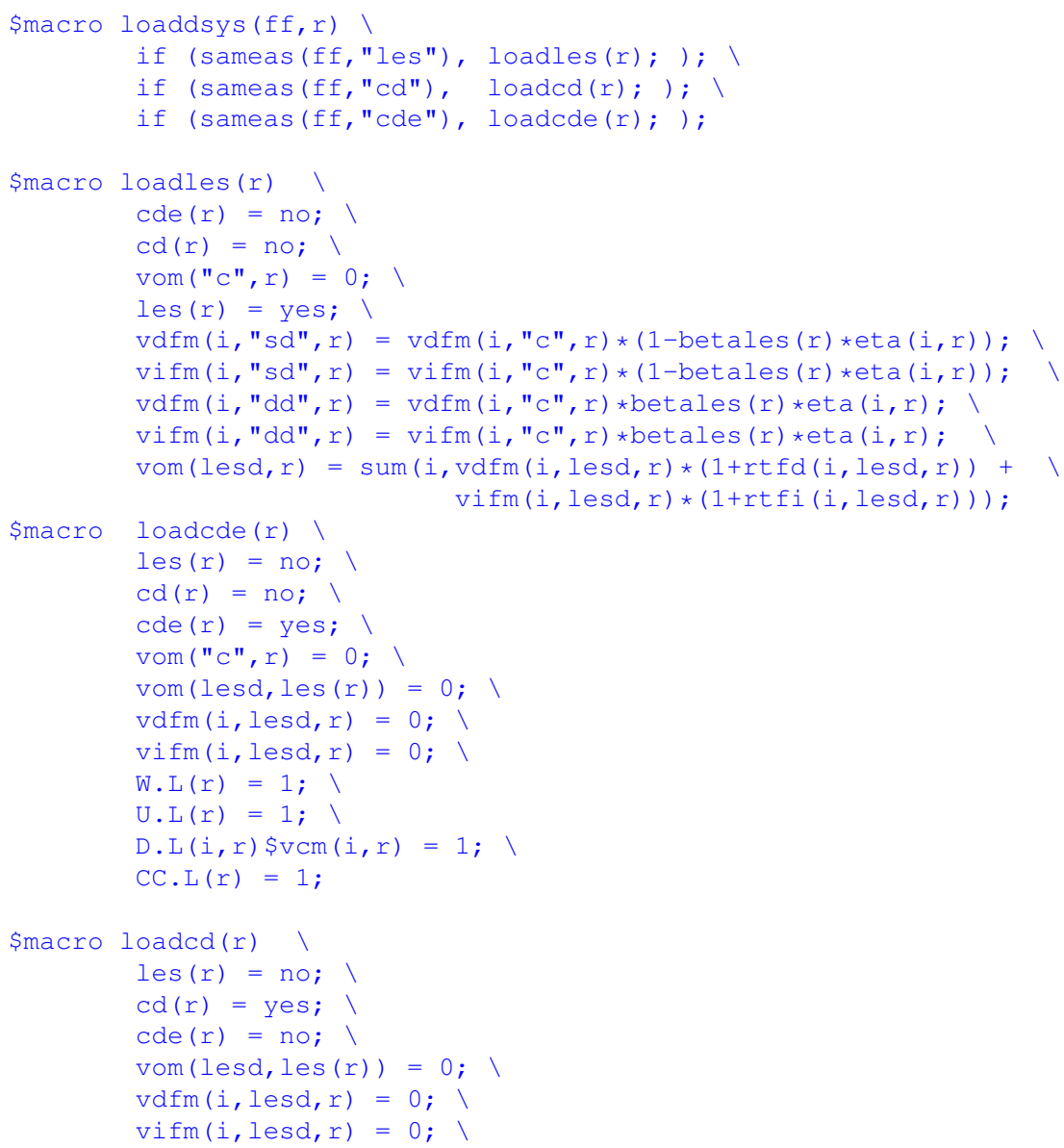




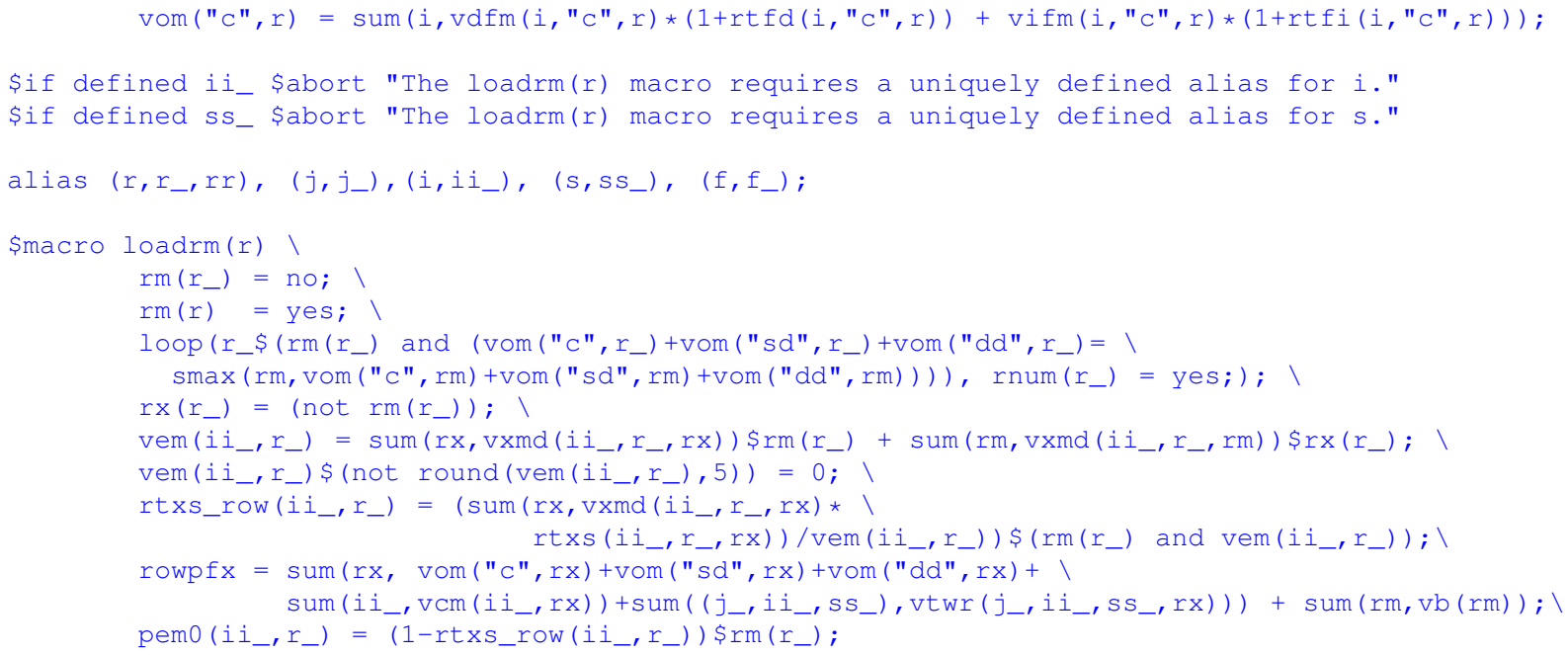

\section{GDP Reporting Code}

\$stitle GAMS Code for GDP Reporting from the MGE Model

\$ifthen.undefined not defined gdpcat

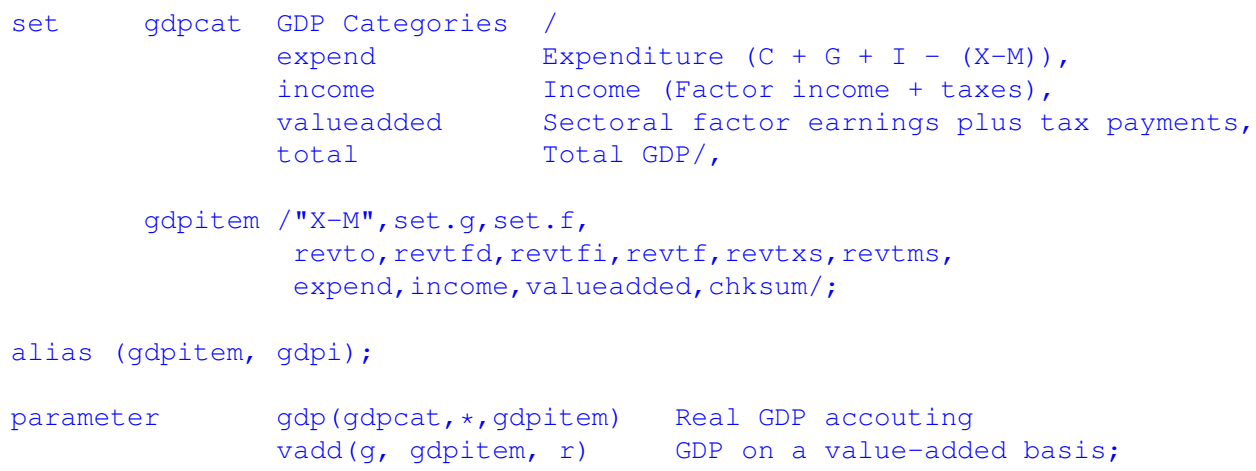

Sendif.undefined

\$ondot 1

loop ( rm $(r)$,

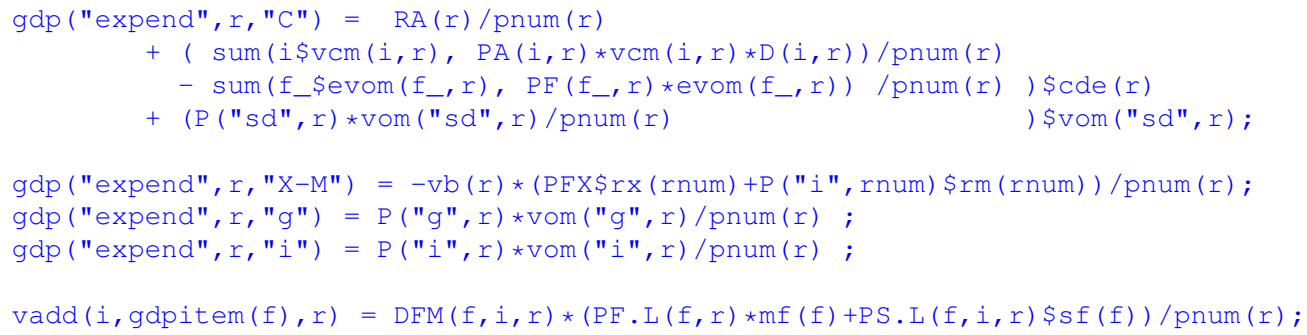


Journal of Global Economic Analysis, Volume 1 (2016), No. 2, pp. 1-77.

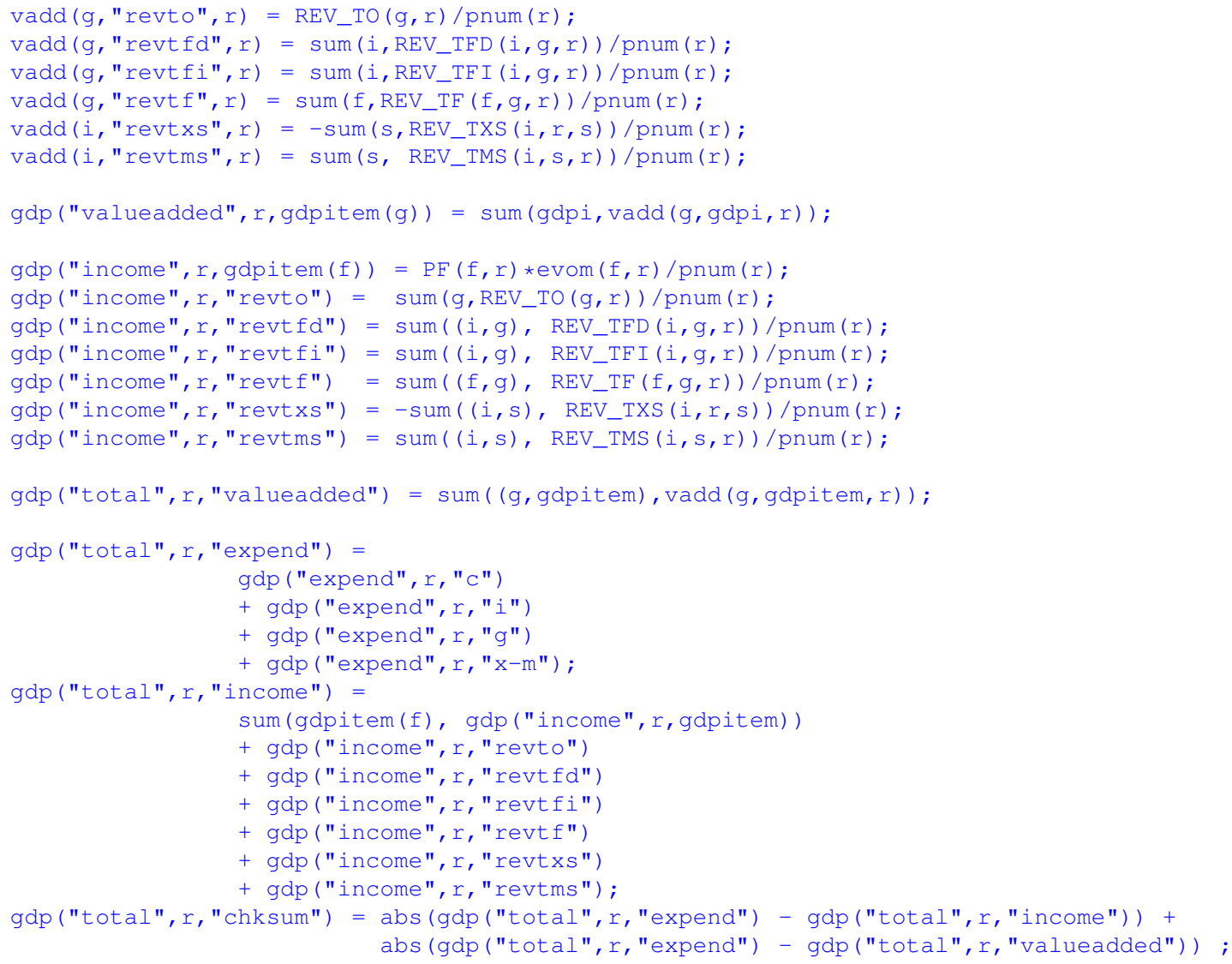




\section{GAMS/MPSGE Version}

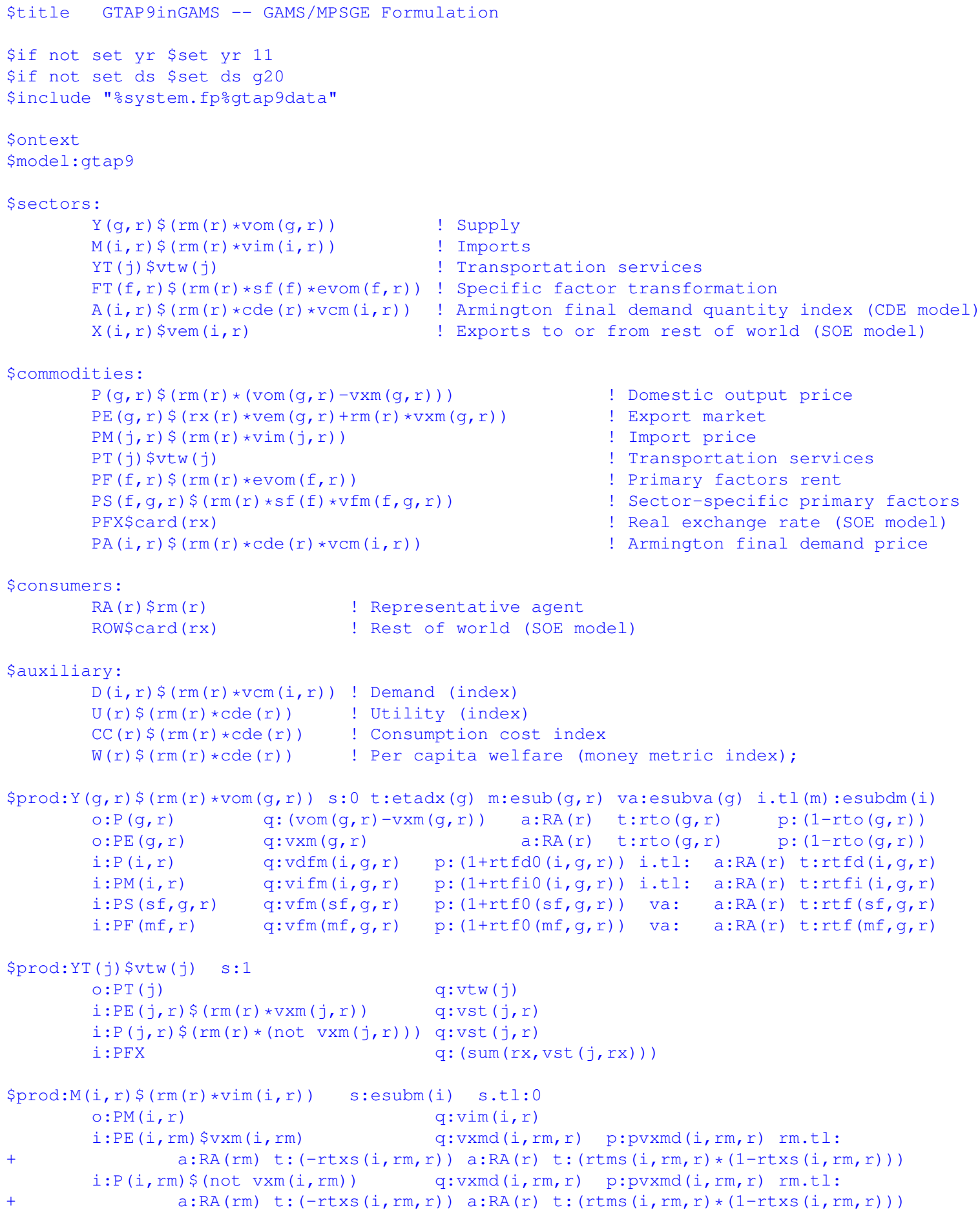




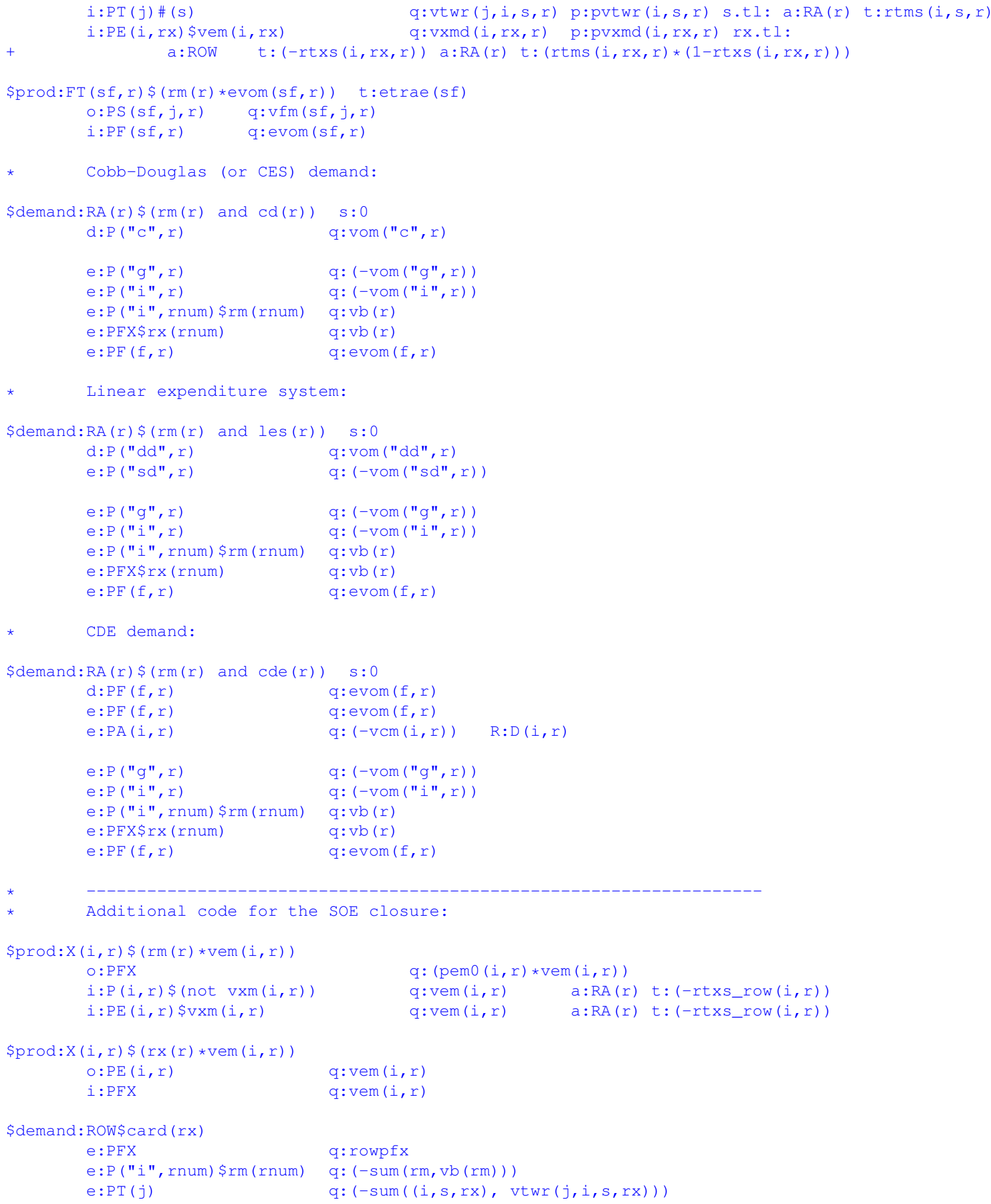


$\mathrm{d}:$ PFX

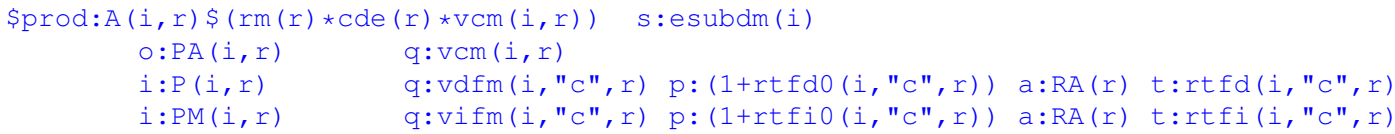


Journal of Global Economic Analysis, Volume 1 (2016), No. 2, pp. 1-77.

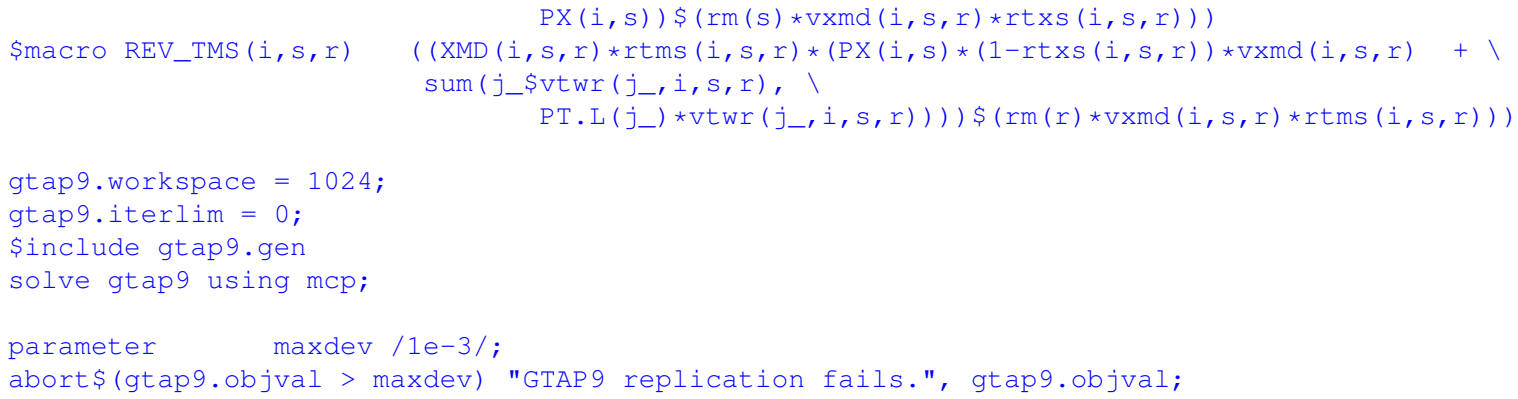




\section{References}

Aguiar, A., B. Narayanan, and R. McDougall. 2016. "An Overview of the GTAP 9 Data Base." Journal of Global Economic Analysis, 1 (1): 181 - 208. doi:10.21642/JGEA.010103AF.

Armington, P. 1969. "A Theory of Demand for Products Distinguished by Place of Production." International Monetary Fund Staff Papers, 16(1): 159-178. doi:10.2307/3866403.

Böhringer, C., J. Carbone, and T.F. Rutherford. 2016. "The Strategic Value of Carbon Tariffs." American Economic Journal: Economic Policy, 8(1): 28-51. doi:10.1257/pol.20130327.

Böhringer, C., and T.F. Rutherford. 2002. "Carbon abatement and international spillovers." Environmental and Resource Economics, 22(3): 391-417. doi:10.1023/A:1016032424760.

Chen, H. 2015. "Economic Projection with Non-homothetic Preferences: The Performance and Application of a CDE Demand System." GTAP Conference Paper, resource 4746, Purdue University, Report. https://www.gtap.agecon. purdue.edu/resources/download/7768.pdf.

De Melo, J., and S. Robinson. 1989. "Product differentiation and the treatment of foreign trade in computable general equilibrium models of small economies." Journal of International Economics, 27: 47-67. doi:10.1016/oo22-1996(89)90077-9.

Devarajan, S., J. Lewis, and S. Robinson. 1990. "Policy Lessons from Trade-Focused Two-sector Models." Journal of Policy Modeling, 12: 625-657. doi:10.1016/o1618938(90)90002-V.

Frisch, R. 1959. "A Complete Scheme for Computing all Direct and Cross Elasticities in a Model with Many Sectors." Econometrica, 28(2): 177-196. doi:10.2307/1909441.

Hanoch, G. 1975. "Production and Demand Models with Direct or Indirect Implicit Additivity." Econometrica, 43: 395 - 419. doi:10.2307/1914273.

Harrison, W., and K. Pearson. 1996. "Computing solutions for large general equilibrium models using GEMPACK." Computational Economics, 9(1): 83-127. doi:10.1007/BFo0123638.

Harrison, W., and K. Pearson. 2007. "GEMPACK User Documentation Release 8.o." Centre of Policy Studies and Impact Project Monash University, Melbourne, Australia, Report. http://www.copsmodels.com/ftp/gpdoc/rel8o/ gpd7.pdf.

Hertel, T., ed. 1997. Global Trade Analysis: Modeling and Applications. Cambridge University Press, Massachutes, USA. https://www.gtap.agecon.purdue.edu/ resources/download/7684.pdf.

Hertel, T., J. Grant, and T.F. Rutherford. 2009. "Dairy Tariff-Quota Liberalization." American Journal of Agricultural Economics, 91(3): 673-684. doi:10.1111/j.14678276.2009.01263.x.

Hertel, T., and D. van der Mensbrugghe. 2016. "Database Documentation, Chap- 
ter 14: Behavioral Parameters." Purdue University, Report. https://www.gtap. agecon.purdue.edu/resources/download/8247.pdf.

Mathiesen, L. 1985. "Computation of Economic Equilibrium by a Sequence of Linear Complementarity Problems." Mathematical Programming Study, 23: 144162. doi:10.1007/BFbo121030.

Narayanan, B. 2015. "What's New in GTAP 9: Chapter 3." Purdue University, Report. https://www.gtap.agecon.purdue.edu/resources/download/7638.pdf.

Powell, A. 1992. "Sato's insight on the relastionship between the Frisch parameter and the average elasticity of substitution." Economics Letters, 40(2): 173-175. doi:10.1016/0165-1765(92)90218-N.

Rutherford, T. 1999. "Applied General Equilibrium Modeling with MPSGE as a GAMS Subsystem: An Overview of the Modeling Framework and Syntax." Computational Economcis, 14: 1 - 46. doi:10.1023/A:1008655831209.

Rutherford, T.F. 1995. "Extension of GAMS for complementarity problems arising in applied economic analysis." Journal of Economic Dynamics and Control, 19(8): 1299-1324. doi:10.1016/0165-1889(94)00831-2.

Rutherford, T.F. 2005. "GTAP6inGAMS: The dataset and static model." mimeo, Report. http://www.mpsge.org/gtap6/gtap6gams.pdf.

Rutherford, T.F. 1998. “GTAPinGAMS." University of Colorado, Report. http:// www.mpsge.org/oldgtapingams/gtapingams/html/gtapgams.html.

Sato, K. 1972. "Additive Utility Functions with Double-Log Consumer Demand Functions." Journal of Political Economy, 80(1): 102-124. doi:10.1086/259864. 